Chapman University

Chapman University Digital Commons

Education (PhD) Dissertations

Dissertations and Theses

Fall 12-2019

\title{
Laughing Back: A Phenomenological Study of Disability Humor Using Culturally Responsive Methodologies
}

\author{
Kinda Abujbarah \\ Chapman University, abujb101@mail.chapman.edu
}

Follow this and additional works at: https://digitalcommons.chapman.edu/education_dissertations

Part of the Disability and Equity in Education Commons, and the Other Education Commons

\section{Recommended Citation}

Abujbarah, K. (2019). Laughing back: A phenomenological study of disability humor using culturally responsive methodologies [Doctoral dissertation, Chapman University]. Chapman University Digital Commons. https://doi.org/10.36837/chapman.000096

This Dissertation is brought to you for free and open access by the Dissertations and Theses at Chapman University Digital Commons. It has been accepted for inclusion in Education (PhD) Dissertations by an authorized administrator of Chapman University Digital Commons. For more information, please contact laughtin@chapman.edu. 


\title{
Laughing Back: A Phenomenological Study of Disability Humor Using
}

\section{Culturally Responsive Methodologies}

\author{
A Dissertation by \\ Kinda Abujbarah \\ Chapman University \\ Orange, CA \\ Attallah College of Educational Studies \\ Submitted in partial fulfillment of the requirements for the degree of \\ Doctor of Philosophy in Education
}

December 2019

Committee in charge:

Scot Danforth, Ph.D., Chair

Kris DePedro, Ph.D.

William Simmons, Ph.D. 
The dissertation of Kinda Abujbarah is approved.

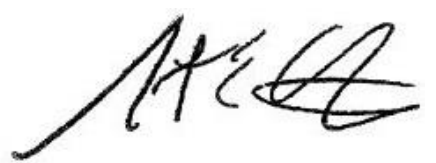

Scot Danforth, Ph.D., Chair

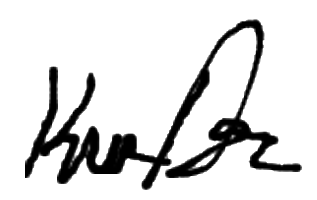

Kris DePedro, Ph.D.

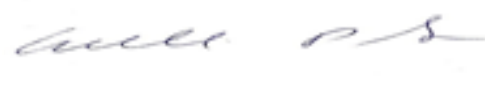

\section{William Simmons, Ph.D.}

September 2019 
Laughing Back: A Phenomenological Study of Disability Humor Using

Culturally Responsive Methodologies

Copyright $\odot 2019$

by Kinda Abujbarah 


\section{ACKNOWLEDGEMENTS}

This dissertation is dedicated to my mom and dad, Juman and Usama Abujbarah, who, besides being my best friends, have supported me emotionally and financially throughout my education. My parents immigrated to the U.S. when I was three years old in order to give me more opportunities. They never listened to anyone who argued I wasn't capable and advocated for my

full inclusion in school and in society. My parents always believed that I could achieve my dreams while thriving with a disability.

I would like to thank my chair, Scot Danforth, who supported me, advocated for me, challenged me, and answered all my questions.

I would also like to acknowledge the following people:

Kris DePedro gave excellent feedback, helping me to improve the manuscript.

William Simmons was my first professor in graduate school and has always supported me in pursuing my education.

My colleague, Lara Ameen, was an excellent typist who has worked with me throughout the whole dissertation process. 


\section{KINDA ABUJBARAH}

kabujbarah@gmail.com

\section{PURPOSE STATEMENT}

My background in Social Justice and Human Rights has offered me the opportunity to study disability as a core social justice issue. I am passionate about protecting the human rights of people with disabilities, especially those who cannot advocate for themselves. My coursework in the PhD in Education and Disability Studies has empowered me to view disability as a social and justice construct.

\section{AREAS OF INTEREST}

- Disability History

- Disability Humor

- Assistive Technology

- Higher Education for Student with Disabilities

- Disability Policy

\section{EDUCATION}

- Doctor of Philosophy in Education (Disability Studies) Chapman University, September 2019

- Master of Arts in Social Justice and Human Rights

- Bachelor of Science in Sociology
Arizona State University West, December 2013

Arizona State University, May 2011 


\section{PROFESSIONAL EXPERIENCES}

- Applied Project: The Reproductive Healthcare Experiences of Women with Physical Disabilities fulfilled the MA degree. Women with disabilities have sexual desires and can choose to be sexually active. They can also choose to have children. As such, they need reproductive health care. Women with disabilities have been denied the right to make their own decisions regarding their own bodies. This project seeks to examine how women with physical disabilities with access to primary health insurance have been treated in relation to their sexuality, and reproductive freedoms. Feminist theory and analytic autoethnography is used to evaluate interview results. Autoethnography is used because the author is a full member of the research group. Sexual violence against women with disabilities is also discussed in order to explain why reproductive health care is so vital to this community.

- Internship with AHCCCS (Arizona Health Care Cost Containment System), Summer 2013. Arizona has been recognized for success in serving high-need individuals. In 2014, United Cerebral Palsy's The Case for Inclusion report identified Arizona as the top-ranked state in providing care for persons with intellectual and developmental disabilities. The report found that Arizona ranked as the best state in the nation for Promoting Independence (including provider care within the community as opposed to within institutional facilities) and for keeping Families Together (including family support and proportion in a family home). Notably, Arizona has held the ranking of the top performing state for serving individuals with intellectual and developmental disabilities for three consecutive years and substantial changes in the reporting methodology, suggesting that Arizona is a topperforming state no matter how the rankings are determined. While the report from Cerebral Palsy has ranked Arizona as a top performer, the issue says many Arizonans with disabilities is the rigidity and complexity of the ALTC (Arizona Long Term care) application. My work involved reviewing and evaluating all the State of Arizona 
eligibility website with respect to persons with disabilities. Through the project I recommended a navigation tool to assist all potential eligible members through the application process.

- Teaching assistant for Intro to Sociology at Arizona State University for four semesters by assisting faculty member with classroom instruction, exams, grading and mentoring the students.

- Assisted with an undergraduate honors thesis that looked into how disability is portrayed in children's literature

- Participated in an academic paper on college students with disabilities

- Spoke about my experience with a difficult birth at the Arizona Prenatal Trust Conference on women and infant health.

- Published an article in the Easter Seals Arizona Newsletter about personal experience with assistive technology.

\section{SERVICE TO THE UNIVERSITY}

- Spoke to Education majors at Arizona State University about my experiences with assistive technology every semester from 2004-2010

- Spoke to Education majors at University of Delaware about my use of assistive technology in 2018

- Spoke to Intro to Sociology class about disability and diversity at Arizona State University 


\section{PUBLICATIONS}

$\underline{\text { Books }}$

- "Intro to Sociology" participated with Lisa Grey Whitaker, $\mathrm{PhD}$ in writing chapter five entitled Life on Wheels.

Where I described my experience as a student with disabilities at a higher education institute. I noted the

challenges and opportunities for students like me from the perspective of access to accommodation services of higher education.

\section{SKILLS}

- Outstanding written and oral communication skills

- Extensive analytical skills

- Talented in public speaking

- Creative problem solving skills

- Sharp critical thinking skills

- Proficient in MS Word, Excel, PowerPoint, Word Perfect and IBM compatible PCs

\section{REFERENCES AVAILABLE UPON REQUEST}




\begin{abstract}
Laughing Back: A Phenomenological Study of Disability Humor Using Culturally Responsive Methodologies

by Kinda Abujbarah

Historically, disabled people have not been viewed as innovators of humor because disability is associated with tragedy. My dissertation challenged the association of disability with tragedy by positioning disabled comedians as educators and ambassadors of disability rights. I reviewed the literature on disability and humor as well as disability oppression, which disability humor challenges. I used phenomenology as well as culturally responsive methodologies to examine what disabled comedians are achieving with their humor and what nondisabled audience members learned from attending their performances. Vygotsky's sociocultural theory of learning was used to examine learning outcomes for audience members. I examined historical and contemporary Black humor, which is much older than disability humor in order to investigate what may be the future of disability humor.
\end{abstract}




\section{TABLE OF CONTENTS}

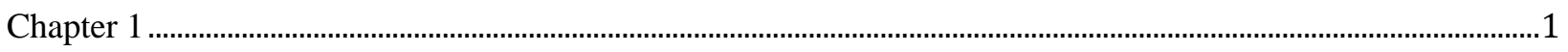

Sieber's Ideology of Ability as an Explanation of Disability Oppression ............................................................

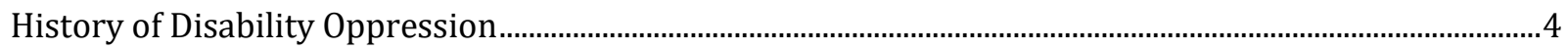

Contemporary Physician Assisted Suicide and Euthanasia .............................................................................

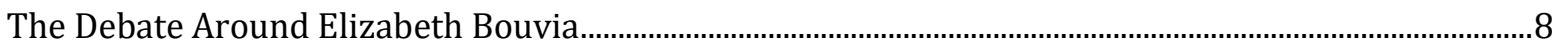

Physical Abuse and Maltreatment of Disabled Children ......................................................................... 10

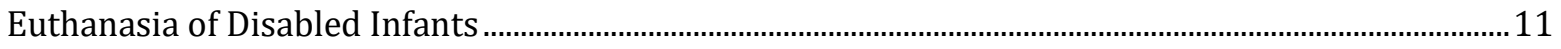

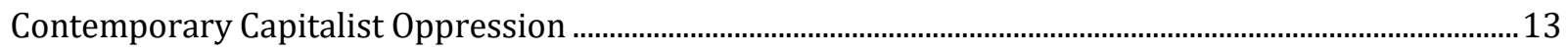

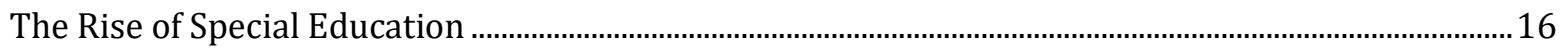

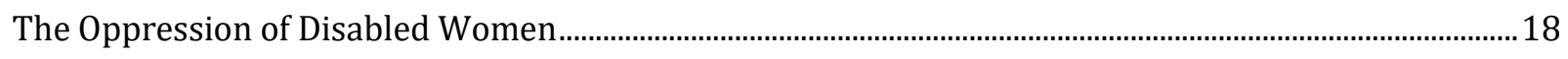

Sexual Abuse of Women with Disabilities ............................................................................................... 21

How Disability Comedy Can Resist Oppression ........................................................................................... 23

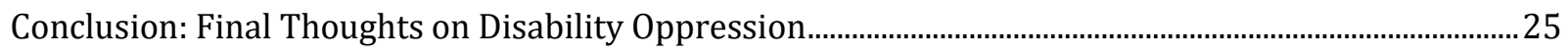

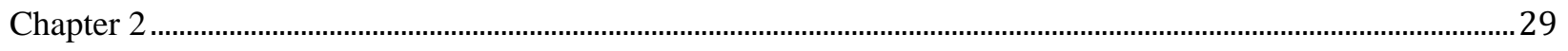

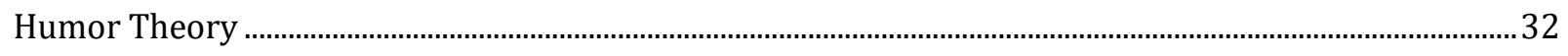

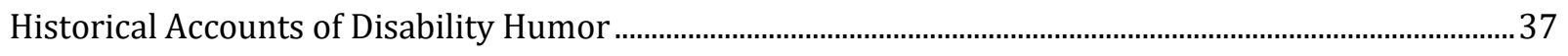

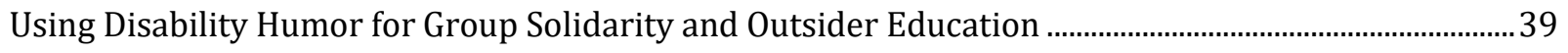

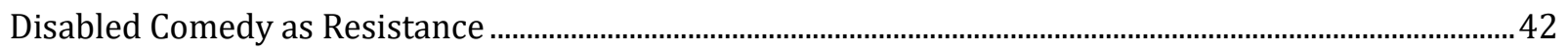

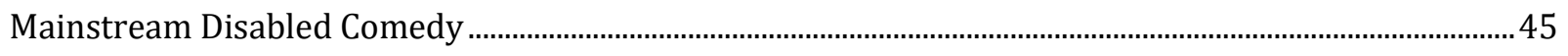


Authentic Comedy on Television

Empowering Humor on Primetime Adult-Themed Cartoons ……................................................................... 50

Disempowering Humor in Mainstream Society: The Case of David Paterson ........................................... 53

Conclusion: Future Research in Disability Comedy ……................................................................................. 55

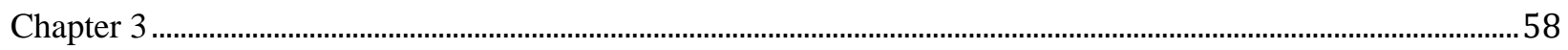

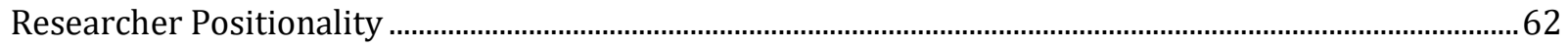

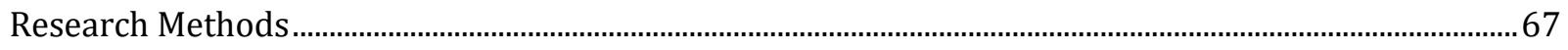

History and Theory Behind Phenomenology ………............................................................................... 67

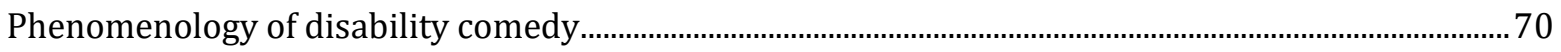

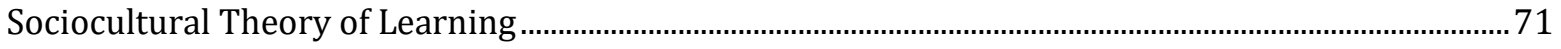

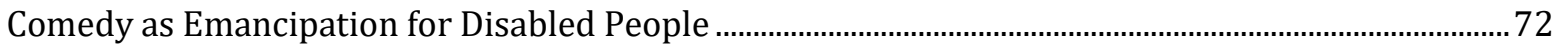

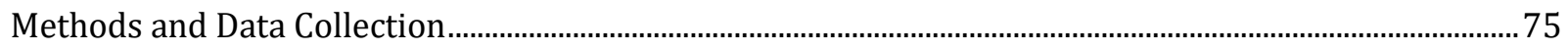

Participant Observations: Attending shows and viewing YouTube archives............................................. 76

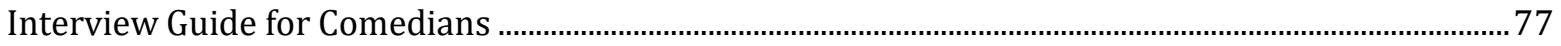

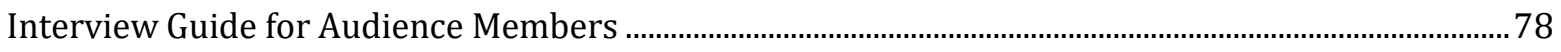

Recruitment of Comedian Participants................................................................................................... 79

Accommodations for Interviewing Disabled Participants............................................................................. 79

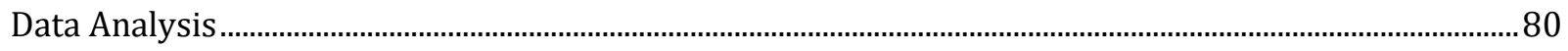

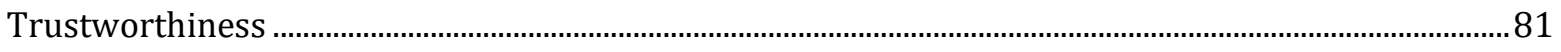

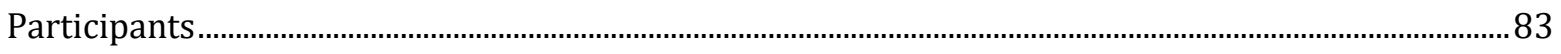

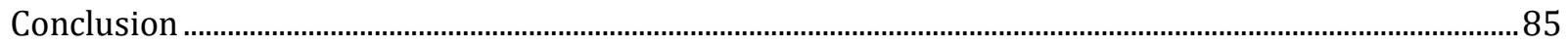




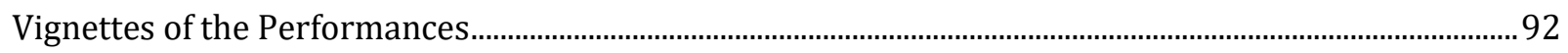

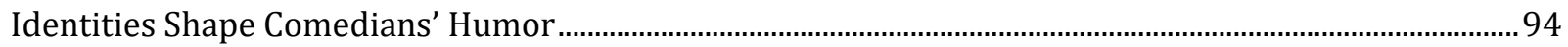

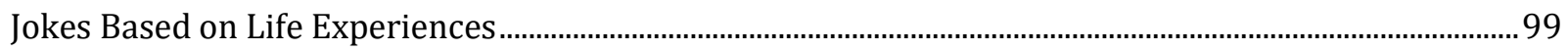

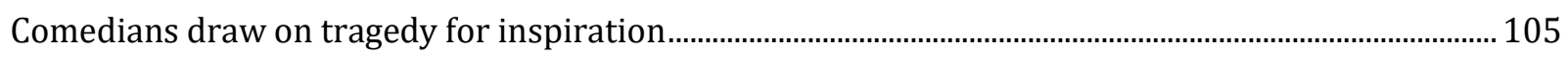

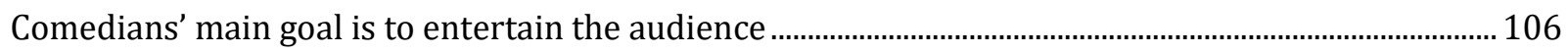

Disabled Audience Members Appreciate the Work of Disabled Comedians ............................................. 109

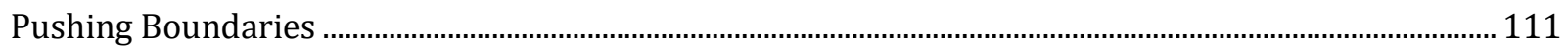

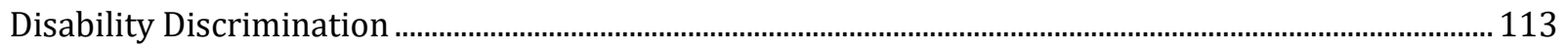

Audience Members' Insights on Performances ............................................................................................. 118

Audience Members' Experience with Disability Before Attending the Performance ................................ 120

Comedy teaches audience members that disabled comedians are capable............................................ 121

Audience members enjoyed the performances of disabled comedians.................................................... 122

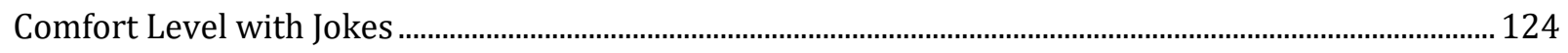

Conclusion: Reflections on Lived Experience of Disability Comedy........................................................... 125

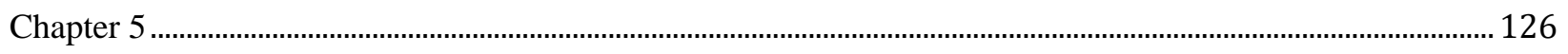

Historical roots of African American humor during slavery and Reconstruction.................................... 128

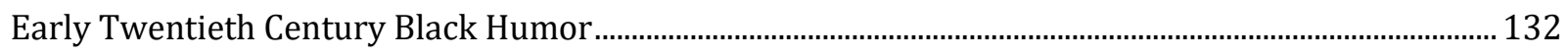

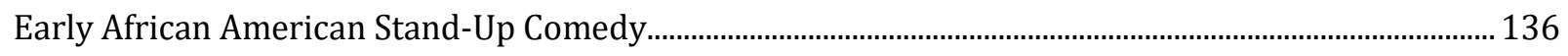

The Evolution of Contemporary Black Comedy ……….......................................................................... 139

Black Humor on Television Sitcoms ............................................................................................................ 143 
Comparing and Contrasting African American Comedy and Disability Comedy .

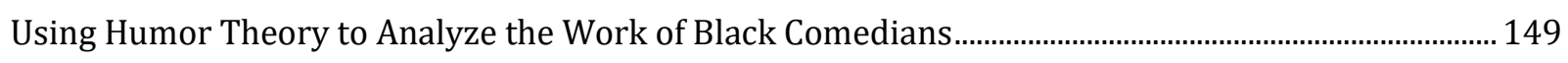

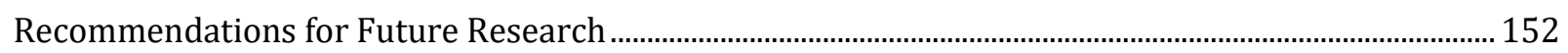

Conclusion: How Understanding Black Humor Can Inform Disability Humor ........................................... 152

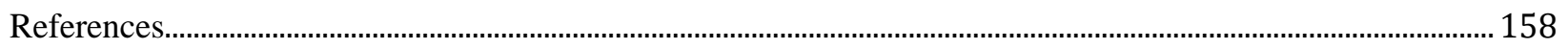




\section{Chapter 1}

"For centuries, people with disabilities have been isolated, incarcerated, observed, written about, operated on, instructed, implanted, regulated, treated, institutionalized and controlled to a degree probably unequal to that experienced by any other minority group” (Davis 1997, p. 1).

An analysis of the ways in which disabled people are oppressed is important because disability exists in every society and every social class. Disability oppression intersects with other forms of oppression. For example, disabled women are oppressed because they are women and because they are disabled. The same is true for disabled members of other minority groups. Disability oppression is a political problem, but it is rarely understood as such. Disability has historically been a justification to abandon, kill, test on, abort and segregate, while ability goes unquestioned and unexamined (Nocella II, 2008).

Due to the intersectionality of disabled people, they experience multiple forms of oppression based on how race, class, gender and sexual orientation interact with disability in various social constructs in order to marginalize disabled people (Garland-Thomson, 2002). For example, the African American civil rights movement sought to distance itself from disabled people because of the association of disability with incompetence. Early feminists did not wish to be associated with disabled women for the same reason. Both African Americans and women were stereotyped as inferior to white males, and disability was often used as a metaphor for this supposed inferiority (Stone, 2017; Garland-Thomson, 2002). 
Disabilities are created by social conditions, constructed by professionals and social oppression (Danforth and Rhodes, 1997). The essence of the experience of oppression is when the dominant group tells the oppressed that they are not experiencing oppression. Disability is associated with being broken or not working properly or something wrong. The term "disabled," like retarded, crippled or lame, conjures up negative images that are used to insult people. The disability rights movement has reclaimed the term "disabled" out of a universal understanding of what it means to be a part of the disability experience. Nevertheless, disability has been associated with a medical problem and the medical model of understanding disability (Nocella II, 2008).

The oppression of disabled people has been prevalent throughout history and remains problematic. Disability oppression exists in multiple forms and can affect anyone at any time. In addition, the marginalization of disabled people affects families and communities as well, making it relevant to all. This is a political problem, reflecting society's failure to integrate disabled people and provide opportunities and resources. However, because disability is widely understood as a medical problem affecting only individuals, the social barriers to inclusion have not yet been removed.

An important way disabled people challenge oppression is through humor, which is the topic of this dissertation. Insider humor helps nondisabled people learn about disability oppression in a non-threatening way, by making disabled people more relatable through the use of shared experiences (Shain, 2013). Disabled comedians confront the fear that nondisabled people have 
about disability by eliciting laughter from the audience, even in uncomfortable situations (Reid, Stoughton and Smith, 2006). Disabled comedians challenge normative views of disability as tragedy by making jokes about their lives (Lockyer, 2015).

This paper will examine how disabled people are oppressed in multiple ways, beginning by exploring Tobin Sieber's ideology of ability as a cultural explanation. This is followed by a discussion of disability oppression in history, which leads to contemporary abuse of disabled people under the guise of physician assisted suicide. Next, physical abuse of disabled children is discussed followed by euthanasia of disabled infants. Then, capitalism's role in disability oppression is considered, which leads to the rise of special education. In the next section, the oppression of disabled women is analyzed, including the prevalence of sexual abuse.

\section{Sieber's Ideology of Ability as an Explanation of Disability Oppression}

Tobin Siebers (2008) described what he called the ideology of ability, the assumption that

ability is the assumed norm and disability is a tragedy to be avoided at all costs. The lesser the ability, the lesser the worth of the human being, while disability is simultaneously banished and turned into a principle of exclusion. If one is not disabled, then one is not really aware of the body; one only feels the body when something goes wrong with it. Along those lines, the nondisabled body has great capacity for self-transformation. It can be trained to do almost anything and adjust to new situations, while the disabled body is limited to what it can do and what it can be trained to do. Therefore, the disabled body experiences new situations as obstacles. Disability is always individual while ability is an essential feature to the human species. The ideology of ability implies 
that it is better to be dead than disabled. While nondisabled people have the right to choose when to be able-bodied, disabled people must try to be as able-bodied as possible at all times.

Overcoming a disability is an event to be celebrated; it is an ability in itself to overcome disability. The value of a human life arises as a question when a person is disabled. Disabled people are worth less than nondisabled people; disabled people should turn their disability into an advantage. Loss of ability translates into loss of sociability, hence the stereotypes of disabled people as bitter, angry, self-pitying or selfish. Because they cannot see beyond their own pain, they lose the ability to consider the feelings of others. People who wish to identify as disabled are psychologically damaged; if they could see themselves as nondisabled, they would be healthier and happier. This ideology has its roots in the history of the oppression of disabled people and their exclusion from mainstream society.

\section{History of Disability Oppression}

Dr. J. Langdon Down, for whom Down syndrome is named, was the first to describe the characteristics of children whom he called "Mongoloid idiots." Down believed in eugenics and was attempting to classify a new "specimen" of idiots who inherited the characteristics of dark skinned people from Mongolia. Although they were born to white European parents, he described them as degenerates who reverted back to an inferior race (Down, 1866). This is an example of the intersection between racism and ableism. It is now understood that Down syndrome is the result of an extra chromosome, so that instead of having 46 chromosomes in each cell, individuals with Down syndrome have 47. It is known as Trisomy 21 because of the extra twenty-first 
chromosome. Down associated people who had the extra chromosome with moral degeneracy, but now they are stereotyped as innocent and angelic (Rodgers, 1987).

Like children with intellectual disabilities, Blacks were deemed a threat to civilized White Americans. They were thought to be criminally insane and were controlled only by slavery's bondage. Disability was used metaphorically to describe the threat posed by the 'Black savage.' Disability exacerbated the presumed relationship between blackness and criminality, especially because Blacks were thought to be mentally ill and in need of control (Stone, 2017). After the slaves were emancipated following the Civil War, the eugenic belief that all Blacks were criminally insane was used to deny Blacks the right to vote. Persons labeled "black," "idiot" or "criminal," were seen as a danger to society by white males in positions of authority, and laws were enacted to strip such people of full citizenship. In this way, disability was used metaphorically to stand in for race. Linking race with disability persists in today's prison industrial complex, where low income minorities with mental health conditions are disproportionately imprisoned and thus are stripped of their civil rights (Dilts, 2012). In public schools, Black children are disproportionately labeled with intellectual or behavioral disabilities and placed in segregated special education. Additionally, Black children who received such labels receive fewer and lower quality services than White children with the same labels. Black children with such labels are less likely to be in inclusive settings (Stubblefield, 2009). As schools became desegregated in the 1950 's and 1960's, Black children began to be labeled with behavioral disorders. In effect, this re- 
segregated the schools, as minority children were pulled out for special education (Danforth, 2007).

Mental illness, during Freud's era, became defined as unwanted behavior identified by someone other than the patient (Danforth, 2007). For example, women have long been thought of as hysterical and irrational. Specifically, this can be found in Freud's treatment of a patient named Dora, whom he considered to be hysterical. The young woman's father asked Freud to treat Dora who believed her father was having an affair, which he denied. Freud believed Dora was hysterical and wanted to have sex with her father. It is not known whether or not Dora's father was having an affair, but having Dora diagnosed as hysterical by Freud would ensure that no one would believe her accusations (Mollow, 2014). This demonstrates how disability labels are used to oppress women. People with hidden disabilities who experience pain are still sometimes thought to be mentally ill until their symptoms are recognized as a formal diagnosis.

The United States Supreme Court decision of Buck vs. Bell in 1927 legalized the forced sterilization of people labeled "feebleminded" (Gallagher, 2001). Carrie Buck was institutionalized in the Virginia Colony for Epileptics and the Feebleminded as a teenager after having a child as a result of rape. Eugenicists, at the time, wanted to use her case to gain legal precedence for forced sterilization. She was given a lawyer to defend her case at the Supreme Court, but, in reality, her attorney helped to seal her fate and that of many others. As a result of the Supreme Court decision, 8,000 sterilization operations were performed without notifying the 
patient. More than thirty American states passed forced sterilization laws, resulting in 60,000 forced sterilizations in the United States. To make matters worse, Carrie was never given any formal IQ tests. Her supposed "feeblemindedness" was based on becoming pregnant and having a child out of wedlock. Her daughter, Vivian, was observed by a photographer and deemed "feebleminded" because she couldn't track an object he held in front of her. These were by no means formal IQ tests, but they in effect took away reproductive rights from many so-called "feebleminded" individuals (Lombardo, 2003). United States eugenic laws paved the way for forced sterilization practices and euthanasia in Nazi Germany.

Mass murder and forced sterilization of those labeled with any kind of disability was a central feature of the German T4 euthanasia program (Gallagher, 2001). For example, nurses who worked in German institutions for children with disabilities were expected to administer lethal doses of sedatives to children whom Third Reich physicians deemed a burden to society and unworthy of life. Unlike the mass killing of adults and older children, this program remained secret. Parents were told that their disabled newborn or young child was being sent to a specialized care facility to receive the latest medical treatment when, in fact, they were being evaluated for "mercy killings." Nurse midwives evaluated newborns in maternity wards and put a plus sign in the child's report if the baby was deemed defective and a minus sign if they were "healthy." No doctor ever evaluated the children or questioned the reports; the children were simply killed. "An estimated 
3,000 to 5,000 children were killed by physicians and nurses in the children's euthanasia program"

(Benedict, Shields and O'Donnell, 2009, p. 509).

\section{Contemporary Physician Assisted Suicide and Euthanasia}

\section{The Debate Around Elizabeth Bouvia}

Elizabeth Bouvia was a 26-year-old woman with significant cerebral palsy who wanted

assistance to end her life. Specifically, she wanted palliative care at a hospital while she starved to death. She had voluntarily checked herself into the psychiatric unit at Riverside Hospital because she was suicidal. While there, she contacted the ACLU and newspapers, saying that she wanted to die. The ACLU agreed to provide legal representation for her lawsuit against the hospital. The trial judge denied her petition, arguing that Bouvia was competent and had a right to privacy, but other members of society would be offended. He also did not want to create a legal precedent for others who were not terminally ill to seek assisted suicide (Kane, 1985). Upon being discharged from the hospital, Bouvia attempted to arrange for private nurses to help her commit suicide, but no nurse was willing. She then went to Mexico to seek physician assisted suicide there, but the doctors and nurses also refused, so she returned to California, where she went to a private nursing care facility. She decided that she no longer wanted to die, but she wanted her feeding tube removed, which her doctors refused to do (Annas, 1984). As a result of this, she returned to court, where her petition was denied. Doctors argued her weight was not ideal and they had the right to rehabilitate her to her ideal weight (Annas, 1986). 
Longmore (1987) argued that Bouvia's social circumstances were not taken into account by either side of the physician assisted suicide debate. Her parents divorced when she was five and at age ten, her mother institutionalized her until she was eighteen. During the intervening years, her mother did not visit her. Upon her release, she had attended a community college where she obtained a two-year degree and then went on to receive her Bachelor's in Social Work from San Diego State University. She was able to live independently with attendant care provided by the state of California, but was denied the opportunity to work because her Social Security benefits, which she needed to survive, would be cut. She attempted to pursue a Master's degree, but could not complete the fieldwork required because no reasonable accommodations were provided. As a result, she was forced to drop out of the program. Subsequently, she had a miscarriage, her marriage fell apart and she lost state assistance to public transportation (Annas, 1984). This preceded her request for assisted suicide. Longmore (1987) believed that her experiences of profound social oppression affected her desire for assisted suicide, not her physical disability. He also believed that if barriers to a quality life were removed, significantly disabled people would not seek assisted suicide. 


\section{Physical Abuse and Maltreatment of Disabled Children}

Children with disabilities are 1.7 times more likely to be abused or neglected than nondisabled children, especially if they are from households with lower socioeconomic status (Sullivan and Knutson, 2000). A lack of family resources increases the risk of abuse for disabled children (Orelove, Hollahan and Myles, 2000). Additionally, abuse and neglect of low income households may be reported more often because these children may have more contact with public welfare and health systems. Regardless of household incomes, low birthweight babies are at a higher risk for abuse and neglect as well as future disability. Maltreatment of disabled children is thought to be related to unrealistic parental expectations, slow progress of a child and excessive physical care needs of the child (White, Benedict, Wulff and Kelley, 1987).

Additionally, parents of disabled children may feel guilt and anger towards their children. Children with language impairments are at an increased risk of abuse and this may be because they cannot communicate what has occurred. Children labeled with conduct disorder, or intellectual and emotional disabilities also experience higher risk of abuse (Govindshenoy and Spencer, 2006). According to CPS workers, disabilities can sometimes be the cause of abuse in children and other times caused by abuse. Disabled children are abused at a younger age than nondisabled children, and unlike nondisabled children, the risk of abuse does not decrease with age (Verdugo and Bermejo, 1997). In addition, more disabled boys are abused than disabled girls, but the reverse is true for nondisabled children. Disabled boys are more likely to be physically abused while disabled girls are more likely to be sexually abused. Boys' proximity to male caregivers puts them at a 
greater risk of abuse (Sobsey, Randall and Parrila, 1997). Sullivan and Knutson (2000) found that neglect was the most prevalent form of abuse, followed by physical, emotional and sexual abuse. Social attitudes that devalue children with disabilities may contribute to their increased risk of abuse. Additionally, disabled families are more likely to be isolated in their community, which contributes to stress and makes abuse harder to detect. Children who live in institutions are even more likely to be abused and neglected than children who live with their families (Verdugo and Bermejo, 1997).

Child protection workers may not have the skills necessary to detect abuse in disabled children, such that while disabled children are at an increased risk, they are underrepresented in CPS caseloads. Therefore, CPS workers need training on disability considerations in child abuse investigations. Parents of disabled children, CPS workers, and special educators have all reported a lack of knowledge on how to detect abuse (Orelove, Hollahan and Myles, 2000).

\section{Euthanasia of Disabled Infants}

The abuse and neglect of disabled children may begin at birth, when the lives of disabled infants are devalued and they are not given proper care. The perspectives of disabled activists and their allies are often at odds with those of bioethicists in regards to many medical and ethical debates, not least of which is providing medical care to babies born with obvious disabilities. Eugenic understandings of disability have not diminished; people born with disabilities are still regarded as a drain on social resources. This belief fuels debates around whether or not infants born with disabilities are entitled to medical care. Nondisabled people may believe that keeping 
alive infants born with disabilities drains resources and prolongs their suffering. Disabled people may have had experiences with discriminatory medical practices. Medical practitioners may be afraid to treat disabled infants because the treatment may fail, and this would be viewed as a failure on the part of the healthcare provider. The differing viewpoints of medical personnel and disabled people may lead to radically different policy choices with regards to providing treatment for disabled newborns. However, disability rights perspectives have been absent from ethical and medical review boards, and this leads to the further marginalization of disabled people with regards to medical decisions. The perspectives of disability rights activists and the history of the abuse of disabled people by medical professionals need to be integrated when making decisions for infants or disabled people who cannot make medical decisions for themselves (Longmore, 1995).

Bioethicist Peter Singer believes that it is morally justifiable to kill disabled newborns, even if they may potentially have a quality of life. He believes that rights of animals who have more capacity to engage with the environment have privileged status over disabled newborns with regard to their right to life (Singer, 2013). Disability rights activist Harriet McBryde Johnson debated Singer in a class he taught at Princeton University. They discussed whether or not disabled infants have more right to life than do animals. They were able to have a civil debate about the fundamental right to life of disabled infants, and McBryde Johnson described her shock when she realized she was starting to like him on a human level. They understood each other's perspectives, but disagreed about the value of disabled infant's lives (McBryde Johnson, 2013). 


\section{Contemporary Capitalist Oppression}

According to UNESCO, 90\% of children with all types of impairments die in infancy and $90 \%$ of those with intellectual disabilities die before age 5 . Thus, the goals of the disability rights movement focus on equality, social justice, and control of resources and decisions that affect disabled people (Davis, 1998). Oliver (2012) outlined how the transition from feudalism to capitalism led to the further marginalization of disabled people in three phases. Phase 1 occurred before the Industrial Revolution, generally known as feudalism. During this time, economic activity was cottage-based and the mode of production did not exclude people with impairments from contributing, although they were at the bottom of the social hierarchy. Phase 2 generally refers to the 18th and 19th centuries across Western Europe and North America when industrial capitalism began (Oliver, 2012). During this time, a shift occurred in the perception of unwanted behavior from viewing such behaviors as evil to a symptom of mental illness (Danforth, 2007). People with impairments were unable to obtain paid work because they were thought unlikely to be able to keep pace with the new factory based production system. Residential institutions began to emerge; regardless, many with impairments were left to beg on the street. People with impairments began to be considered a social and educational problem. Because of this, asylums and special schools emerged in order to segregate disabled people. Phase 3 began in the second half of the 20th century and saw the rise of the medical model. New technologies were seen as promising to cure impairments and liberate disabled people from society's segregative practices. 
The promise of a cure for impairments was overstated, but this ideology continues to inform much of education and rehabilitation policy.

Under capitalism, disabled people are excluded from society and until they are included, they will need assistance to exist (Nocella II, 2008). During the 1970's and 1980's, disabled activists began to resist individual medical understandings of disability. The Union of the Physically Disabled Against Segregation, in its fundamental principles document, asserted that people were disabled by society and not by their impairments. This was the first articulation of what came to be known as the social model of disability (Oliver, 2012). Disabled activists demanded passage of federal laws such as Section 504 of the Rehabilitation Act of 1973, which prohibited the federal government from discriminating against disabled people. During the 1980's, the Supreme Court began to limit disability rights, including the rights of disabled children to a free and appropriate education as well as the rights of people with intellectual disabilities to live in their communities (Longmore, 1995).

People with impairments are still oppressed by capitalism's emphasis on productivity. For example, the Americans with Disabilities Act was written by members of the National Council on Disability who were appointed by the corporate-friendly Reagan administration. By removing barriers to the workplace, the ADA was meant to lessen the social burden of disabled people on public assistance. Corporate culture viewed the ADA more favorably than individual state regulations because ADA policies were more uniform. Disabled employees are thought to be a 
drain on revenues because of the mandate for reasonable accommodations. Under capitalist ideology, members of oppressed groups are thought to be responsible for their own oppression and when they seek equal treatment, they are thought to be seeking "special treatment." By focusing on this, capitalists deflect attention from their exploitation of oppressed groups (Roberts, 2003). Internationally, people with disabilities have lower employment rates than nondisabled people and this is true in both developed and developing countries. Household members may not support disabled people entering the workforce and employers may not see disabled people as capable. Additionally, in developing countries, most employment of disabled people is found in the informal sector. It was found that the countries which did not have a disability gap were low income, and middle income countries did have a disability employment gap. Therefore, employment programs may be especially important for households and people with disabilities. Moreover, disability employment programs need to be tailored to the needs of disabled people in each country's context. Women with disabilities tend to have similar employment rates as nondisabled women in their countries, but men with disabilities have lower employment rates compared to nondisabled men in their countries (Mizunoya and Mitra, 2013). Overcoming disability oppression would necessitate a militant and focused disability rights agenda, which would garner support from a wide spectrum of workers. Gaining equal treatment for disabled employees would help all workers (Roberts, 2003). 


\section{The Rise of Special Education}

People with disabilities have not only been excluded from employment, but also segregated

in schools. Under a capitalist ideology, schools increasingly rely on standards and competition;

those who don't meet the standards fail. The inclusive education movement encompasses more than just disability because disability intersects with other oppressed identities. Special education, which has its roots in eugenic ideology, is now thought to be reformist at best and at worst, reinforces segregation in education. "Special education was created to segregate children who were labeled as 'deviant' and a challenge to the 'established order of regular schooling'" (Dyson, 1999, pg. 40). Medical and educational Professionals were construed as having special knowledge of disabled children and discouraged critique of a system that constructed difference as deviance. According to Tomlinson (1982), special education benefits professionals who are able to advance their careers, while children placed in special education receive an inadequate education. According to Oliver (1996), special schools violate the human rights of disabled children by setting up barriers that need to be removed. However, inclusive education on its own does not challenge the social construction of disability. Disability studies in education critique capitalism, normalcy and corporate media and provide space for the experience of disabled voices in educational settings to be recognized. Some inclusive educators critique how class, race and gender interact with disability to produce oppression. Some inclusive pedagogues believe that only until capitalism is abolished will schools become truly inclusive. 
Of particular concern to proponents of inclusive education is how schools label certain behaviors as deviant and symptoms of disabilities that only exist within educational settings. A primary example of this are students labeled with emotional disturbances. These are students who disrupt the routines within schools and pose a threat to the efficient management of schools. Historically, it is no coincidence that the majority of students labeled with emotional and behavioral disorders are African American males from low socioeconomic status households. During the 1960 's, behaviorism, modeled on Skinner's theory of stimulus and response, heavily influenced special education research and practice. Rather than asking why children misbehaved, behaviorists seek to modify unwanted behavior by rewarding desirable behavior and sanctioning undesirable behavior. This occurs in segregated classrooms in schools. This process does not take into account inequalities that exist in schools, such as the overrepresentation of African American males in these programs. The practice of labeling students with emotional disturbance by schools differs widely from state to state, which demonstrates the lack of objectivity and the social construction of such a label (Danforth, 2007).

"The weakness in the brand of social constructionism that has been articulated in special education is that it has depicted the forces of the social making of disability as enormous and unassailable, looming like unmovable mountains beyond the small scope of concern and practicality of the professional at work" (Danforth and Rhodes, 1997, p. 359). In reality, the meanings of disability are constructed socially by people in relation to others. Special education is 
a bureaucracy, defined by organizational hierarchy in which decision-making authority is at the top. This authority is carried out by those at the bottom of the organization, who have little say over how their superiors dictate its implementation. This makes collaboration with parents very difficult because of the inflexible nature of special education bureaucracy, as consensus is not sought but rather conformity. School districts wield enormous power over parents in decisions made about a child's education. This system ignores the fact that everyone has needs at some point, but not all are categorized as "special" (Danforth and Rhodes, 1997).

\section{The Oppression of Disabled Women}

Feminist theory has historically not acknowledged disability. Feminist issues, which are directly implicated in disability issues, are discussed without including a disabled perspective. These include: reproductive technology, the source of bodily differences, the particularities of oppression, the ethics of care, and the construction of the subject. Disability studies and gender studies were ignored by mainstream academics because they were perceived to have little to do with the majority; they were thought to be niche fields. "Feminist disability theory addresses: the status of the lived body, the politics of appearance, the medicalization of the body, the privilege of normalcy, multiculturalism, sexuality, the social construction of identity, and the commitment to integration" (Garland-Thomson, 2002, p. 4).

Considering disability can show how multiple systems intertwine and redefine each other to produce compulsory able-bodiedness. Integrating disability perspectives into feminist theory can show how the system functions to support an imaginary norm and the structure that ensures 
power and privilege to that norm. The disabled figure acts as a representation for everything the non-disabled culture deems "non-normative." Disability is a cultural system that stigmatizes different kinds of bodies. Thus, disability has four aspects: a system for disciplining certain kinds of bodies, a relationship between bodies and their environments, a set of practices that produce both the able-bodied and the disabled, and a way of describing the inherent instability of the embodied self. The disability system calls into question the fantasy of the body as a neutral instrument of our will. Disability involves bringing identities into consideration, all of which disenfranchise people who are labeled in a particular way (crazy, deformed, sick, maimed, etc). Likewise, the disability system serves to privilege certain statuses such as intelligent, beautiful, fit, etc (Garland-Thomson, 2002). The notion of disability as a social construction challenges medical model views of disability as individual pathology (Ferri and Gregg, 1998).

The voices of women with disabilities are silenced, which results in an ableist feminist movement and a sexist disability rights movement. Women and girls with disabilities experience educational disparities, particularly in developing countries, but also in wealthy countries. Being a woman with a disability is associated with reduced social opportunities (Samuels, 2002). Women with disabilities are often single parents living below the poverty line without social supports. Despite greater access to employment, they fare much worse than men with disabilities or nondisabled women. Disabled women are also thought to be asexual compared to nondisabled women (Ferri and Gregg, 1998). Feminist theory and body theory didn't incorporate disability 
studies until the early 2000's and disability is lacking in most feminist inquiries. Incorporating disability can inform about the body and body studies. Disabled bodies have occupied Western imaginations as a metaphor, but have not been critically examined academically (Samuels, 2002). Both femininity and disability are associated with dependency. Images of the beauty queen and the poster child perpetuate stereotypes about women. The beauty queen is hypersexualized, while the poster child is not seen as a sexual being yet both of these feminine archetypes reinforce bodily normativity and deny disability. The bodies and sexuality of disabled women are also directly controlled by such practices as abortion, forced sterilization and denial of custody to their children. Forced sterilization does not prevent sexual abuse of those with disabilities; instead, it has been used historically as a means to hide it (Samuels, 2002).

Western thought has conflated both female-ness and disability, viewing both identities as a departure from the norm. What was abnormal in traditional cultures became a spectacle in the heydays of the freak show. A disability analysis challenges the cultural norm that unusual bodies are inherently inferior. Female, disabled and dark bodies are presumed to be incompetent and incapable. Women and disabled people are thought to be in need of rescue by white, male, ablebodied, cisgender heroes. Eliminating disabled bodies from history erases the opportunity to use disability as a feminist critical category. People with disabilities, women, and other minorities are often victims of hate crimes such as mercy killings, honor killings, bride burning, infanticide, eugenic sterilization, selective abortions, domestic violence, genocide, racial profiling and neglect. 
All of these practices are legitimated by culture norms that pathologize the Other (GarlandThomson, 2002). Disability occurs within a large social context, which dictates how it is experienced. Feminism should be concerned with the control, abuse and exploitation of disabled women's bodies as it is with nondisabled bodies. The issue of choice around disabled fetuses, for example, is controversial in both the feminist and disability movements, but choice requires adequate information, which is not always available. Low income women carrying disabled fetuses have less access to accurate information and quality, reliable childcare. This is complicated by myths about disabled people as dependent, powerless victims (Ferri and Gregg, 1998). For example, disabled women activists in Lebanon confronted this myth by challenging the experiences of everyday oppression they faced in an ableist and sexist society and helping to strengthen their community through volunteerism (Wehbi, 2010).

\section{Sexual Abuse of Women with Disabilities}

As established, women with disabilities face multiple forms of oppression because of the intersection of disability and gender (Benedet and Grant, 2014). The limited research on sexual assault of disabled people indicates that they are at a higher risk, especially if they have significant intellectual disabilities (Mahoney and Poling, 2011). For example, women who need personal assistants are sometimes pressured to have sex in exchange for caregiving services. People with intellectual disabilities, in both institutional and community based settings, have limited freedom to direct their own lives, and this puts them at a greater risk for abuse of all forms. In addition, women with intellectual disabilities may be reliant on others to bring complaints of abuse to 
authorities, which may contribute to the under-reporting of abuse and increase their vulnerability (Benedet and Grant, 2014). Most perpetrators are male and known to the victim; they are service providers, bus drivers, caregivers, family members or acquaintances. As of 2011, it was found that women with significant disabilities were four times more likely to be sexually assaulted than nondisabled women (Mahoney and Poling, 2011; Peckham, 2007).

Women with intellectual disabilities may be targeted for sexual assault because of the belief that they are less likely to complain or unlikely to be believed if they do complain. Offenders may also believe that intellectually disabled women are lucky to have any sexual encounters, even if it is in the form of assault. They are neither protected from sexual violence by the legal system nor allowed sexual autonomy by society at large. There is a mistaken belief that sterilizing women with intellectual disabilities will make them less vulnerable to sexual assault, but in reality, sterilization only makes sexual assault more difficult to detect (Benedet and Grant, 2014). In addition, service providers and staff in institutions are less likely to report sexual abuse of disabled people because they may not be trained to do so, and the victim may not be able to tell someone about their abuse (Mohoney and Poling, 2011).

The legal system is often unfair to women with disabilities because the charges made by disabled women are determined by whether or not they have the cognitive ability to consent. This is not a standard that nondisabled women are subjected to in order to prove that they were assaulted (Benedet and Grant, 2014). The proportion of prosecutions in which the victim has intellectual 
disabilities is very low and the proportion of convictions is even lower (Peckham, 2007). This may be because women with intellectual disabilities are infantilized and also stereotyped as hypersexualized and animalistic. These women are also not granted the sexual privacy that nondisabled people take for granted; their lives are documented by social services, teachers and family members. This leads to the silencing and lack of agency of intellectually disabled women (Benedet and Grant, 2014). Sexual abuse may result in trauma, anger, depression, behavior problems and low self-esteem (Peckham, Corbett, Howlett, McKee and Pattison, 2007). All women lack power in the case of sexual assault, but for women with disabilities, this problem is magnified (Benedet and Grant, 2014).

\section{How Disability Comedy Can Resist Oppression}

Humor can raise awareness about disability oppression (Smith and Sapon-Shevin, 2009).

Nondisabled people view disability as pitiable and sad because of the history of oppression and marginalization of disabled people; therefore, disability is not commonly associated with comedy (Lockyer, 2015). Yet positive emotions are able to sustain social movements and social interactions. They can be a catalyst for social change, empowering disenfranchised people. Social scientists have done very little work examining the ways in which joy, for example, can be subversive, transgressing social norms in favor of the empowerment of oppressed people (Simmons, 2019).

Historically, comedy has relied on stereotypical images of disabled people. Disability humor is any humor that centers around disability, whether it is used by disabled or nondisabled 
people, while disabling humor is humor that denigrates and ridicules (Reid, Stoughton and Smith, 2006). Joy and enthusiasm can act as a catalyst to ensure a radical human rights movement, which critiques a stable liberal order. "After all, enthusiasm with its 'disdain of authority' is amenable to the 'spirit of liberty' and could be essential for the idealism of human rights" (Simmons, 2019, p. 95). In order to advance human rights, the current model of political hierarchies with its structural violence must be challenged. Humor may be ideal for this endeavor (Simmons, 2019). It offers disabled comedians a venue to challenge and critique mainstream society's perspective on disability and provides a more nuanced view of living with a disability (Lockyer, 2015; Reid et al., 2006). Comedy can promote social inclusion of disabled people and a conversation about the social construction of disability (Shain, 2013). The disability arts movement also gives disabled people a space to share common experiences, which were previously understood as individualistic (Lockyer, 2015; Reid et al., 2006; Smith and Sapon-Shevin, 2009).

Although most disabled comedians view their work as primarily entertaining, they recognize that comedy can inform audience members about the disability experience and potentially change public policy (Lockyer, 2015; Reid et al., 2006). Disabled comedians also use comedy to cope with life experiences (Reid et al., 2006). This involves viewing the oppression of disabled people as political and offering comedy as a way for mainstream audiences to understand the social forces that contribute to disability oppression (Lockyer, 2015). Disabled comedians provoke laughter in a socially acceptable form and in this way, laughter allows audience members 
to collude with the comedian. Disability humor privileges multiple perspectives and is legitimized through audience response (Reid et al., 2006). Disabled comedians may be seen as outsiders to audience members, but creating a sense of shared experiences with audience members helps disabled comedians be more relatable. For example, disabled comedians may joke about everyday experiences that most people have, such as dating, but from a disabled perspective (Lockyer, 2015;

Shain, 2013).

Comedy also allows for the discussion of taboo topics such as having sex as a disabled person (Shain, 2013). Humor helps build connections that nondisabled people can relate to in their own lives (Smith and Sapon-Shevin, 2009). Audience members are treated as insiders to the comedian's experience while the stereotypes and prejudices are challenged (Shain, 2013). The fact that disabled people are performing and laughing at life confronts stereotypes. This humor can dissolve fear that nondisabled people have about disability. In moving from being objects of ridicule to laughing at themselves to laughing at disabling experiences and encounters, disabled comedians are performing disability in new ways (Reid et al., 2006).

\section{Conclusion: Final Thoughts on Disability Oppression}

Disability oppression needs to be understood as a political problem, requiring multiple political solutions. Minority groups, such as African Americans and women, have historically distanced themselves from disabled members of their community, but this can no longer be justified. Some disabled people do not identify as part of the oppressed minority because disability 
is associated with being less valuable and the word disability carries assumed negative connotations.

Disability oppression has existed since the days of feudalism, but prior to the Industrial Revolution, disabled people were at least included in their communities, although they were still subject to discrimination. The rise of capitalism meant that disabled people who could not work became surplus, and this led to the advent of institutions to warehouse people who could not contribute. Physicians began to experiment with curing and educating people in these institutions, but the promise of cure was overstated. However, this ideology, called the medical model by scholars in disability studies, continues to play a large role in the lives of disabled people today (Oliver, 2012). It has led to segregated special education, which marginalizes disabled children, isolating them from their nondisabled peers (Dyson, 1999; Danforth and Rhodes, 1997). Because blackness and disability have historically been linked, African American male students are disproportionately labeled with disabilities, such as emotional disturbance, which require special education (Danforth, 2007). In addition, women with disabilities are oppressed by a sexist and ableist society, which has historically excluded them from the mainstream feminist movement and the early disability rights movement. Disabled women are more likely to experience sexual exploitation and less likely to be able to report abuse (Garland-Thomson, 2012; Ferri and Gregg, 1998; Samuels, 2002; Mohoney and Poling, 2011; Benedet and Grant, 2014). 
However, disabled people have not endured abuse silently; during the 1960's and 1970's, The Union of the Physically Disabled Against Segregation began to articulate the social model of disability, stating that disabled people are oppressed by society and not their impairments (Oliver, 2012). This led to legal gains such as the passage of Section 504 of the Rehabilitation Act of 1973 , the Individuals with Disabilities Education Act of 1975, which guaranteed disabled children their right to a free and appropriate education, and the Americans with Disabilities Act of 1990. These legal protections have led to an increasing number of disabled people in inclusive schools and in the workplace, but discrimination remains a problem (Longmore, 1995; Roberts, 2003).

Disabled newborns are still denied medical treatment, and physician assisted suicide is still thought to be an alternative to the oppression disabled people faced (Singer, 2013; Longmore, 1987). These are not political solutions to the social oppression; they are individual solutions for a life made unbearable. A political solution would begin with the recognition that disability oppression affects all, and the inclusion of disabled voices is paramount (McBryde Johnson, 2013; Longmore, 1995, 1987).

In the past twenty years, disabled comedians have begun to address the oppression of disabled people through humor. They are able to make people laugh at the stereotypes and misconceptions around disability and, thus, challenge those stereotypes. This is a way of educating people about disability oppression that is non-threatening. Comedy may be an effective tool for 
disability advocacy and the inclusion of disabled voices in the mainstream (Bingham and Green, 2016; Lockyer, 2015; Reid, Stoughton and Smith, 2006). 


\section{Chapter 2}

All too often people with disabilities are portrayed as objects of pity by popular media

(Schwartz, et al., 2010). According to Nelson (1999), there are six major stereotypes in mainstream media: disabled people are portrayed as victims, as heroes, as a threat to others, as unable to adjust, as someone to be cared for, or as someone who should have died. In fact, many nondisabled people view disability as pitiable, tragic or sad (Haller and Ralph, 2003). These images persist in dramatic representations of disability and are harmful because they misinform the public about what life with a disability is like and the capabilities of disabled people. The lack of familiarity with disability makes it harder to combat these stereotypes (Rieger and McGrail, 2015). Humor can be used as a tool to either dispel or disseminate these stereotypes. Subversive forms of humor have been used since the days of the Greek comedy and the court Jester of the Renaissance period, and continue in the work of contemporary disabled comedians. Humor is unique in that it can challenge privilege and reveal hypocrisy (Bingham and Green, 2016).

Empowering humor infuses disability rights and disability knowledge into portrayals of disabled people, while disabling humor perpetuates these stereotypes and misunderstandings. Humorous narratives of either type have significant cultural power, especially when challenging the stereotypes surrounding marginalized groups (Chapple and Ziebland, 2004). Humor can be 
used to analyze social norms and practices in any given society (Bingham and Green, 2016). By

analyzing humorous exchanges and people's reactions to them, scholars can understand more about the society and culture that produced the humor (Chapple and Ziebland, 2004). For example, Terrion and Ashforth (2002) found that putdown humor among police officer candidates either reinforced group solidarity or created tensions between members. Sexist putdowns were upsetting to female recruits, while jokes about the hometowns of other recruits were interpreted to be nonthreatening. This study showed that the intentions of the joke were important in determining whether or not they were considered humorous. Overall, banter was found to be helpful for building group solidarity in the workplace.

Humor can be used to reinforce group solidarity by marking the boundaries between insiders and outsiders, reduce or exaggerate the power imbalance between people, reduce tension or embarrassment, cope with uncertainty, explore ambiguous situations or distance oneself from unpleasantness (Chapple and Ziebland, 2004). Demjen (2016) found that cancer patients who were part of an online support group used humor to make fun of the consequences of their cancer and treatments, enabling users to talk about frightening, sensitive or taboo experiences. This reduced the psychological impacts of their experiences and facilitated individual and group 
empowerment, diminishing feelings of isolation. The role humor plays to reinforce group solidarity among disabled people and to educate nondisabled people about life with a disability deserves closer scholarly examination.

This chapter will review the relevant academic literature on humor about and by disabled people. First, the three major theories of humor - superiority theory, incongruity theory and relief theory - will be discussed. Then, the first documented instances of disabled people creating comedy will follow. Next, there will be a review of insider disability humor and disability humor as resistance. Empowering portrayals of disability humor on television will come next. Finally, disempowering humor on NBC's Saturday Night Live will be critiqued.

Humor, when used by disabled people and their allies, can humanize disabled people to those who are unfamiliar with disability. By dispelling stereotypes, humor can be used as a powerful teaching tool. However, humor has yet to be conceptualized as a means to educate people about the issues faced by disabled people. I'm interested in conceptualizing humor as a way to break down barriers and create a dialogue about disability issues and disabled lives. 


\section{Humor Theory}

The oldest theory of humor, superiority theory, was first articulated by Thomas Hobbes

and posits that humor arises when people realize they are superior to another. Often, discussions

of superiority theory overlook the fact that people may not only feel superior to others, but to

themselves in the past, recognizing their own growth (Lintott, 2016). Superiority theory cannot

account for situations in which people laugh at things they relate to rather than feel superior about

(Bingham and Green, 2016). Superiority theory can, however, predict humor that is both harmful

to others and helpful to oneself. For example, it would be harmful to find humor in somebody else

falling, but it may be helpful to laugh at oneself when one encounters the same situation.

Superiority theory should be understood as limited in that it does not attempt to explain all forms

of humor. However, much of comedy is directed at the misfortune or ignorance of others, such as

ridiculing politicians and their blunders (Lintott, 2016). Superiority theory cannot describe all

humorous situations, but rather explains a kind of amusement people sometimes experience when

they feel more competent than someone else or their former selves (Lintott, 2016). Superiority

humor can reinforce the dominance of those in higher social classes who have more political power

by belittling those who have fewer resources. This can be seen in jokes that ridicule people with

disabilities, for example (Bingham and Green, 2016). 
Analysis of the content and context of the humor becomes central to understanding its function (Moran, 2003). Superiority theory does not attempt to distinguish between laughing at the foibles of others and laughing with them (Lintott, 2016). According to Plato, laughter at the ridiculous is tainted with the pain of malice, so there is a fine line between comedy and tragedy (Moran, 2003). Superiority humor can be used to reinforce social norms, placing the blame on individuals who transgress these norms rather than an oppressive society. Thus, the medical model, which focuses on individual impairment, aligns with superiority theory because disabled people are viewed as inferior and, therefore, it is permissible to laugh at them (Bingham and Green, 2016). One example of this are the freak shows of the 1930's and 1940's, in which disabled people were put on display for the amusement of nondisabled people (Bogdan, 1988).

Superiority theory can be used to understand the performances of some comedians who mock people with disabilities, although this practice is becoming less and less accepted by mainstream society. During medieval times, the court jester, who was often a little person, was the only one allowed to mock the king because of the jester's inferior status. Contemporary disabled comedians sometimes use superiority humor offstage when someone else is making fun of disabled people. The comedian will ridicule the person who is using derogatory humor against disabled 
people. Comedians may use these encounters onstage to demonstrate that a nondisabled person making fun of someone's impairment is not acceptable. In this way, superiority humor can be used to educate audiences about the difference between disabling and empowering humor (Bingham and Green, 2016).

One example explained by superiority theory is how disabled people are the subject of humor in Morocco. Islamic beliefs and culture influence the way disability is viewed in this society (Karimova, Sauers and Dakka, 2015). Historically, Muslims have believed that disabled children are a curse bestowed upon fathers who have sinned. Thus, much of the humor reflects the idea that these children are a burden to parents who would, under normal circumstances, rely on their adult children to take care of them in old age. Instead, parents of disabled children will be expected to continue to care for their children until they die. Rather than dispelling stereotypes and myths, these proverbs reinforce and disseminate them (Karimova, et al., 2015).

The incongruity theory was first articulated by Kant and states that humor is experienced when there is an unexpected association of two normally unrelated or contradictory concepts. Incongruity is described in four ways: surprise, juxtaposition, atypicality and violation. Surprise functions as a deviation from what was expected, which is a key component of humor. Juxtaposition is a contrast between two concepts that are not usually associated with each other. 
Atypicality describes a departure from accepted social norms. Violation is defined as a disparity between the way things are and how they should be (Warren and McGraw, 2015).

Incongruities can result in a buildup of tension, but when the context changes or is less threatening than expected, the tension becomes unnecessary and is seen as an affection that arises if a strange expectation is suddenly reduced to nothing. Humor arises when a person no longer feels threatened; there is a release of tension and the person experiencing the humor feels relief (Warren and McGraw, 2015).This kind of humor is predicated on a shared understanding of cultural beliefs and social phenomena. It relies on a sociological understanding of the phenomenon being joked about; without this shared understanding, there is no incongruity to be laughed at. In this way, incongruous jokes can make fun of those in power and give voice to the underrepresented (Bingham and Green, 2016). For example, a stand-up comedian who is also a little person may joke about how very tall he is, and the incongruity between his actual height and how tall he claims to be might be funny. One limitation of incongruity theory is that incongruity alone is not enough to differentiate humorous and non-humorous situations. An alternative conceptualization, benign violation, may be more a more accurate description of this kind of humor because it reduces the 
likelihood that tragic or amazing situations are falsely predicted to be humorous (Warren and McGraw, 2015).

Freud, in his psychoanalytically oriented relief theory, saw humor as an expression of repressed emotions and anxieties. Laughter occurs when a person is permitted access to the source of his or her repressed emotions in a manner that is not threatening to the ego. Humor occurs when a person gains insight into his or her own impulses; one's psychic sensor has temporarily been deceived by the humor. For example, if you were to get home and find that someone unexpected is in your house, you may feel a build-up of tension, but when you realize it is a loved one trying to surprise you with a practical joke, you may feel a release of tension as well as finding humor in the situation. Disabled comedians may use relief humor to allow audience members to explore unknown or critical aspects of being disabled (Bingham and Green, 2016).

Freud viewed humor more positively than many of his followers; he described it as one of the highest forms of psychic defense and considered it to be a healthy means of dealing with the world (McDonald, 2012). It is important to note that personal humor may not be a sign of repressed feelings, but is sometimes a reflection of a full awareness of one's circumstances; this can be especially true for the coping humor that disabled people often engage with. Regardless, having a 
disability does not mean that the humor one engages with always functions differently (Moran, 2003). Relief theory would posit that people with disabilities laugh to keep from crying about their situation, but this thought is connected to the medical model view of disability as personal tragedy. However, sometimes relief humor can be used by disabled people to cope with a disabling society. This kind of humor creates a space for disabled people to interact with society on an equal playing field (Bingham and Green, 2016).

Theories of humor attempt to distinguish between humorous and non-humorous situations.

For example, the presence of an incongruity alone does not necessarily mean that a situation is funny. Likewise, not all feelings of superiority result in the experience of humor. In addition, relief is not always humorous (Warren and McGraw, 2015).

\section{Historical Accounts of Disability Humor}

The first documented instance of disability humor in the United States occurred as a result of slavery's prohibition against fighting. The most disobedient slaves were purposely disabled and disfigured by owners to serve as an example for other slaves who were contemplating running away. Additionally, slaves were forbidden from fighting because this would lead to property damage. Instead, the slaves would insult each other to keep their spirits up. Disabled slaves were sold together for a substantial discount as a dozen. Thus, this process became known as The 
Dozens. This insult humor was essentially a humor of disability as it empowered the disabled slaves to be resilient in the face of their purposeful disfigurement (Smith, 2013). The classic "yo mama" joke is a prime example of black insult humor. One joke goes, "Yo mama's so fat that when she fell, no one was laughing, but the ground was cracking up" (www.laughfactory.com/jokes/). This comedy was passed on through generations and continues to influence contemporary black humor (Smith, 2013). Blackness has historically been associated with disability under racist and ableist ideologies. In fact, slaves were thought to be both physically adept and mentally inferior; this ideology was influenced by eugenic beliefs, which assumed that all racial minorities were somehow disabled (Pickens, 2013).

This type of comedy has also been documented among wealthy Victorian White women. In her diary, Alice James, sister of novelist Henry James and psychologist William James, pokes fun of the sympathetic gaze she encounters from acquaintances. Alice James had breast cancer and psychiatric disabilities, which left her bedridden and eventually led to her early death. She used humor to deflect the attention she received as a result of her illness (French, 2014). During the Victorian era, wealthy disabled women were expected to be pleasant patients. Cheerfulness was 
of utmost importance so that others were comfortable in the presence of the invalid. James used

her diary to mock the expectations of society and reclaim her subjective stance.

For example, one entry in the diary discusses how her family was not taking her illness seriously and mocked her for being sick. "How well one has to be, to be ill! These confidences reveal to you, dear Inconnu, so much mental debility that I don't want to rehearse herein my physical collapses in detail as well, although I am unable to escape the general tone of lamentation. But this last prostration was rather excessive and comic in its combination, consisting of one of my usual attacks of rheumatic gout in that dissipated organ known in the family as 'Alice's tum' in conjunction with an ulcerated tooth, and a very bad crick in my neck" (James and Edel, 1965, p. 129). The diary was published after her death and provides insight into how she coped with her illness and society's expectations. This is one of the first published instances of insider disability humor used for coping (French, 2014).

\section{Using Disability Humor for Group Solidarity and Outsider Education \\ Shakespeare (1999) argued that attempts to censor the issues people joke about were}

unhelpful. Historically, humor has played a dual role for disabled people, both liberating and

stigmatizing depending on the context of the joke and who is telling it. Cultural responses to impairments are ambiguous and reflect embarrassment of nondisabled people. Disabling jokes are 
found in the margins of civilized society. Many of the jokes told by disabled people, which nondisabled people may find embarrassing, focus on flawed performances or deformed physique. Telling these jokes has become more and more taboo as people with visible impairments have been increasingly integrated into the larger society. The comedic stereotype of a disabled clown is part of a cultural response, which sees physically different people as an object of curiosity, hostility or pity rather than part of mainstream society. In this way, disabling humor shares a lot with racist or xenophobic humor in which difference is exaggerated in order to humiliate.

Shakespeare (1999) argues that this humor reflects a discomfort with disability because historically, disabled people have been segregated and many nondisabled people did not come into contact with a person with impairments. Therefore, nondisabled people may be ignorant as to how to interact with disabled people and anxious to say the right thing. This anxiety can lead to a strain in the interactions between disabled and nondisabled people, preventing communication or a rapport developing. During these strained interactions, the disabled person must find a way to acknowledge the difference while at the same time showing that it is not important, so that the interaction can progress. Families of children with disabilities allow their children to dictate their own perceptions of humor, and this humor may make their nondisabled peers more comfortable 
around them (Rieger, 2005). Making a joke is one way to reduce tension or anxiety in the nondisabled person. For example, men with testicular cancer found it helpful when colleagues or loved ones made jokes about their situation to lighten the mood (Chapple and Ziebland, 2004).

However, outsiders need to be respectful about how they joke about disability; some jokes can only be told by disabled people (Rieger, 2005). When disabled people laugh at themselves, they develop a rapport, which allows communication to overcome stigma (Chapple and Ziebland, 2004). A comedic language around the body makes impairment less unsettling as disabled people have shown that impairment is not the end of the world. For example, Deaf comedian Terry Galloway uses humor to combat oppression and attitudes of xenophobia against disabled and queer people (Bingham and Green, 2016). Disabled people and their families have found humor to be a helpful way of managing stress and as a way to protest the dominant culture's ideas about and misconceptions of disabled lives (Rieger, 2005). In fact, research in the field of psychology suggests that using humor to cope with stressors and trauma is positively associated with increased selfesteem. Unfortunately, humor is an understudied area and is under-utilized as a coping mechanism. Humor can make negative situations more acceptable and is, thus, very useful for disabled people who encounter structural barriers in everyday life (Geisler and Assuncao, 2014). For example, 
people might recall an incident which was tragic at the time, but find humor in its retelling. These jokes may allow for a wide range of emotions including anger, anxiety, guilt, disappointment and grief (Chapple and Ziebland, 2004). Using humor can make one feel more in control in difficult situations and may also aid in coping with life's stressors (Marziali, McDonald and Donahue, 2008).

\section{Disabled Comedy as Resistance}

Empowering forms of humor have enabled disabled people to come together on the basis

of a shared political ideology and assert a positive identity. Disability artists challenge normative views of disability by directly confronting sympathy and other problematic attitudes towards disability. This art has been used to teach about stereotypical portrayals of disabled lives (Seidler,

2011). Sometimes humor is the only way for disabled people to connect with others on an equal footing (Chapple and Ziebland, 2004). This comedy is used to identify barriers and to challenge cultural values and taboos, which dictate everyday interactions with nondisabled people. In this way, disabled people have moved from passive objects of scorn towards a political development of satire. Radical disability comedy makes light of disabling encounters and environments, not disabled people themselves. In this way, disabled people have moved from being laughed at to laughing at themselves to laughing at disabling situations and nondisabled people (Rieger, 2005). 
One example of this kind of humor is the dizABLED comic strip created by John and Claire

Lytle, which politicizes the way disabled people are viewed in a humorous way (Seidler, 2011).

This humor may help nondisabled people recognize their assumptions about disabled people and change them, and this might lead to the inclusion of disabled people in their communities (Smith and Sapon-Shevin, 2009). Humor of this kind relies on people's understanding of the stereotype surrounding disability in order to debunk it (Walters, 2013). Thus, people with impairments are performing disability in new ways, challenging prejudicial attitudes and demanding acceptance and inclusion (Shakespeare, 1999). Disabled comedians view their work as in line with the work of comedians of color and female comedians who challenge racism and sexism. Disabled comedians not only describe everyday life with a disability, but describe it in a way that makes disability accessible and relatable to all (Bingham and Green, 2016).

Resistance theory can be used to understand the goals of empowering comedy around disability issues. Resistance theory emerged from critical theory and can be used to analyze power relations and social oppression. Disability becomes a product of structural inequities and social injustice. Resistance theory acknowledges individual agency and group agency, which can produce positive social change for oppressed groups (Gabel, Peters and Symeonidou, 2009). Resistance 
will look different depending on each social context. It can be used to push against dominant forces and allow others to acknowledge the social oppression experienced by disabled people. The social model of disability has been used as a form of resistance in itself to the medical model, which equates disability as pathology in individuals. The social model asserts that disability is created in the interaction between a person with impairments and barriers in the larger society (Oliver, 2013). A problem with the strong social model is that it does not attempt to account for how impairment itself can be experienced as limiting. In some cases, no amount of barrier removal can ameliorate the effects of impairment (Shakespeare, 2006). The original articulation of the social model did not take this into account, but there has been a recent push in disability studies to acknowledge the effects of impairment (Gabel and Peters, 2004).

However, one of the strengths of the social model is that it can be used in conjunction with other theories such as feminist theory, critical race theory and queer theory to examine the intersectionality among disabled people (Garland-Thomson, 2002). Some scholars find it useful to theorize about both impairment and social structures to understand disability more holistically (Gabel and Peters, 2004). In this way, disabling structures remain central to understanding disability oppression, but disabled people's subjectivity is also taken into account. The diversity 
among disabled people and their experiences needs to be acknowledged in disability studies, but a strong social model leaves no room for dissent and debate. These debates around the social model should not be silenced by proponents of critical theory and a strong social model because they themselves push disability studies into resistance (Gabel and Peters, 2004). Disabled comedians may hold views that are consistent with the social model of disability and resistance theory, but may not see themselves as activists in their work (Bingham and Green, 2016).

\section{Mainstream Disabled Comedy}

In the last twenty years, disabled comedians have emerged to challenge mainstream notions

of disability with their own perspectives (Lockyear, 2016; Reid, Stoughton and Smith, 2006).

Disabled comedians are able to debunk stereotypes and make audience members laugh at their

own false assumptions regarding disability. As children, these comedians may have employed humor to help others feel more comfortable interacting with them (Bingham and Green, 2016).

This comedy, fueled by insider knowledge, has challenged mainstream disabling humor and offered a new paradigm in disability humor. Rather than focusing on physical or intellectual differences, disabled comedians focus on access barriers or misunderstandings that nondisabled people have about day-to-day life with a disability (Reid, et al., 2006). 
Many audience members are reluctant to laugh at disabled comedians because of the taboo against laughing at someone who is different or perceived to be less fortunate. Additionally, disability is thought to be a serious subject, which means that most nondisabled people do not get to see that disabled people like to have a good time (Haller and Ralph, 2003). Nondisabled people may focus on the surface differences between themselves and disabled people, but the strategic use of humor can humanize disabled people for mainstream audiences (Rieger and McGrail, 2015). Disabled comedians sometimes make fun of the incongruity between cultural understandings of disability as tragedy, informed by the medical model of disability, as opposed to the richness of their own lives. They use humor to combat oppression and stereotypes around disability in ways that had not been explored before the 1970's, when a few disabled comedians began performing in local comedy clubs. Disabled comedians are able to educate about the physical barriers they encounter in their everyday lives when the stages in comedy clubs are inaccessible to them; they make jokes about it in order to inform the audience. They also educate about attitudinal barriers, which perpetuate stereotypes surrounding disability (Bingham and Green, 2016). In 2006, Josh Blue, a comedian with a physical disability, brought disability humor to the mainstream and won 
NBC's Last Comic Standing. For the first time, large audiences were exposed to humor from a disabled person's perspective (Lockyear, 2015).

\section{Authentic Comedy on Television}

Television comedy has begun to catch up with a more empowering humor of disability.

When disabled people are involved in writing scripts for sitcoms and adult-themed cartoons, the comedy often takes a satirical look at nondisabled perceptions of disabled people, revolutionizing disability humor (Haller, 2010). This humor confronts social oppression and can serve to protest the ways in which disabled people have been portrayed historically. Audience members can laugh at their own perceptions of disability and, in this way, stereotypes are challenged in a nonthreatening environment. This is how humor builds bridges of understanding between disabled and nondisabled people. Authentic representations of disability portray disabled people as able to appreciate and produce humor (Rieger and McGrail, 2015).

Two popular television sitcoms, The Big Bang Theory and Community, featured major characters who exhibited characteristics of Asperger's Syndrome, although they were never labeled as such. Sheldon, in The Big Bang Theory, and Abed, in Community, were both fully integrated and valued members of their social circles. Much of the comedy in the two sitcoms centered around their misreading of social cues. However, their friends were willing to help them 
through complex social situations. Sheldon exhibited many signs of what used to be called Asperger's Syndrome, including always sitting in the same place in his apartment, eating the same meals on certain days of the week, or requiring a sarcasm sign to understand his roommate. He was temporarily fired when he insulted the intelligence of his boss in the Physics department where he worked. In The Big Bang Theory, neurotypical characters were portrayed as struggling with social situations as much as Sheldon did, which produced many humorous moments. Because Sheldon was an integral member of his friend group, the show resisted the stereotype of people on the autism spectrum being asocial.

In Community, Abed was always fully integrated whether he was aware of being included or not. These shows demonstrated how labels were dependent on the cultural context for meaning and exploited the tensions between sameness and difference. Community and The Big Bang Theory had the potential to tear down categories and barriers. This kind of humor shows how things could be in a more inclusive society (Walters, 2013).

The cartoons created by John Callahan, who wrote for the Miami Herald and acquired a disability as an adult after a car accident, also debunked stereotypes surrounding wheelchair users and paralyzed individuals. Many nondisabled people wrote to his newspaper that they were 
offended by his cartoons until they realized that he was disabled and his cartoons were satirical.

Callahan's cartoons exaggerated the stereotypes surrounding disability to an absurd extreme in order to ridicule them. He also mocked the helping professions such as social workers and nurses for their lack of understanding of the disability experience (Haller and Ralph, 2003). For example, in one cartoon, he illustrates three men on horses going after someone who uses a wheelchair, but the wheelchair is vacant. The caption reads: "Don't Worry, He Won't Get Far On Foot." Some disabled people understood the humor right away because of the shared experiences of using wheelchairs. His work challenged some of the stereotypes that the disability rights movement had opposed for years (Shultz and Germeroth, 1998). These kinds of jokes can help establish solidarity among disabled people and also helped politicize individual struggles (Chapple and Ziebland, 2004).

In 2000, Nickelodeon began airing a cartoon written by Callahan, Pelswick, whose main character was a 13-year-old boy who used a wheelchair due to a car accident, similar to Callahan's own personal experience. This cartoon targeted younger children and featured a realistic portrayal of a disabled teenager; it normalized and demystified life with a disability. Pelswick was a rambunctious youngster who was fully included in his peer group and got into trouble with his 
friends as an equal. This cartoon was trailblazing because it normalized disability and introduced a younger audience to the insider humor of disabled people (Haller and Ralph, 2003).

The long-running TV show Monk, which aired on the USA network between 2002 and 2009, featured main character, Adrian Monk, who exhibited symptoms of Obsessive Compulsive Disorder (OCD). The humor in the show revolved around how he managed the symptoms and the odd behaviors he exhibited towards others. However, the behaviors he exhibited also enabled him to solve crimes because he was so meticulous and focused on details. His phobias and obsessions made him exceptional and drove the humor of the show. Monk also hired caregivers to help him manage his symptoms and stay focused on his work. Pickens (2013) argued that Monk's African American female caregivers represented the historical figure of Mammy and one of his caregivers, Varla, was uncomfortable with his behaviors, insisting that there was nothing wrong with him. This is a comedic representation of situations in which a person's invisible disability is unacknowledged and the individual has to suffer the consequences (Pickens, 2013).

\section{Empowering Humor on Primetime Adult-Themed Cartoons}

The adult-themed cartoon Family Guy, which airs on the FOX network on Sunday nights,

has many characters with disabilities. The main character, Peter, has a next-door neighbor, Joe, who is a police officer and was paralyzed on the job. Joe uses a wheelchair and is included as one 
of the guys who hangs out at the bar. Much of the humor surrounding Joe pokes holes at assumptions about people who use wheelchairs. One episode of Family Guy, which aired during the 2008 election, involved Peter's son, Chris, who had a crush on Ellen, a girl with Down syndrome. Chris assumes that Ellen will be sweet and low maintenance. However, he is disappointed when she turns out to have a mind of her own and opinions on how their relationship should go. At the end of the episode, Chris tells Ellen that he thought she would be different, but she is as demanding as everyone else (McKeown and Darke, 2013). This directly debunks the stereotype of people with intellectual disabilities being very innocent and pliable.

Another adult-themed cartoon, South Park, which airs on Comedy Central, features two disabled characters, Jimmy and Timmy, who are fully included in their elementary school. The cartoons are crudely drawn and not politically correct (Reid-Hresko and Reid, 2005). Timmy has a speech impediment and intellectual disabilities; the only word he can say is his name, Timmy. Nevertheless, he is integrated into the show's landscape and is a recurring character. The adults in the program feel bad for Jimmy, who uses a wheelchair, but the children treat him as one of their own and are not afraid to tease him as children do. The show portrays the children as more inclusive and enlightened while the adults are uncomfortable around Jimmy and Timmy. Much of 
the humor is in this dynamic, using children to drive social analysis (Reid-Hresko and Reid, 2005).

In one episode, a main character, Cartman, called another character a "retard"; this created an alliance among people who have been oppressed by the use of such language and exposed how harmful language can be (Smith and Sapon-Shevin, 2009).

The long-running cartoon The Simpsons, which also airs on the FOX network, featured an episode in which the main character, Homer, attempts to gain a substantial amount of weight to qualify for workplace accommodations at the nuclear plant where he works (Fink, 2013). This is a satirical look at the Americans with Disabilities Act mandate of reasonable accommodations in the workplace. Homer is allowed to work from home and is given a computer and a chair that accommodates his size. Ironically, given that he is working at home, Homer is the only employee who identifies a potential nuclear spill and rushes to the power plant as quickly as his large body will allow. He ends up getting stuck in a nuclear reactor and saves the day by literally plugging the hole with his body. At the end of the episode, Mr. Burns, the nuclear plant owner, agrees to help Homer lose weight by paying for weight loss surgery and the show ends with Homer as the town's hero (Fink, 2013). 
While political humor centered around disability issues can be empowering when it is created by disabled people and their allies, humor can also be derogatory and offensive when disabled people become the target of highly stereotyped portrayals. Saturday Night Live's portrayal of former New York governor, David Paterson, is one example of disparaging humor directed at a person's disability.

\section{Disempowering Humor in Mainstream Society: The Case of David Paterson}

Blind former New York governor David Paterson was the subject of ridicule on the popular

comedy show Saturday Night Live (SNL), which airs on NBC Primetime. Actor Fred Armisen

portrayed Paterson as unaware of what he was doing; in one skit, he held a statistics chart upside down and crossed in front of the camera, wandering back onto the stage unaware of where he was going. Interestingly, the skits never make fun of Paterson for being Black, but, instead, focus on his blindness to drive the humor. This may have been because in the majority nondisabled society, ableist comedy is not seen as offensive because of ignorance around the day-to-day experience of disabled people. The skits would have had more resonance if they critiqued Paterson's political behavior rather than making a mockery of his disability (Haller and Becker, 2014a). From the start of his administration, Paterson was plagued with political, sex, and drug scandals, a declining state economy and low public approval ratings (Haller and Becker, 2014b). The Daily Show with Jon 
Stewart and The Colbert Report with Stephen Colbert focused on Paterson's foibles as governor, which Paterson acknowledged to be fair game.

Saturday Night Live, in contrast, focused on the physical humor associated with blindness and used blindness stereotypes. Despite criticism from both Paterson and blind advocates, Armisen continued to play Paterson on $S N L$ throughout 2008 and 2009, emphasizing physical difficulties thought to be experienced by blind people. In fact, Paterson was invited to appear alongside Armisen, and what started as a critical visit with Paterson mocking Armisen for using his blindness as a crutch ended with Paterson engaging in the same physical humor intended to ridicule blind people (Haller and Becker, 2014a; Haller and Becker, 2014b).

This juvenile physical humor is a departure from $S N L$ 's usual critique of political figures for their blunders. $S N L$ has a rich history of inviting politicians to appear on the show and engage in self-directed humor, which research shows has a positive impact on viewers, encouraging them to sympathize with the comedic target who is willing to take ownership of his or her shortcomings (Haller and Becker, 2014b). In fact, Haller and Becker (2014b) conducted a study in which college students in New York City were shown either Armisen's portrayal of Paterson or Paterson's own self-directed performance and found that those who viewed Paterson's appearance on $S N L$ had a 
more favorable opinion of both the governor and blind people than those who saw Armisen's

portrayal. Viewers identified Armisen's parody of Paterson as hostile and were least favorable of those clips. This demonstrates that comedic interpretations of disability are powerful in shaping attitudes and opinions towards disabled people and should be portrayed accurately and responsibly. Comedy is a powerful tool for affecting social change when used to convey a shared humanity. Furthermore, disabled people are not against the use of humor, but activists may question the way disempowering humor portrays disabled people (Walters, 2013).

\section{Conclusion: Future Research in Disability Comedy \\ Humor has the potential to shift people's perceptions of what it means to be human}

(Walters, 2013). Constructive humor can create environments where people mutually support each

other, promote individual self-esteem, and create meaningful connections between people;

destructive humor does the opposite. Without the involvement of disabled people, humor around

disability becomes patronizing and highly stereotypical (Haller and Ralph, 2003). Research on

disability comedy has yet to apply any of the theories of humor to the work of disabled comedians

or empowering forms of humor on television. Dramatic representations of disabled people tend to

disseminate harmful stereotypes while the comedy of disabled people and their allies debunk these stereotypes, offering a more realistic view of disabled lives (Nelson, 1999). Disabled comedians 
are able to make audiences laugh at their own misconceptions of the disabled experience. This gives audience members a more accurate insight into the disability experience, fueled by real insider knowledge (Lockyear, 2015; Reid, et al., 2006). Furthermore, families of children with disabilities consider themselves insiders to humor related to their children's impairments and help their disabled children create their own unique humor (Rieger, 2005). In addition, empowering humor can make disability less mysterious to children and help promote inclusive practices in classrooms (Haller and Ralph, 2003; Smith and Sapon-Shevin, 2008).

In order to find out if nondisabled audience members' perceptions of disabled people have shifted, it would be useful to conduct exit interviews after they've seen a live performance by a disabled comedian. I'm also interested in exploring the barriers disabled comedians face when performing and preparing for live performances at comedy clubs. For example, some of the comedians I've talked to informally have told me that stages and green rooms are often not wheelchair accessible and they do not find out about this until they arrive. This may make it difficult to be funny because audience members may feel sympathy rather than humor toward a comedian who has to do his or her performance from the front row of the audience instead of on stage. 
The history of empowering disability comedy in the United States began in slavery, when slaves who purposely became disabled by their masters would insult each other in order to keep their spirits up (Smith, 2013). This comedy continues to influence African American humor as well as disability humor because it is a comedy of resistance. Disability comedy became mainstream when Josh Blue won NBC's Last Comic Standing in 2006 (Lockyear, 2015). However, stereotypes still remain a problem in popular media, as was demonstrated by Saturday Night Live's portrayal of former New York governor David Paterson as incompetent and bumbling because of his blindness (Becker and Haller, 2014a; Becker and Haller, 2014b). Adult-themed cartoons are another avenue of empowering humor, which has reached mainstream audiences. These cartoons exaggerate stereotypes for the purpose of showing the ridiculousness of widely held beliefs about disabled people (Fink, 2013; Haller, 2010). The voices of disabled comedians and the stories they tell need to be heard in order to change the way the way mainstream nondisabled audiences view disabled people, and this is the goal of my dissertation. 


\section{Chapter 3}

Historically, disabled people have not been asked about their own lives or seen as experts

by researchers in academia (Bricher, 2000). This is because disability is associated with incompetence and disabled people are not seen as knowledge producers. My dissertation challenges this history of exclusion by situating disabled comedians at the center of my research.

My first research questions that I am exploring are: What are disabled comedians achieving with their comedy, in terms of teaching audience members a different perspective of disability?

Disabled comedians may be social change agents, although they may not see themselves as such.

My second research question is: What do audience members gain from attending performances by disabled comedians, specifically in regards to learning about disability? This may lead to a change in attitudes towards disabled people. I used phenomenology to examine disability comedy. As a disabled researcher, it is paramount for me to position the experiences of other disabled people in the center of my research. In order to achieve this, I used culturally responsive methodologies to complement phenomenology. My participants are comedians with a variety of impairments as well as audience members, both disabled and nondisabled. Comedians may not view themselves as educators, but they fill a very important role: they bring awareness of disability issues to mainstream audiences. 
Nondisabled audience members can judge whether or not disabled comedians are effective in educating about the barriers disabled people face in day to day life. Disability comedy has not been conceptualized as an educational tool, and that is a gap I have filled. Comedy is an effective way to teach about disabled lives. I used Vygotsky's sociocultural theory of learning to analyze the effectiveness of the jokes and teaching about disability issues. Vygotsky posited that culture is formed through the use of tools and symbols. Intelligence is achieved when the learner can internalize the tools, and these tools are provided through language. My dissertation posited that the comedians are the instructors and the audience members are the learners. This teaching and learning is seen as what comedians are achieving.

I defined achievement in terms of how audience members gained a new perspective into disabled life. It can also be reflected in how performing comedy raises the comedians' self-esteem and ability to cope with the challenges of being disabled in an ableist society. Empowering forms of humor have enabled disabled people to come together on the basis of a shared political ideology and assert a positive identity. Disabled comedians have not been positioned as educators or social change agents by researchers, and this is a gap my research has filled. Disability artists challenge normative views of disability by directly confronting sympathy and other problematic attitudes 
towards disability. This art has been used to teach about stereotypical portrayals of disabled lives

(Seidler, 2011). Sometimes humor is the only way for disabled people to connect with others on an equal footing (Chapple and Ziebland, 2004). This comedy is used to identify barriers and to challenge cultural values and taboos, which dictate everyday interactions with nondisabled people.

In this way, disabled people have moved from passive objects of scorn towards a political development of satire. Radical disability comedy makes fun of disabling encounters and environments, not disabled people themselves. In this way, disabled people have moved from being laughed at to laughing at themselves to laughing at disabling situations and nondisabled people (Rieger, 2005).

In the last twenty years, disabled comedians have emerged to challenge mainstream notions of disability with their own perspectives (Lockyear, 2016; Reid, Stoughton and Smith, 2006). Disabled comedians are able to debunk stereotypes and make audience members laugh at their own false assumptions regarding disability. As children, these comedians may have employed humor to help others feel more comfortable interacting with them (Bingham and Green, 2016). This comedy, fueled by insider knowledge, has challenged mainstream disabling humor and offers a new paradigm in disability humor. Rather than focusing on physical or intellectual differences, 
disabled comedians focus on access barriers or misunderstandings that nondisabled people have about day to day life with a disability (Reid, et al., 2006).

Many audience members are reluctant to laugh at disabled comedians because of the taboo against laughing at someone who is different or perceived to be less fortunate. Additionally, disability is thought to be a serious subject, which means that most nondisabled people do not get to see that disabled people like to have a good time (Haller and Ralph, 2003). Nondisabled people may focus on the surface differences between themselves and disabled people, but the strategic use of humor can humanize disabled people for mainstream audiences (Rieger and McGrail, 2015).

Disabled comedians are able to educate about the physical barriers they encounter in their everyday lives when the stages in comedy clubs are inaccessible to them; they make jokes about it in order to inform the audience. They also educate about attitudinal barriers that perpetuate stereotypes surrounding disability (Bingham and Green, 2016). In 2006, Josh Blue, a comedian with a physical disability, brought disability humor to the mainstream and won NBC's Last Comic Standing. For the first time, large audiences were exposed to humor from a disabled person's perspective (Lockyear, 2015). 
There is a paltry amount of research on disabled comedians, and academics have not studied their motivations or what audience members gain from attending a disabled comedian's performance. My research has filled this gap by including the perspectives of the comedians themselves as well as audience members.

The first section of this paper discusses my positionality as a disabled researcher working with disabled participants. This is followed by a discussion of history and theory behind phenomenology as a research methodology. A description of how phenomenology is used to analyze disability comedy follows. The methods section details plans for the collection of data, including interview guides for both disabled comedians and audience members. The data analysis of the information comes next, including the discussion of trustworthiness, the limitations of the research, and a description of participants.

\section{Researcher Positionality}

Research with disabled participants must be reflective of their perspective. Historically,

research has been on conducted on disabled people rather than with disabled people (Bricher, 2000). I have spoken publicly on disability issues and about my experiences with disabling barriers. In my speeches, I utilize a lot of humor to make people more comfortable with concepts that might otherwise be unfamiliar. Personally, I use humor to break down barriers between myself 
and people who are unfamiliar with disability. I used to talk to pre-service teachers who were taking a class on inclusive education; I used humor to show them that I'm not as radically different from them as they may think. At the time, I was also an undergraduate facing some of the same stresses that they were, so I would joke about some of the stresses of being a college student with a disability. I think my humor helped the other students open up and ask me questions. This is one of the ways I relate to disabled comedians; I believe that humor can be one of our most powerful teaching tools.

Another aspect I share with the comedians I interviewed is the barrier of transportation. Accessible transportation to and from venues affects the comedian's ability to perform. This can be a significant hurdle to having a successful career in comedy. I understand this personally because I rely on accessible transportation to get me to and from class and other places I need to go. If there's no accessible transportation, I have to rely on friends and family to drive me and this would curtail my independence.

Many of my participants have multiple minority identities as I do. This can affect their comedy. As a Palestinian Muslim American with a disability, there are many stereotypes I am expected to conform to and one of these is that I should not be assertive or demanding. People are 
sometimes surprised when I stand up for myself and demand to be treated fairly. Disabled comedians push the envelope of what is acceptable conduct for disabled people. Some of their comedy is angry and confrontational, which is not conduct associated with disability. Assertiveness and having a demanding personality are not attributes usually associated with disabled people. Disabled individuals are expected to be passive and eternally grateful for everything they have. Disabled comedians can be irreverent and loud, which can make some people uncomfortable because this is not conduct expected from disabled people. This is something I share with participants. I can't stand being overlooked and ignored, and I'm not afraid to let people know.

My multiple minority identities help me understand the perspectives of disabled comedians who are also minorities. They tend to blend in jokes about being from another minority group and being disabled. This is an important difference from the material of white male disabled comedians. The disabled women comedians I've spoken to have told me that they include a lot of jokes about sexuality because of the stereotype that disabled women are either asexual or should not have sex. All the comedians had different material depending on their background and life experiences. Disabled comedians are not a monolithic group. I used the literature on 
intersectionality and disability to understand how disabled comedians bring in their own backgrounds to make their acts more authentic (Moshe and Magaña, 2014; Warner and Brown, 2011).

It is important to recognize that I am an outsider to my participants. I am not a comedian. Although I use comedy in my public speaking and everyday life, prior to this work, I had never been to a comedy club or gone on stage specifically to perform comedic routines. The primary goal of my public speaking has always been educational and comedy is one tool I use. The goal of comedians is, first and foremost, to make people laugh.

I've never travelled to give a speech, which means I have never experienced barriers associated with travelling to and from performances. Some of my participants have told me that travelling to perform is prohibitive because they have to pay for an attendant to travel with them, which essentially doubles the cost. I have never experienced financial barriers because my parents can afford to pay for whatever accommodations I need.

Unlike my participants, I am a PhD student. Many disabled people have experienced significant barriers to higher education. My education affords me a higher status in society. Many 
of my acquaintances are shocked when they learn that I'm a PhD student because disabled people are not associated with higher levels of education or achievement.

My $\mathrm{PhD}$ student status may have initially been intimidating to participants, but my status as a disabled person interested in disabled comedy made participants more comfortable interacting with me. I purposely told participants stories about the barriers I have had to deal with to show them what we have in common. I also told jokes of my own about people's perceptions of me in public and the reactions I get from others. I am fully aware that my economic status makes me an outsider to many disabled comedians who have to struggle with financial limitations, which impacts where they can perform. Participants perceived me as very lucky to be able to afford the education and financial advantage to be able to do this research in the first place. A few of them thanked me for the opportunity to discuss their experiences as comedians.

Being an insider into the disability experience may have led to many benefits with the research, but it also presented challenges. "Positionality affects the type of data that is collected, how it is collected, and how we interpret it" (Greene, 2014, p 13). The way insiders interpret participants' stories and represent each interview is affected by the insiders' understanding of the shared experience. Because I understand the barriers disabled people face, participants were more 
willing to describe challenges they have faced while performing comedy. However, it was important for me to get a full description and not make assumptions because of my insider status.

\section{Research Methods}

History and Theory Behind Phenomenology

The term phenomenology was coined by Immanuel Kant and derives from the Greek word

phainein, which means "to appear." German mathematician and logician Husserl first articulated the methodology to bring rigor to qualitative research by studying the "lifeworld." He described phenomenology as the study of pure consciousness, a discipline to illuminate how the world is experienced through conscious acts. Phenomenologists seek to go back to the phenomenon itself to understand experiences from participants' point of view. Phenomenology attempts to explore hidden meanings that participants create about their experiences. It analyzes lived experiences and their meanings for all involved in a particular experience. Phenomenological writing attempts to bring the reader as close to the experience as possible. The writer attempts to paint a clear picture of the experience (Weiss, 2016).

Phenomenological research should be nonjudgmental. It is important to recognize that all interpretations are founded on preconceptions. In phenomenology, knowledge is achieved gradually, through cycles of interpretation and analysis (Padilla, 2003).

The critical ideas that stem from phenomenology include eidetic reduction, constitution of meaning, and intentionality. Eidetic reduction refers to bracketing of the researcher's prior 
knowledge or beliefs so that he or she may be immersed in the experiences of participants. By contrast, Heidegger argued the impossibility of suspending assumptions and worldview (Kleiman, 2004). Phenomenologists emphasize that language brings about communal understanding and selfunderstanding. Phenomenology is pure description of human experience. The purpose of phenomenology is to make things stand out, and this is also its challenge (Priest, 2002; Earle, 2010).

The purpose of phenomenological research is to show how people experience a given situation, in this case disabled comedy, experienced by audience members as well as performing comedians. Epistemologically, phenomenological research is grounded in participants' experiences from their own viewpoint. Phenomenology is a powerful tool for understanding subjective experiences and is particularly useful for examining the experiences of marginalized people such as disabled people. Feminist phenomenological researchers argue that it is impossible for researchers to detach from the research as an impartial observer (Finlay, 2009; Baird \& Mitchell, 2014). When researching historically marginalized groups, such as disabled people, it may be unethical to remove oneself from the research, as this may contribute to the further segregation of vulnerable people. Phenomenological research may challenge normative assumptions about disabled people by bringing forth their experiences from their own perspectives (Lester, 1999). 
Phenomenology has one serious shortcoming when working with any historically marginalized group such as disabled people and that is the recommendation that the researcher brackets his or her experiences and understandings in order to be fully immersed in the phenomenon. The problem with this is that historically, researchers have attempted to distance themselves from disabled people in order to be objective, and this has led to exploitative research in which disabled voices have been silenced. In order to account for this shortcoming, I used a culturally responsive ethical framework, which positioned the voices of participants at the center of the research. Epistemologically, culturally responsive methodologies emerged from critical theory and Kaupapa Maori theory (Berryman, Soohoo and Nevin, 2013). Culturally responsive methodologies emphasize humility and a willingness to learn from participants. These methodologies resist domination, allowing researchers to unpack dehumanizing methods in favor of more inclusive research strategies. In order to be culturally responsive, researchers should respect participants' experiences and attempt to cultivate relationships that are meaningful beyond just the purpose of the research. This is important to disabled people because, historically, nondisabled professionals have built careers trying to normalize disabled people rather than including their perspective (Tomlinson, 1982). A culturally responsive methodology involving disabled participants would seek their experiences, challenge isolating practices and pose new questions (Nevin, 2013). 
In addition to critical theory, Kaupapa Maori theory challenges Westernized ideas of what is valid research. This involves challenging the dominance of what constitutes knowledge and who dictates representation. Like disabled people, the Maori have been subjected to harmful forms of research in which the researchers benefit at the expense of those being researched. This led the Maori to develop their own ethical codes about research and its dissemination (Berryman, Soohoo and Nevin, 2013). Because I am disabled and understand the history of exploitative research on disabled people, I will develop meaningful relationships with participants and bracketing my experiences and prior knowledge would not allow for these relationships to occur.

\section{Phenomenology of disability comedy}

Phenomenology uses thick descriptions and intimate analysis of the lived experiences of disabled comedians themselves to understand how they create meaning through their embodied perspectives. Phenomenology examines participants' experiences and their perceptions of those experiences. Phenomenology puts the experiences of disabled comedians at the forefront of the research; researchers are expected to position the participants' experiences and insights to make their research authentic to the views of disabled comedians. By closely examining individual experiences, phenomenological analysis of disabled comedy captured the meaning and essence of the experience of being a disabled comedian (Starks \& Trinidad, 2007). I asked comedians about what motivates their comedy and the experiences that they had on stage shed light on the phenomenon. Likewise, I asked disabled and nondisabled audience members about their experiences and their reactions to disabled comedy broadened the research. Historically, research 
on disabled people has not prioritized disabled perspectives. My research shed light on the phenomenon of disabled comedy by making the voices of disabled comedians the central focus. Comedy had not been analyzed as an educational tool to dismantle disability stereotypes, which is what I did with my research.

Phenomenology assumes that participants are going through a conscious experience and are aware of their own motivations (Kleiman, 2004). Disabled comedians are aware of the political impact of their comedy and they tell certain jokes to dispel the stereotypes. However, the comedy of disabled people has not been examined for its political nature.

\section{Sociocultural Theory of Learning}

My research analyzed the work of these comedians as a political tool for promoting inclusion for disabled people in society. Specific jokes have been analyzed for how they expose audience members to the life experiences of disabled comedians. Jokes have also been analyzed for their political content. This was done by analyzing the language used in the joke using the sociocultural theory of learning (Morcom, 2014). Comedians joked about mobility issues or how current debates around healthcare reform affect their lives directly.

Vygotsky's sociocultural theory of learning has two elements, which are relevant to my study: culture and language. He argued that cultures are formed through the use of tools and symbols. Sociocultural theory argues that learning, emotions and motivation are interconnected. Knowledge is social and created through interactions with others. Social interaction is a means of 
developing appropriation and internalization of new information (Gutierrez, 2006). Learning emerges through social context and through collaboration with more experienced others. This learning is mediated through a shared language and happens in everyday contexts (Morcom, 2014; Gallucci, 2008).

This process can be seen through disabled comedians' use of a shared language and cultural understandings to explore disability issues, which may be new concepts for audience members. Vygotsky places an emphasis on language and how language is used to further learning (Morcom, 2014). Learning involves internalizing social tools (Gallucci, 2008). This is why analyzing the language of jokes for their content is important to my study. Speech establishes a point of reference between the comedian and the audience member and becomes a means by which comedians influence audience members' perception about disability. Applying Vygotsky's theory, I argue that audience members internalize social speech as a way to mediate their own thinking about disability issues (Shephardson, 1999).

\section{Comedy as Emancipation for Disabled People}

Historically, disabled people have rarely been asked about their lives by academic researchers (Bricher, 2000). My research added to the literature by asking disabled comedians about their experiences performing comedy and overcoming barriers. Disabled comedians are able 
to joke about disability stereotypes because they have experienced them in their everyday life. Many times they are dealing with a topic some people are uncomfortable discussing, and they have to fully understand the stereotypes in order to debunk them. Some comedians I have spoken to have experienced barriers getting into comedy clubs and getting on the stage because of the lack of physical access for people with mobility disabilities. When disabled comedians have to perform in the front row of the audience, because they are unable to reach the stage, members of the audience may feel sorry for the performer, and this makes it more difficult to be funny. Comedians have also told me they have to give audience members permission to laugh at jokes involving disability because disability is stigmatized in U.S. culture. My research shed light on this phenomenon by involving disabled comedians and both disabled and non-disabled audience members. I interviewed audience members about their experiences after they had watched a performance by a disabled comedian. I wanted to know if their perceptions of disability had changed, and if so, in what way.

Oliver (1990) argued that disabled people have been portrayed as less than human, rarely as ordinary people doing ordinary things. Comedians are able to debunk this image by showing audience members that they have commonalities with nondisabled people and that the comedians can make fun of life challenges. Nondisabled people may perceive disability as something to be overcome and cured, whenever possible, but disabled comedians experience disability as part of their identities. 
In phenomenological research, description and discovery are emphasized. Phenomenological research needs to be nonjudgemental. Because I am disabled, I can relate to the comedians and this is one of the strengths of disabled researchers working with disabled participants. Phenomenological knowledge emerges from cycles of pre-understanding interpretative sources of information and what is being revealed (Davidsen, 2013). The comedy of disabled people is very political, as it pokes holes in people's assumptions of what life with a disability is like and describes the barriers disabled people face on a day to day basis.

Traditional medical model research has left out the voices of disabled people in favor of quantitative research focusing on the effects of impairment on individuals (Bricher, 2000). This research has not taken into account social barriers that disabled people face. For example, professionals are often gatekeepers to services that disabled people need in order to survive (Winchcombe, 2008). These professionals have built careers serving disabled people, which keeps disabled people in a role of dependency (Brechin \& Swain, 1988). Although many researchers have acted with good intentions on behalf of disabled people, the absence of emancipatory research has perpetuated this dependency on professionals. Social model epistemology attempts to liberate disabled people by bringing disabled perspectives into research (Crook, 2015). My research into comedy used a social model lens by focusing on how comedy empowers disabled people. The voices of disabled comedians are essential for this emancipatory research. By performing comedy, disabled people challenge the medical model assumption of dependency. Comedy is a form of 
liberation from disability stereotypes. Comedians may not even be aware of this aspect of their performance, but comedy also is a coping tool for living in a disabling society.

I wrote vignettes to represent data ethnographically. Vignettes are descriptions of scenes re-created from observation notes in the form of a short story. They are intended to describe in detail to the reader what happened. This presents data to the reader that is more accessible, especially since there were some interactions between disabled comedians and audience members (Scamell, Altaweli and McCourt, 2016).

\section{Methods and Data Collection}

I interviewed eight comedians for an hour individually. I used the same interview guide for

each interview, and I asked follow-up questions during the same interview. In addition, I prepared by familiarizing myself with the comedians prior to the interview by visiting their YouTube videos and websites, but excluding their personal social media. When coding, I looked for patterns and similarities across all areas. I achieved data saturation when I found the same patterns over and over again. I ended up with rich data, so that I could write thick descriptions about the experience of being a disabled comedian. I had to spend a significant amount of time as a participant observer at comedy clubs, watching shows and talking to disabled comedians. Field notes are very important to this study, so I recorded my thoughts directly after each and every interview or observation. In 
addition to interviewing, I observed audience reactions through participant observation

(Traustadottir \& Sjgurjonsdottir, 2008).

\section{Participant Observations: Attending shows and viewing YouTube archives}

I kept notes on my research electronically on my computer to record my observations

following each interview and live performance. I used pseudonyms to protect the identity of participants. Maria and Bill were interviewed before their performances and all other comedians and audience members were interviewed afterwards. I attended one live comedy performance for each comedian participant, and I recruited audience members for interviews after the performances. I bought drinks for audience members who volunteered to participate. I interviewed eleven audience members at the venues after the shows. Additionally, I watched archives on YouTube to find comedian participants and used Twitter, Facebook, and e-mail to recruit comedians. I made sure they were legitimate performers by tracking their websites. I used the voice recorder on my iPhone to take notes after performances. This way, there was no time delay and my memories were fresh. I had eight comedian participants and eleven audience members at the end of my research. The audience members were interviewed in groups and the comedians were interviewed individually. Below are my interview guides for both comedians and audience members: 
Interview Guide for Comedians

- Why did you decide to go into comedy?

- When did you become disabled?

- How does being a disabled person influence your humor?

- What kinds of reactions have you gotten from audience members? Is there a difference between how disabled and nondisabled audience members react?

- How long have you been a comedian?

- Which comedian has had the greatest impact on your comedic style?

- (If the comedian has a physical disability) What did you do when you encountered an inaccessible venue?

- I went to your YouTube site and I saw you performed this particular joke. Can you tell me why you did xyz?

- Can you tell me the origin of that joke?

- What do you do when the audience is not receptive to the performance?

- What are the factors that contribute to this response? 
- Tell me about a great moment for you as a comedian?

○ Tell me about a time you realized you went too far, and how did you resolve it?

- What sort of feedback have you gotten from audience members, both disabled and nondisabled?

- Have you had any difficulties with transportation to and from the venue? If so, how did you resolve this difficulty?

- Where do you get material? What is the most important content that you include in your material?

- Do you have any questions for me?

\section{Interview Guide for Audience Members}

- What experiences have you had with disabled people before attending this performance?

- Were there any jokes that made you feel uncomfortable? What were they? Why did they make you uncomfortable? 
- How did you feel about tonight's performance?

- Why did you attend this comedian's show?

- How has tonight's show changed your perception of disability?

- Would you attend another show with a disabled comic? Why or why not?

\section{Recruitment of Comedian Participants \\ I contacted many comedians through e-mail and social media. Several comedian}

participants put me in touch with other comedians through e-mail and social media. Many potential

participants were not available or did not respond to my interview request. Scheduling was difficult because I was travelling to Los Angeles or Northern California from my home in Arizona to collect data.

\section{Accommodations for Interviewing Disabled Participants}

There are specific accommodations one needs to keep in mind when working with disabled

participants. Some participants had trouble meeting for an interview, so I spoke with them over the phone or met them at a place that was accessible to them. I met most participants at the venues they were performing, or at the same plaza where their performance was located. One participant 
asked to be interviewed over the phone. I asked my participants what they needed to be able to

participate in the research and did my best to accommodate them.

\section{Data Analysis}

Interviews were transcribed verbatim by the Disability Resource Center, and once the

transcripts were received, I read them while listening to the interviews to make sure that they

reflected accuracy. The data was divided into meaningful sections and then each section was

integrated into categories that had a similar focus. Findings were elaborated by including

descriptions of the essential meanings that were discovered. Then, the raw data was revisited to

confirm my interpretations of the essential meaning and general structure. Findings included

descriptions of the essential meanings, with direct quotes from participants, and articulation of the

phenomenon discovered through essential meanings (Vaughn and Turner, 2016).

I used incident by incident coding for my initial round, meaning that I broke up the interview data into incidents and assigned a code for each incident (Saldana, 2016). Because disabled people have not historically been asked about their lives by researchers, I used as many in vivo codes as I could. After I coded all of the interviews, I opened a Word document and wrote down each code that was repeated. This led to a list of fifty-seven second level codes. I went through each transcript and found quotes from each participant that matched each code and pasted 
them into a document. Codes that did not correspond with quotes from participants were dropped.

After this, I wrote a paragraph about what each code meant and sent it to my advisor to review.

Then, I combined some of the paragraphs with other codes to develop themes and a cohesive

narrative. I wrote section headings for the different aspects of the phenomenon of disability

comedy. Next, I added quotes from my participants to demonstrate that interpretations were data

driven. I used my field notes to write about the performances I saw and the experiences I had while

interviewing. The field notes were written directly after each show or interview, so I could record

the events that took place (Saldana, 2016).

\section{Trustworthiness}

I was true to my data; this means that I had to examine my own biases and beliefs

surrounding disabled comedians and their humor. When interviewing participants, I did not make

assumptions; instead, I asked follow-up questions so that I really understood what they were telling

me. My interview guide was examined after each interview to see if any changes needed to be

made to get a fuller picture of what disabled comedians do and how they do it. I was already very

familiar with the culture of disability and particularly the culture of disabled comedians, so I was

able to explain my research goals to participants and ensure that we understood each other. I

obtained informed consent from each participant and told them both verbally and in writing that 
they could withdraw from the study at any time. I built relationships with participants based on trust and sharing of information. I let participants read sections of my writing that discussed their responses. I also let participants read transcripts to ensure that what my transcriber wrote was what they actually said.

In order to ensure trustworthiness, I was in the field engaged with disabled comedians for an extended period of time in order to achieve data saturation. This also ensures a level of trust between me and my participants due to the fact I attended their shows and got to know them personally. In order to achieve crystallization, I immersed myself in the data, and then stopped to reflect and journal on where the data led. This helped me identify patterns in the data and identify where these patterns led. My analysis was reviewed by my committee to ensure dialogical validity and that the analysis is credible and true to the data. I examined my biases as a researcher by looking at how I am an insider and an outsider to my research participants. I also was aware of how my level of education affected participants. I shared my analysis with participants as a way of member checking to ensure that it reflected exactly what they told me (Varpio, Ajjawi, Monrouxe, O’Brien, Rees, 2017). Participants know how my work was disseminated and how the final report reflected them. 


\section{Participants}

Participants were eight disabled comedians with a variety of impairments. I also

interviewed eleven audience members with and without impairments. I am using pseudonyms to

protect the identity of participants and am not disclosing any locations where the research was

conducted. This process led to a sufficient amount of data for coding and analysis. I chose

participants with multiple identities because this yielded a diversity in their material and how they

deliver it. For example, comedians from different regions of the United States had different

perspectives and material to pull from. Audience members from different areas and with different

backgrounds had different reactions to the jokes. This informed audience members' familiarity

with disability and its social construction.

I've learned that disabled comedians are diverse and come from varying backgrounds.

Many of them went into comedy after being public speakers for years (Lockyer, 2015). I've learned

the biggest difference between public speaking and stand-up comedy is that with public speaking,

performers want to advocate for something or change people's perceptions of disability; with

comedy, they want to challenge people's perceptions and make them laugh at the same time. Some

of the people I talked to went into comedy because they have stage fright and wanted to challenge

themselves. Some comedians with physical disabilities face challenges of getting to and from the 
venue because of the lack of reliable, accessible transportation. During my observations, they also had difficulty getting on the stage itself because the venues are inaccessible to wheelchair users or people with mobility difficulties. Some of the people I've talked to didn't see themselves as educators until I asked if they've had anyone approach them and say that they changed their perceptions of disabled people.

Some comedians I've talked to say that part of what they do challenges the stereotype that disabled people are asexual (Drummond \& Brotman, 2014). They purposely push the envelope to make people uncomfortable because disabled sex is particularly taboo. Joking about the subject matter makes audience members uncomfortable enough to challenge their assumptions.

Disabled comedians also sometimes joke about suicide and assisted suicide. A common misconception is that it is better to be dead than disabled. Jokes about suicide are also meant to make people uncomfortable and to challenge assumptions about how terrible disabled lives are.

Disability studies scholarship (Oliver, 2013; Shakespeare, 2013) examines the social norms and expectations around disabled people. The humor of disabled people challenges these norms and expectations directly, so that audience members end up laughing at their own misconceptions and prejudices surrounding disability. This is an under-researched area, and the work disabled 
comedians do needs to be expanded and examined. The work I did filled in this gap and contributed

to disability studies scholarship.

The interviews with comedians were conducted in a variety of locations. I interviewed

Cathy at her wheelchair accessible home in a Los Angeles suburb. My parents drove me to

Jasmine's home, but when I got there, I discovered that it was not wheelchair accessible. She suggested that we conduct the interview at a restaurant across the street. Jack performed in the show with Cathy and Jasmine and asked if I could interview him over the phone. Maria arranged to bring Bill to a restaurant in the same shopping center where they were performing in Oakland after the interviews. I interviewed Violet after her show on the sidewalk outside of the venue in downtown Oakland. Tom took me to a side room for the talent, which was quiet, at a theatre in Arizona.

\section{Conclusion}

Phenomenology is a nonjudgemental method in which data emerges from the participants themselves. Asking disabled comedians about their motivations in their performances will uncover how they use comedy. However, phenomenology emphasizes bracketing the researcher's previous experience and knowledge, which will not be appropriate for research conducted by a disabled researcher with disabled participants. In order to account for this weakness, I used culturally 
responsive methodologies to complement phenomenology. Previous research has shown that disabled comedians encounter barriers, but there is little work on how those barriers are transcended (Lockyer, 2015). My dissertation filled this gap. I recruited disabled comedians by contacting them on social media and attended their performances. After the performance, I interviewed audience members with and without disabilities to explore how they perceived the comedians' work. This led to rich data and added to the gap I filled.

Interviews were transcribed verbatim and coded for meaning. After initial coding, categories emerged and these categories provided guidance for writing the findings. The same interview guide was used for each comedian and audience member. The follow-up questions were given during the interviews.

My positionality as a disabled researcher affected the findings. I have done public speaking on disability issues in the past, and I have used comedy as a way to bridge the gap between myself and audience members, but I do not consider myself a comedian. I use comedy to build a connection with other people, but I have never performed stand-up. I have only used humor as a tool to communicate with those around me. Like some of my participants, I have multiple oppressed identities; as an Arab American, disabled woman, I need to be aware of how this affects my worldview. Disabled comedians may see themselves as primarily comedians and not as educators. I also have had more educational opportunities than some of the comedians I interviewed. I am aware of how this influenced their interaction with me as a researcher. 
My dissertation has limitations. I did not examine television comedy because there are a few academic articles which have already critiqued television sitcoms. I interviewed eight comedians and eleven audience members, but there are many more that I was not able to talk to. I only interviewed comedians with actual impairments and not those who use disabling comedy in their performances. Additionally, the comedians had videos of past performances available online.

To ensure trustworthiness, I stayed true to the data. I established trust with participants by being in the field for an extended period of time. I used several different data sources: interviews with comedians and audience members, attending live comedy performances, reading comedians' websites, and examining YouTube archives.

For disabled comedians, humor is a tool for coping with barriers in a society which does not accommodate disabled individuals. Emancipatory research aims to remove such barriers, and my research will fit into this tradition. Phenomenology has one serious shortcoming, in this case, which is that researchers are supposed to bracket their prior knowledge and experience. This is not appropriate for a disabled researcher working with disabled participants. In order to enhance phenomenological research, I used culturally responsive methodologies, which prioritizes working with historically marginalized people to produce non-exploitative research. This reflects the fact that Disabled comedians challenge medical model notions of dependency and tragedy by poking holes in nondisabled people's assumptions about disabled lives. 
Comedy has not been examined for its educational value in shaping how society views disability. Through my work, I conceptualized disabled comedians as educators. However, they may not realize the educational value of their comedy. Vygotsky's sociocultural theory of learning was used to analyze what audience members learn about disability from the comedians (Morcom, 2014). Disability is a taboo subject, but comedians break down this barrier by joking about topics rarely discussed. This is why it is important to interview both comedians and audience members. 


\section{Chapter 4}

The jokes of disabled comedians can advance disability rights by informing audiences of the experiences of disabled people in a way that is not threatening. Audiences can learn about the lives of disabled people while being entertained. The comedians' jokes came from their diverse backgrounds, which made each joke unique and reflective of their experiences. Audience members were interested in the comedy because it was entertaining, but through comedy they were exposed to the perspectives of disabled people, which led to changes in attitudes.

The theoretical framework of this study was humor theory and the social model of disability. Theories of humor attempt to explain why certain situations are funny. The oldest humor theory, superiority theory, posits that when a person compares themselves to someone they find inferior, they find the comparison funny. For example, in the Middle Ages, the court jester, who was often a little person, was ridiculed, but he was also able to satirize the king. The king felt superior to him, which gave the court jester freedom to mock those in power.

Incongruity theory suggests that humor can arise when two unrelated or contradictory subjects are compared. Incongruities can result in surprise, juxtaposition, atypicality or violation. There is usually a build-up of tension, but when the person experiences the incongruity realizes there is no threat, humor is experienced. For example, there can be an incongruity in how a disabled comedian perceives him or herself as capable and how the audience perceives that person. These 
differences can be used by comedians in their set. Relief theory views humor as an expression of repressed emotions. Humor can occur when a person accesses these emotions in a way that is not threatening to the ego. For example, disabled comedians can use relief theory to help audiences understand aspects of their lives that they have not been exposed to before.

I used phenomenology as my methodology, which was first described by Husserl as the study of the "lifeworld." Phenomenology brings rigor to qualitative research because it analyzes the meanings that participants bring to the phenomenon under study. I used phenomenology to understand the lived experiences of disabled comedians and what they are trying to achieve through the use of humor. I also interviewed audience members to investigate what they learned from attending performances by disabled comedians in terms of changing attitudes towards disabled people. Phenomenology informed my data analysis by grounding it in participants' perspectives; I stayed true to what they told me.

Traditional phenomenological research involves bracketing or setting aside the researcher's experiences and distancing oneself from the participants. This would not be appropriate for my research because I'm a disabled person interviewing other disabled people. To counteract this issue, I used culturally responsive methodologies, which epistemologically emerged from critical theory and Kaupapa Maori theory. Culturally responsive methodologies resist the domination of participants by researchers making research more inclusive. My participants shared their stories with me openly and trusted me. This was in part because I have 
an obvious disability and also because I shared about myself during the interviews. I also shared the results with participants.

This chapter presents the results of my study. I interviewed eight comedians who had a variety of impairments for an hour each; they all self-identify as disabled comedians. When I interviewed them, I discovered that many had multiple minority identities, which they drew upon to write jokes. They use instances of discrimination to tell jokes that inform audience members about what their lives are like. The audience members I interviewed appreciated being informed about the lived experiences of disabled people. The interviews showed that disabled comedians accurately represented disability issues through comedy in a way that educated and entertained audience members simultaneously.

I recorded all interviews on my iPhone and the recordings were transcribed by the Disability Resource Center. I listened to the recordings and made corrections to the transcriptions. I attended one performance for each comedian. I wrote detailed field notes for each show or interview I conducted. One comedian, Maria, shared a recording of her performance with me and this helped me recall the specifics of her jokes. My friend, who graduated from the PhD program recently, took notes for me on her laptop at two of the shows. These notes were helpful when writing my field notes. I also recorded my thoughts on my phone after each interview or performance. 
Below are the findings from the interviews and my observations from the comedians' shows. My findings fell into seven themes, which are broken down by section headings. The first two sections demonstrate how the comedians' life experiences impact their joke writing. Comedians draw inspiration from their lives to write jokes and they have been discriminated against because of their disabilities. Subsequently, the next part discusses how comedians push boundaries to entertain the audience. Following this is a discussion of why disabled audience members appreciate the material of disabled comedians.

Cathy is a single Hispanic woman in her thirties who uses a wheelchair as a result of an accident. Jack is a white man in his forties who identifies as a member of the LGBTQ+ community and uses crutches as a result of the disability he was born with. Jasmine is a little person of Hispanic origins and is in her forties. She is married. David, who is an immigrant from Asia, is in his thirties and uses crutches because he was born with deformities in his hands and feet. Bill is a single white man in his forties who is a recovering alcoholic. Maria is a married Italian American woman in her forties who stutters when she talks. Violet is a single white woman in her twenties who uses a wheelchair. Tom is a married white man is his thirties who has a physical disability.

\section{Vignettes of the Performances}

Cathy, Jack, and Jasmine perform at a restaurant in Los Angeles. The stage is a small, raised platform with a microphone. The room is full and all the wheelchair users in the audience are sitting in the front. All of the lights are dimmed except for the spotlight above the platform. 
David's show is in a small theatre in downtown Los Angeles. The only place for me to sit is in the front row. There is one step in the front of the stage, which David climbs. He is the host of the show and introduces all of the other performers. There is furniture and props on stage to make it look like a living room. David pushes things around with his crutches and makes a joke about feeling like he needs to tidy up. There are three spotlights illuminating the stage.

Bill and Maria perform in an urban biker bar in a shopping center in Oakland, where a small area is cleared for the talent and microphones are set up across from the bar. Spotlights are used to brighten the area. The crowd is very rowdy and the performers have many interactions with audience members. Maria paces back and forth, engaging audience members in a conversation, including myself. Bill doesn't use the stage space as much, but calls out to the audience and interacts with them.

Violet performs at an urban marijuana dispensary in downtown Oakland. She thinks she will be the last on stage, but the host asks her if she is ready to go first. He holds the microphone for her while she performs. She sits very still in her motorized wheelchair and doesn't use the stage space. She has a soft voice and it is hard to hear her over the noisy people sitting next to me.

Tom performs at an upscale theatre in an urban part of Arizona. The theatre can accommodate a large audience and it is full. Tom is provided a stool to sit on, but does not use it. He paces up and down the stage during his performance. He shows us how long the cord for the microphone is and asks, "Where did they think I was going to go?" 


\section{Identities Shape Comedians' Humor}

In the beginning of their careers, all eight comedians were impacted by the work of famous

comedians, both disabled and nondisabled. At first, they would emulate the comedic style of famous comedians whose work they enjoyed, but as they became more experienced and comfortable performing comedy, they began to experiment with their own style. For example, Violet was able to incorporate physical humor in her act after seeing Tig Notaro use physical humor; Violet will push chairs around with her wheelchair. When Maria began her comedy career, she "...wanted to be the female, disabled, white Paul Mooney. So getting into comedy, him and Dave Chappelle and Chris Rock and Wanda Sykes were my bigger influences, but then as a kid, people I really liked were Eva Phillips, who is more surrealist." Jack wanted to pursue comedic storytelling because the comedians he looked up to, Mike Nichols and Elaine May, created a picture with their joke telling.

Cathy explains, "I love Natasha [Leggero]. Like, her joke writing is so funny and so tidy.

I like how brash she is. I think like more contemporary, like, those before we were started doing comedy. I was like oh, I like comedy." Tom was motivated by the work of Chris Fonseca, a disabled comedian. "You should look him up. He actually is a guy that kind of paved the way for disabled folks." Tom says that Chris Fonseca was not supportive when Tom first became wellknown as a disabled comedian. In fact, he accused Tom of stealing his material to place in a competition, but Tom chose not to respond to the criticism. Since this incident, they have reconciled. Jasmine was mentored by Margaret Cho, who inspired her to go back into comedy 
after leaving it for a number of years “... [Cho]'s been a direct impact. Like a real, you know. Not somebody from afar. She's impacted my life in many ways." David was influenced by the Asian American comic Russell Peters, but like all the other comedians, he is now developing his own style. He says, "At the beginning, Russell Peters and maybe Jon Stewart type of humor, a very strong point of view and a lot of research, and points out a lot of unfairness. That kind of thing. And now I'm just developing my own thing." The comedians were motivated by the work of famous comedians when they began their careers, but they later developed their own comedy style and jokes based on their experiences.

Their life experiences as minorities play a role in their joke writing. Most of the comedians have multiple minority identities and this influences their humor and joke writing. David is Asian American and performs many jokes about being an Asian American disabled man. He wants to be known as the "Asian guy with an opinion," which is not something he sees frequently. He points out, "How hard it is for an Asian male to lead in a Hollywood movie. In history, there were only three major ones. Three of them do martial arts, so my Hollywood career is over [laughing]." Being a disabled Asian American man gives David a unique vantage point with which to write jokes. This makes his humor more complex and compelling. When I went to David's show, he had a joke about being a disabled Asian American exchange student in a rural high school. He was the student leader for the Asian club, the Disabled Students club, the Black Students Club, and the Jewish Students' club because he explained to rural white students what Hanukkah was. This is a 
joke about people's expectations of someone who is disabled and also an ethnic minority. He was expected to represent all the minority experiences on campus.

Cathy said that before she became disabled, she was a woman of color and so many of her jokes are not about her disability. She is interested in representation of disabled women of color and she feels empowered that she is working in a field where she can write a TV show and it can be produced. Through comedy, she is able to challenge stereotypes and influence the representation of disabled women of color. One of the jokes she performed at the show I attended was about her grandmother putting pressure on her to meet a nice man. "Why don't you go to those meetings? Those meetings for people in wheelchairs. You could meet a nice man.” This joke has to do with the perception that Latinas are pressured into marrying by their family and having a disability doesn't change the social expectations. It was also very funny that her abuela thought there were meetings for people who use wheelchairs. This may reflect a cultural difference in regards to the inclusion of disabled people in society.

According to Jasmine, disability is not prioritized in discussions about diversity. "You've got women, then you've got people of color, then you've got gays, and by the time they get to disability, I'm going to be dead." For this reason, she thinks it's important for disabled people to create their own work to influence disability representation in the wider society. Creating their own work leads to empowerment of disabled people and can challenge misconceptions. "You can't just wait for someone to write you a part or cast you or think of something. You have to do your 
own work if you want to be a performing artist." At the show that I attended, she performed a joke about little people on reality TV. "There are only five little people in the world and they are all either on reality TV or Cirque Du Soleil." In fact, she gets calls from producers who will ask her if she knows any little people who are pregnant and interested in starring in a reality show. She tells them that she's 45 years old and doesn't know anyone in their 20's who is pregnant anymore. When I interviewed her, I asked her about the origins of this joke and she told me that it came from real life. According to Jasmine, the Hollywood industry can be brutal and producers don't care about hurting people's feelings. They have a job to do and that is to find performers. She finds stand-up comedy liberating for her as a disabled person because in comedy, no one cares who the performer is. "[Comedy] is the only platform in entertainment where nobody cares what you look like, nobody cares who you are. Nobody cares if you are old or young for the most part, as long as you can make them laugh." It is easier for her as a disabled minority female comedian to express herself through comedy than through any other creative medium. Through comedy, she is able to be her authentic self and, in doing so, gives audience members a realistic portrayal of her life.

Jack argues that as a disabled queer person, any statement he makes is political. Jack's jokes center around the lived experience of being a disabled member of the LGBTQ+ community. For example, Jack performed a joke about straight men wanting to have sex with him because his disability makes it OK to have sex with him since he's "less of a man." This was a joke about the stereotype that disabled people are asexual or not capable of having sex at all. Straight men can 
justify experimenting with Jack because, in their minds, his disability made him less sexual and therefore this doesn't count as an encounter with a man. This joke exposes the audience to discrimination that disabled members of the LGBTQ+ community experience. They are regarded as sexual deviants and asexual at the same time.

The comedians recognized that much of their humor was political and they sometimes used their platform to advocate for disability rights. Because some of the comedians have multiple minority identities, they were able to expose audiences to viewpoints that they may not have encountered before and this could teach audience members about disability issues. Their identities impacted the way they performed comedy. Tom asked me why I thought disability was the last issue to be addressed concerning representation. "Why do you think that the disability stuff is the last? I think we need to address that." He told the audience that most portrayals of disabled people in Hollywood are played by nondisabled actors. Disabled comedians want to represent disability accurately and it is difficult to make it in the entertainment industry. Tom makes enough money to support himself without needing another job. Jack and Bill make a more modest income, but are able to support themselves as comedians. Bill explains, "I would say the average gig I do [earns me] anywhere from $\$ 20$ to $\$ 100$ ? Depending on the show and whether I'm headlining. Yeah, I do make a living right now as a stand-up comedian - it is not like a huge living." As comedians, they have to find others ways to support themselves because comedy doesn't pay well. They do odd jobs or manage property. Cathy explains, 
"Typically, if you are doing a show and you want to make money, what you do

is you contact the venue and you say, what does it cost to rent the space for this

amount of time? And they give you the number. And you are like, okay, cool.

I will pay that, and then I get to keep ticket sales. But nothing is set in stone.

Everyone kind of has to negotiate it on their other terms, and some venues are

pretty cool about that. But you know, rent is very expensive and in Los Angeles,

businesses want to make money, comics want to make money."

Maria makes her living from public speaking about disability issues, but not necessarily

from comedy. Some comedians are not in comedy to make a living; they do it to have fun.

\section{Jokes Based on Life Experiences}

Because the comedians I interviewed want to portray disability realistically, they turn their

life experiences into jokes. For example, Bill had a joke about himself before he recognized he

had a substance abuse problem, which was pointing him in the direction of getting clean. It is about how drugs and alcohol cause a vicious cycle of addiction.

"It starts with weed. I drink some beer and I up the ante and then I go, 'what would go well with beer?' and I shout, 'cocaine!' And I say three to five days later after a good healthy binge works well with weed, beer, and cocaine. Second, third, and fourth DUI at the exact same time because that's when the acid kicks in. And then I say leads to LSD, which is a psychedelic drug, and that's my joke on why I can drive 
three cars in four different dimensions, 32 colors and 56 flavors into the sky with diamonds and I still hit a cop."

In fact, this joke led Bill to pursue recovery.

Jasmine uses experiences from her life as a little person and tries to make them relatable to the audience, which she argues is what most comedians do.

“Well, doing stand-up comedy, you have to pull from your own personal experience. At least for me, the thing with stand-up comedy is that it is observations about life, and I think that's pretty generic for most comics, but the trick to it is to make it relatable, universal. It can't just be about you. If you have to discuss your experiences you have to make it relatable to just about anybody and you need people on board with you. So, my perspective on life, you know, it comes from my daily life experience, my challenges. You know, I am inspired by adversity because on some level everyone has adversity, everyone has their own struggles, everyone has their own path, and so I try and make mine relatable. So for me personally, that's just where I come from, and being disabled, it is what I am, so that's where my material comes from."

For example, she made a joke about being married, which she said is like having a slumber party every night for the rest of your life. Sometimes, she wonders, "When is his mom going to pick him up?" 
This is a joke that most people can relate to because most people have had romantic relationships. Jasmine's joke about marriage shows that it is possible for disabled people to have fulfilling romantic relationships, but not without conflict. This mirrors the romantic relationships of nondisabled people.

The comedians use instances of discrimination as a basis for some of their jokes. For example, Tom tells one joke about how men will move women out of his way as an act of chivalry protecting women. He told me that this has actually happened to him. He has had a lifetime of those sorts of interactions. When I attended his show, he performed a joke about when he goes to a restaurant with a group of people and the waiter will ask one of his friends, "What will he be having?" And he says, "A talk with your manager and it's going to be a free dinner." Maria introduced herself as the only female comedian with her type of disability in the area. This received applause from the audience. These jokes help nondisabled audiences learn about what life with a disability is like. Being exposed to the personal experiences of disabled comedians can teach audience members about the multiple forms of discrimination experienced by disabled people.

Because the comedians have been discriminated against, they want equal opportunities and to be viewed as professionals. For example, Jack was once hired and flown to perform at an international LGBTQ+ event and to headline at a theatrical venue that had 900 seats. He was wellpaid and put up in a nice hotel. He describes the experience as validating. "I was like, oh, this is actually my job. This is what I do. Someone is flying me halfway around the world to perform for 
a month in a big theatre. I still look back and it feels like this hallmark moment that was very special." Jasmine used to tour with shows where all the expenses were covered. "It is all professional. Everything is covered. You know, it is a job. At least the shows I have toured with. It is not the case for everybody, but I've been very fortunate to work on certain level shows that I mean, I would be doing it if everything is covered. I am not in it to lose money." It is important that their work is taken seriously and they are treated professionally. Insisting on being treated as a professional challenges the notion that disabled people are incapable.

Comedy comes from comedians' life experiences and points of view. Jasmine says, “This is my opportunity to kind of clarify it for my life. It is very personal, and people don't realize that's why I'm doing it. It just makes me feel hurt, that's all, like my struggle." She told me that as a child, her psychological needs as a disabled person were neglected, so through comedy she is able to explore issues specifically about her disability. As disabled people, the comedians have had disability-specific experiences and they use these to write their jokes. Violet explains, "I think with every comedian, they kind of draw their stories from their own experience. So, as a disabled person, I have a lot of disability-specific experiences." If they've had an experience that annoys them, they will purposely write and perform a joke about it. Maria says, "If something annoys me a lot, it is a sign that I need to write it about it. If it is something I have been perseverating on, I think I'm good with self-awareness, so when I notice myself doing something weird and thinking something weird, I think, Oh, this is something I should consider there." For example, she joked 
about men telling her that she stutters because she has "the wrong kind of orgasms." Bill adds, "When things don't leave my brain and they are bothering me, that's when I know I have to channel it into a bit." David has many opinion pieces from the perspective of a disabled Asian American male:

"Nowadays, I do more opinion pieces, more angry [laughing]. I didn't do my Hollywood bit. That's the kind of thing I want to talk about more. The Asian guy with an opinion, which I don't see a lot of."

Because disability is not associated with comedy, the comedians have a unique opportunity to inform audiences based on their own perspectives. All of the comedians write their own material because their comedy is very personal to them. Jasmine says, "I have had people, writers, write my material, and I've done shows that were really good. And a writer would come and up afterward and say, I would love to write jokes for you. I say I appreciate it very much. It is very flattering. I have tried it in the past, and I cannot - it didn't feel right to me. It wasn't coming from my heart, so I can't deliver it unless I wrote it or by pulling from experience."

For each of the comedians, comedy comes from a personal place, so they felt they could not deliver material written by anyone else. Even Tom, who is the most well-known participant, writes his own material, although he acknowledges that there are other influences. For example, 
friends will give him a line and then he will develop the rest of the joke. Cathy told me not to trust any comedian who doesn't write their own material.

The first joke that Violet wrote was about "inspiration porn," which is largely known in the disability community as the objectification of disabled people in order to make nondisabled people feel better about themselves (Grue, 2016). The joke was that she saw a meme on the Internet of someone with prosthetic legs jogging with a caption that said, "The only disability in life is a bad attitude." She showed it to her doctor who re-diagnosed her as having a bad attitude. She was trying to write about a classic disability issue that was very important to her. "And in seeing those memes [about inspiration porn] and, you know, and they always annoy me, so that's like the first time I sat down and wrote out a joke and wrote out every piece of the joke, and I really concentrated on it." This joke exposes audiences to a disability stereotype and debunks it at the same time.

Although all of the comedians use their own personal lives as inspiration for their jokes, they all recognize that comedy has to be relatable for their audience in order to be successful. David explains that likeability is very important. He says, "If you are disabled, people will not put their guard up, or if you have any kind of unfortunate - you mention to people, people will not have that guard up as quickly, so that's easier to get people's attention and also earn their trust. Then usually, you make fun of yourself on top of that, people will like you." 
Comedians have to gain the audience's trust within the first 30 seconds. Cathy has gotten feedback from people who have been disabled at some point in their lives and are therefore able to relate to her humor. According to Bill, his best tool is to be sensitive to the crowd and responsive to their reactions. Audience members are more open to learning from comedians if they are able to relate to them in some way and the comedians are aware of this. For example, random strangers approach Jasmine and tell her, "God bless you," to which she says,

"I mean, I try to be gracious. They need to feel like they did something good, so it is

like, okay, fine. Go pray for me. [Laughing] I used to refer to it like Jesus insurance.

Make sure you have coverage because we need to be blessed."

When I interviewed her, I told Jasmine that this was my favorite joke because I encounter these kinds of attitudes all the time. She further said that when people say these things it's all about them.

\section{Comedians draw on tragedy for inspiration}

"Comedy is about tragedy plus time," quotes David. Violet says that comedy comes from a dark place and if comedians don't have darkness inside, she doesn't know how they do standup. They use their past traumas to expose audience members to their experiences as disabled people through humor. The comedians don't see their lives as tragic, but because they have faced discrimination, their comedy tends to be dark. Their disability identities are often labeled tragic by nondisabled people. The traumas from their lives involve nondisabled people discriminating 
against them for simply existing. For example, Maria, who stutters when she talks, became very angry while telling me about the reaction she gets from nondisabled white liberal women who make faces and whimper while she is stuttering through her jokes. The sympathy of the audience gets in her way of making them laugh. Tom says that everyone asks for sympathy and he doesn't want anybody's sympathy. He recently was accepted into the largest comedy festival in the world this year. When he asked his agent why it took so long, he was told that the festival organizers said he talks too much about disability. He compared this to a Black comedian being told that they talk too much about being Black. By confronting people who are inappropriately sympathetic, the comedians challenge the stereotype that disabled people are to be pitied. They make fun of these stereotypes and audience members who react this way. This teaches audience members not to sympathize with someone just because they are disabled; instead, the goal is an attempt to understand what their lives are actually like.

\section{Comedians' main goal is to entertain the audience}

The comedians' first goal is to entertain others. By this, they mean that they want to give people joy and a positive experience. Tom recognizes that his comedy has a message, but his goal is not to educate, it's to entertain. He says, "I mean, overall, I know there is a message, but I'm not going out there like, this is my point. I'm here to make you laugh." David says that "the first laughter is addictive," and being able to express himself in a way that makes people laugh is a wonderful feeling. Jasmine explains that humor is an equalizer and that all comedians want to make people laugh. She challenges misconceptions about disability because nobody wants to talk 
about it, so nondisabled people imagine what it is like to be disabled and the reality is very different. She says, "Every disabled person I know who's funny... everyone has done it as a way of survival. And they say, why not make it a career now?" The comedians recognize that through comedy, they can challenge misconceptions about disability, but that is not their goal. Tom says that he never intended to advocate for disability through comedy, but is aware that with some of the jokes from his life experiences, this is what he's doing. Bill achieved this through his joke about suicide prevention PSAs at commuter stations, which he found disrespectful. He was able to make a joke about it while also getting his message across. The billboard he saw years ago at the commuter station said, "Suicide is not the answer." His first joke about it was, "Suicide is not an answer, it's a solution!” The commuter station was only addressing suicides that occurred during commuter hours.

"What the billboard is really saying is, 'Hey, are you gonna kill yourself? Well, please, don't kill yourself HERE. People are trying to get to work on time.' BART has a sense of humor also and updated the billboard the current billboard [to say], 'Suicide is not the route.' A transportation pun. Cuz that's what keeps me from killing myself, good puns."

After each show, the comedians refine their work by reviewing which jokes went over well with the audience and which ones did not. This helps them improve their jokes for their next show. It also helps them memorize their jokes. They do not keep jokes in their repertoire that they don't 
feel connected to and this makes their performance more authentic. Jasmine says that sometimes if she only changes one word from a joke, she will get a better response from the audience. Tom doesn't write anything down, but will play with what's happening in the room and improvise his jokes from there. Improving on their jokes helps comedians connect with the audience. Cathy took a storytelling class where she was taught not to tell a story that is still traumatic to her, so when she does comedy, she only performs jokes that don't cause her emotional pain and makes it clear that it is acceptable for the audience to laugh. This has to do with the stereotype of disability as tragedy, which disabled comedians have to confront.

Comedians have to earn the audience's trust and keep them engaged throughout the show. If the audience is argumentative, comedians have to deflect them without being hostile. Tom says that because he has a disability, he knows he can "get away with murder" with his comedy. He doesn't write anything down. He improvises from what's happening in the room, and goes with the flow. Comedians have to know their audience and their demographics to be able to tailor their jokes. Some of the comedians have performed at locations where the audience was not aware there was going to be comedy, so comedians have to be ready for there to be no laughter. For example, a show at a dive bar is going to get a different audience than a show at a restaurant, according to David. He explains, "People are not ready to hear whatever you are going to say. They are doing something else. They are busy and they are not paying attention.” 
They also have to tailor their jokes when they perform at disability service fundraisers, because that crowd is very different. Disabled comedians sometimes perform at these fundraisers in order to support the disability community. For example, Bill once performed at a fundraiser for a disability non-profit. He began by explaining why he was involved in disability issues and doing crowd work. Crowd work is when the comedians engage the audience in a back and forth discussion in order to keep their interest in their performance.

"Then I made a slight mistake in performance, where I started doing my club act. I should've just talked to them, and done crowd work more and had fun with it. I did have fun with it, but none of my jokes I would say went over badly."

Many of them record their performances and review their recordings after each performance, so that they can tailor their performances to certain audiences. Bill says, "You want to kill them [with] kindness and good humor and joy, and let them know that your goal is to entertain them..." This is where understanding the demographics of the audience is very important to comedians because they need to adjust their jokes to keep the audience engaged. It is easier for the comedians to do crowd work when they know more about their audience and their interests.

\section{Disabled Audience Members Appreciate the Work of Disabled Comedians}

Disabled audience members understand that the comedians are performing jokes that challenge misconceptions about disabled lives. Some of the participants have had people with disabilities ask them for advice on how to get into comedy. Tom says, "I mean, I have to say that 
99 percent of disabled folks appreciate me putting it out there on a grand scale and letting the world hear our voice." Maria had one young man come up to her and say, "I talk the way you talk," because he didn't want to stutter on the word "stutter." He was 27 years old and Maria was the first person he ever met who also stutters. David says that in Asia, most disabled people stay home because there are no civil rights protections for them. People are surprised to see him performing in comedy. Disabled people ask him how they can do comedy, but David says it is harder for people with more significant disabilities because of travel issues.

When disabled comedians perform at shows where there are disabled audience members, they feel understood. They don't have to explain the premise of their jokes as much and can go deeper. They don't often have disabled audience members that they are aware of, so when disabled audience members come up to them after their shows, it has a significant impact on them. Tom explains, "I will say that the disabled community does definitely... like Facebook. [I receive] at least four or five messages per week by people saying I have cerebral palsy or I have spina bifida, and I just see you and [it] makes me be where I want to be. That's a cool thing." Maria had a show at a stuttering conference “... and it was just the best. I mean, I was the headliner, I did all of my dirtiest jokes, even though I was kind of afraid to, but we were all on the same page. They laughed at my premises, like in the punch line, and they interrupted me in my premise [in] the middle of my punch line, and I forgot where I was. I didn't get to finish the joke. It was awesome.” 
There are some jokes that can only be told by disabled comedians; if nondisabled people told the same jokes, they would be offensive. Bill explains, "There are some things that only disabled people know amongst themselves. There are people that you know - there are shared jokes with each other about dealing with the able-bodied world, and you were just cracking me up over there about all of that." I was joking with Bill and Maria about how difficult it was to get a cab to my hotel room the night before. Disabled comedians have been told by other disabled people that they are glad that the comedians are informing the general public of what it's like to be disabled. Jasmine adds, "[A little person] came up after the show and was just really excited to have seen a little person do stand up. And it made me feel really good and it made me feel really purposeful, and... she really enjoyed it. But it is pretty isolated because I rarely see disabled people in shows. I mean, they are there, but I rarely see them." This is why realistic disability representation is important to the comedians.

\section{Pushing Boundaries}

Comedians are exposed to the humor of other comedians at shows backstage that is much more subversive than the general public is exposed to, so their tolerance of jokes that may be perceived as inappropriate is much higher. Disabled comedians push these boundaries even further in order to challenge people's misconceptions of disability. They joke about situations that make audience members uncomfortable. For example, sexualized behavior of disabled people is taboo in our society, so disabled comedians joke about disabled sex to challenge the taboo. They do this without apologizing or feeling embarrassed because they feel that these are issues that nondisabled 
people need to grapple with. Jack made a joke about one-night stands: "If you have sex with me, I won't run away. I will slowly amble out of your life." Tom explains, "I push it to the very edge of that, and every once in a while, I will slip up a little bit, but then I can bring you back." David adds, "Pushing the envelope is why you do this [laughing]. Having a thought - you know, comedy is about being direct, right?"

They can re-adjust by improvising and having a discussion. For example, Violet was flirting with the host of the show and thought that might have made him uncomfortable. "I said something to that guy, and I thought about like oh, man, that was a little bad. Oh, I was kind of like, being romantic and hitting on him, and I thought, oh, maybe I went too far." When Bill performs in marijuana dispensaries or dive bars, people are uncomfortable because a lot of his comedy is about being an addict in recovery. Although he has no issue with medical or recreational marijuana, he says that audience members assume that he is a cop. Maria says that people get uncomfortable when she stutters on stage, so she sometimes purposely exaggerates her stuttering, forcing them to confront their discomfort.

Cathy and David told me that they have been to several places where they are expected to not swear and if they do, they will not get paid. Cathy says that comedians shouldn't do those shows if they cannot abide by the rules, but David will use curse words if he feels his art requires it, even if it means forgoing pay. "For example, you might do a college show. They pay me $\$ 3$ 6,000 , but tell me, hey, you can't tell this joke. Are you going to cut it for the sake of that? 
Sometimes no. I am for the arts. It is your call." Being able to push the envelope and challenge misconceptions about disability is the reason that a lot of the comedians went into comedy in the first place. For example, Jasmine once performed a joke about suicide, which she thought was funny, but it didn't go over well with the audience. Violet records all of her sets and then listens to them later in order to improve. She sometimes hears things she said and immediately regrets them. "When you listen back to a set, a lot of times it can be difficult because you hear things, like mistakes. You say things and then you move on and you go okay. That's why it is so hard to listen back to the recording." Bill says that it's very important to him to be honest and to be himself, and part of that honesty might be offensive to some people with a different viewpoint. Jack was the only participant who said he doesn't worry about going too far because he can gauge a room and he doesn't believe that anything is off limits if he can make it funny. However, he also says that his quotes have been taken out of context on social media to make him look bad.

\section{Disability Discrimination}

Disability based discrimination is pervasive in comedy clubs as well as inaccessible transportation. Because their disabilities are invisible and not physically apparent, people have questioned why Maria and Bill are considered disabled comedians. Maria even has a joke about it.

"I'm part of [a] comedy troupe. It's me and a bunch of guys who have more apparent disabilities and people say I shouldn't be in that comedy troupe. I tell them I should 
be in it because I stutter and I have a learning disability. I tell them if you look at

the definition of the ADA, a disability is a physical or mental impairment that

substantially results in having to deal with assholes."

Bill did not recognize himself as a disabled person until Maria told him that being an addict in recovery is protected under the Americans with Disabilities Act. He says that he has not experienced the levels of discrimination that other disabled people have. Invisible disabilities are often not recognized, but by claiming their identity as disabled people, Maria and Bill expose audiences to the fact that not every disability is apparent.

Cathy has difficulty using Uber because although she uses a small manual wheelchair, Uber drivers are reluctant to help her fold up the wheelchair and put it in their trunk, even if their trunk is empty. Tom is often not recognized as part of the show. People will question why he is backstage with the other talent. David, who has performed comedy in other countries, says he can measure how civilized a country is by how long it takes people to give him a seat on the subway. "If it takes longer than a minute, your country's a piece of shit." The comedians also get heckled by audience members. Violet has had people tell her that she's beautiful by yelling it out during her performance. Maria has been told by men that she stutters because she's had the wrong kinds of orgasms, but what makes her angrier is when women make a face and are patronizing during her performance. In fact, at the show I attended, she made a few jokes about the inappropriate reactions she's gotten. One joke was about someone telling her the fact that she does stand-up comedy was 
the bravest thing they'd ever seen and her reply was, "In your face, 9/11 first responders!", meaning that because of her disability, the fact that she performs comedy is braver than the emergency personnel who saved lives on 9/11. This joke is about how disabled people view nondisabled people seeing inspiration when disabled people do ordinary things as inappropriate. Joking about full range of disability discrimination exposes the audiences to the realities that disabled people deal with every day.

The comedians with mobility disabilities had a harder time performing because venues were inaccessible to them. Some of the theatres have stairs. Jasmine, David, and Jack are able to climb the stairs, but it takes them extra time. Cathy uses a manual wheelchair and has been lifted onto the stage. At the show I attended, Jasmine, Cathy, and Jack performed on a raised platform. Cathy was lifted up onto the platform and people cheered for the men who helped her. "I make a joke about it or something like that, but you know. Like, there was like, one show that used to like, happen, like in the bottom of a big wine store and every time I did that, and I said, 'I feel like you guys just invited me so you can set off the fire alarm." Jack was able to climb up onto the platform using his crutches. He has a joke about it that I saw him perform. "You didn't think I was going to make it. That was inspirational. You're welcome." Cathy told me in the interview that she always insists on being on stage, even if she has to crawl. Jack told me that there was a beautiful theatre downstairs, which would have been inaccessible to audience members who use larger motorized 
wheelchairs. So, the performers made a last-minute decision to move the show upstairs to the bar area.

David encounters more inaccessible venues in Asian countries that are not as modern or advanced as the United States. He says that since he's from that part of the world, he's able to accommodate these venues. "And in this country [the United States], I had a couple - I think three out of hundreds of performances, probably three to five places [where] it is very hard for me to get up." When David came to the condo I was renting for the interview the next day, he was not using his crutches and I did not comment. When I escorted him to his car, which was parked in an accessible parking spot in the garage of the condo, he commented that he was surprised I did not ask why he wasn't using his crutches. He was using them the day before at his show. I told him that I thought it would be inappropriate for me to ask about that. In the U.S. and abroad, watching comedians navigate inaccessible venues shows audiences the barriers that disabled people confront on a daily basis.

Many of the comedians have been called inspirational and struggle to understand why. Accurate representation of disability is very important to them. As Jasmine says, she's just having fun and not doing anything special. She may be only at a nightclub talking to drunk people, but people will call her very brave. Challenging these misconceptions is a very important part of her comedy. David was laughing as he told me that people find him very inspiring when he goes out and performs. Violet has a joke about what she calls "inspiration porn," which was the first joke 
she ever wrote because it always has annoyed her that people find her inspiring. At the show I attended for Maria, she had a joke about this, too. "How many [disabled] people does it take to screw in a lightbulb? One to screw it in and five able-bodied people to say, 'You are such an inspiration!'" Tom says that some nondisabled people come up and tell him that, for example, they've always wanted to paint and became inspired by him to try to paint. "And I'm like, well what has that got to do with me? Why are you so dumb?" Rejecting the label "inspirational" can teach how patronizing it is to label a disabled person as such when they feel they haven't earned it, and this challenges the stereotype that disabled people are only there to inspire nondisabled people.

According to Jasmine, viewing comedy is a gamble for audience members and not every comedian is going to make every audience member laugh. However, what frustrates disabled comedians is when the audience reacts with pity. Maria says, "I get faces from women, like, like, this one woman was - she was making a face like, [whimpering] kind of confused but also kind of bitchy at the same time. So a lot of... all those things... I feel like sometimes women have the reaction that they might [have had] when they were in middle school and that throws me off more." Comedians are comfortable with going on to the next joke when the last one did not make people laugh. Jack explains, “...So as a storyteller, first, before I became more of a comedian, it is okay to sit in storytelling and not have a laugh happen every 20 seconds or every 10 seconds. So, I don't judge my success based on a really boisterous reaction alone. I mean, I feel like you could tell if 
an audience is with you or not with you, and I'm willing to meet them in the room and find out where we're at. I think all reactions are allowed and I don't take it terribly personally." When the audience doesn't respond with laughter, the comedians commit to their act in the moment. They review their jokes at a later time and make changes.

\section{Audience Members' Insights on Performances}

The interviews of audience members were conducted at the venues where the comedians were performing. I used pseudonyms to protect the audience members' identities. The interviews with Sarah, Beth, Tara, and Mary were done at a restaurant in Los Angeles following the performances of Jasmine, Jack, and Cathy. After David's show, I interviewed Wayne, Nick, and Aaron at a pizza parlor on the same street as the theatre where David performed in Los Angeles. Frank and Carson were interviewed following Maria and Bill's show outside of a biker bar on the sidewalk. Following Tom's show in Arizona, I interviewed John, Paul, and Ryan in the lobby.

Tara is a member of the Navajo tribe, is in her thirties, and identifies as having a learning disability and traumatic brain injury. Sarah is a Black transgender woman in her thirties who is a social worker and works with disabled people. Mary is a white woman in her thirties who identifies as nondisabled. Nick is a white man in his thirties who went to a school for disabled high schoolers because he has depression and learning disabilities, although he does not consider himself disabled. Wayne has an older brother with multiple sclerosis, works in the mental health field and is not disabled. Aaron is a white, nondisabled male in his thirties who once worked in hospice care with an autistic person. Frank is an Arab American man in his thirties who has a physical disability. 
Carson is a white man in his sixties who is losing his vision, although he does not consider himself disabled. After the interview, he confided in me that he was contemplating suicide because he was worried that if he lost his vision, he would be a burden to others. He became very emotional and may have been intoxicated. Paul is a white nondisabled male in his thirties who has a disabled younger brother. John is a white nondisabled male in his forties, and Ryan is a white nondisabled male in his forties who works in behavioral health with children who have multiple disabilities.

The following sections discuss the findings from my interviews with the audience members. The first section explores the audience members' experiences with disability prior to the performance. Many audience members who volunteered to be part of my study were disabled themselves, had disabled loved ones, or worked with disabled people. The next section highlights the way comedy teaches audience members that disabled comedians are competent. Some audience members were able to reflect on how they've been discriminated against themselves because of their minority identities. Following this, the results show that audience members enjoyed the performances and that they were comfortable with the jokes. They would all attend future performances by disabled comedians.

The comedians at each show volunteered to announce that I was interested in interviewing audience members and the audience members who were interested approached me after each show. The interviews with audience members were a half-hour each and took place immediately after the comedians' performances. There were no follow-up interviews. I did not specifically ask for 
those with disability experiences. However, one question in my interview guide for audience members was about their experiences with disabled people before attending the performance. People who had experiences with disabilities were more likely to volunteer for interviews.

\section{Audience Members' Experience with Disability Before Attending the Performance}

Frank and Tara self-identify as disabled. Tara explains how her disability affects her. "I struggled in college and couldn't keep up with the other students and I didn't know what was wrong. I found out that I had - at first I found out I had a learning disability, but it was mostly with reading. I didn't know about [it] because my parents didn't tell me until I got to college. But four years ago, when I came here to L.A., I found out that the doctors missed the diagnosis and that I have a brain injury." Frank has a physical disability and is an aspiring comedian who received help with his career from the comedians in the show he attended. He explains, "I have been disabled all my life. People [are] making jokes and being mean or whatever. Like why are you walking like that? Are you trying to be a pimp? What is going on? Stuff like that. I have a disability, so this is how I walk. If you like it you like it. I always say, man, the walk is nothing, but the face is handsome, so I'm okay." Having past experiences with disability may have predisposed these audience members to being open-minded and willing to engage with disability perspectives. I also wonder if audience members who have had previous experiences with disabled people were more willing to participate in my research. Most of the audience members who volunteered to be interviewed were either disabled or had disabled family members. This is not surprising because the shows 
were for disabled comedians and audience members who were interested in attending were more likely to be familiar with disability issues.

\section{Comedy teaches audience members that disabled comedians are capable}

Being able to perform comedy demonstrates that disabled people are capable and for the

audience members, this challenges the stereotype of disabled people as incompetent. Paul learned that comedy "...highlights the capabilities of somebody who is not necessarily able-bodied. There's no limits no matter what your disability may be. Seeing someone on stage, [who] maybe [to] some people may not seem to be able to do it, do it - it just shows anybody can do it if they put their heart to it." Carson recognized that the comedians were proud of their disability identity, but he has not accepted his own disability. Disability comedy forces audience members to confront disability issues, which they hadn't thought about before attending the performance. Mary explains, "I never really think about disabilities too much as an able-bodied person, I mean, why would I?"

Some audience members were surprised by how invalidating the experience of being disabled can be. Sarah says, "I think for me, what I realize is there are terms that all communities who have been oppressed, and to hear that there's no policy towards midget, but be respectful." She saw parallels between being disabled and thought to be asexual, and the experience of being a member of the LGBT+ community. She had not considered the parallels before attending the show. "... I know like, one experience of a disabled person is different from another's, but I remember [the feeling] when I was a kid growing up queer, and having talked to other queer 
disabled folks, and it sounded very lonely, and a lot of stigma from able queer folks. And to see other queer disabled folks talking about dating, being married, and having healthy relationships that was really encouraging to me, not only as a non-profit professional, but as a queer person. It is encouraging to hear that queer love exists in all intersectional conversations." All the audience members said they would attend another show with disabled comedians because what was most important was that the jokes were funny.

\section{Audience members enjoyed the performances of disabled comedians} Most of the audience members were invited by a friend who was either performing or attending the show. For example, Beth explains, "I was invited by a friend of mine and I was like, sure. And then I invited my friend and I'm really glad I came because it was so funny." Frank, who's disabled himself, came to Maria's performance "because Maria is my friend. Yeah, and I actually performed here before." Some attended to celebrate a loved one's birthday. Ryan says, "I actually brought my girlfriend for her birthday. She surprised me with it. I didn't know we were coming here, but it was for her birthday, so it was a pretty cool surprise." Paul and John came to celebrate their cousin's birthday. Paul says, "It is actually for my cousin's birthday, so a couple of friends and my cousin had planned to go to a comedy show and this is the one they chose." Sarah says, "Oh, personally, it was in memory of my mother because eleven years ago we were in a car accident, actually a hit and run by a drunk driver, and we lost my mom. She passed away on this day. And she saved my life and I wanted to - I didn't know what to do to help honor her memory. I was like, well, she likes - we both like comedy, so I thought it would be great to do this in memory 
of her." Attending a comedy show was a way for the audience members to celebrate or commemorate a loved one.

All audience members said the shows were very funny and they were glad they came. Ryan says, "I find anybody who wants to spread that joy of comedy to be really helpful. I don't feel like it really matters if they are disabled or not. If their comedy is good, it is good." He recognizes the capabilities of disabled people because of his work experience in behavioral health, so coming to the show affirmed his beliefs. Frank adds, "They did a really great job. They are always helping disabled community out. Maria is always, you know, she is an advocate, so she is always trying to help people with disabilities. Like, she helped me a lot. Like any booking shows and helping me with certain things, so I can further better my life and my career." The audience members were interested in hearing the comedians' stories, which are about experiences they are not often exposed to. Paul explains, "It was funny. It was really good. And again, it is one of those things where it is normalizing [disability]. It is just another person. How they go through life may be different, but [they're] going along their journey." Beth adds, "They're super talented. These were very accomplished people and really funny. It was very fun. I would recommend it to anybody.” Audience members understood that the comedy comes from comedians' personal experiences, which they found to be genuine. John explains, "I really liked seeing Tom go up there. Like, seeing him not only embrace it, but has sort of a - not that cynical, but laughing along with it and make 
the best of the situation. I really liked Tom." Comedy that comes from personal experience can confront stereotypes about disability and teach audiences a more realistic view of disabled lives.

\section{Comfort Level with Jokes}

The audience members were comfortable with the jokes. John says, "I have a pretty dark sense of humor, so I don't really get bothered or uncomfortable by most jokes." Other audience members agreed with this. The sex jokes didn't make anyone uncomfortable, although participants appreciated the comedians' openness to discuss sex. Beth says, "I think what surprised me the most was when the last comedian was telling sex jokes and her mom was in the audience, and she was like, this is my mom. I could never [do that] in front of my mom or dad..." She further explains, “...I [don't just mean], like, the openness to talk about sex, like other comedians do, but how many other parallels I found between sex, especially, like, trans and disability. Things like you have limitations and also ableism. Like really thinking about ableism and how even I may not necessarily have openly discriminated, but I may have some biases that I didn't think about." A few audience members mentioned that they didn't know if it was okay to laugh at some of the jokes, because a lot of the jokes that the comedians made were self-deprecating. Audience members may have been hesitant to laugh because disability is associated with tragedy and laughing at disabled people is taboo. Engaging with disability comedy may lessen the taboo around discussing disability issues. Sarah recognizes that disability is part of the comedians' identity. 'It's like, being able to not only make people laugh. It is not just like, I am a disabled, laugh at me no. It is one of the things that's a part of me." 


\section{Conclusion: Reflections on Lived Experience of Disability Comedy}

Disabled comedians use life experiences as a basis for writing jokes. Although they do not

intend to educate the audience about disability issues, they do expose people to aspects of living with a disability which they may not have considered before. This challenges stereotypes and misconceptions about being a disabled person and the way disability is viewed by society. In the beginning of their careers, the performers drew inspiration from famous comedians that they admired, but were able to develop their own style and jokes. Their multifaceted backgrounds led them to create material from their rich life experiences. Comedians use stories of discrimination they've experienced to tell jokes, which add to audience members' understanding of how the comedians are perceived. Disabled audience members have also shared experiences with the disabled comedians and appreciate their stories being told to a wider public.

Audience members gain insight from the shows. Most of them had prior experiences surrounding disability before attending the performances; some self-identified as disabled, others were labeled disabled although they did not identify as such, and some had siblings or friends with disabilities. Audience members felt that being able to perform comedy highlights the capabilities of the comedians; all audience members were comfortable with the jokes, as they understood that the jokes came from the comedians' lived experiences. 


\section{Chapter 5}

Disabled comedians use humor to portray their experiences in an ableist society. The findings from my study show that disabled comedians use their life experiences including instances of discrimination to write jokes. For example, comedians with physical impairments have difficulty accessing venues and they make jokes about the inaccessibility. They push against boundaries to entertain, forcing audiences to consider disability issues of which they may not have prior experience. Disabled audience members enjoy comedy from disabled performers. Many audience members I interviewed had disabilities themselves, loved ones with disabilities, or worked in the disability field. They appreciated that disabled comedians show audience members that disabled people are competent. Nondisabled audience members with minority identities reflected on how they have been discriminated against themselves; this helped them identify with disabled comedians. All of the audience members enjoyed the performances and would attend future performances by disabled comedians.

My study revealed that disabled comedians recognize themselves as part of an oppressed minority group and their humor reflects their experiences. Comedians with multiple minority identities are able to use their stories to create jokes. African American comedians have a longer, more recognized history of using humor to combat stereotypical representations in the larger society. Because African American humor also responds to injustice, examining historical and contemporary Black humor can reveal parallels to disability humor. 
Because disability humor is much newer, emerging in the 1970's, understanding the history of Black humor can demonstrate the path that future disability humor may follow (Watkins, 1999; Reid, Stoughton and Smith, 2006). "African American humor, like other humor that arises from oppression, has provided a balm, a release for anger and oppression, and a way of coping with the too-often-painful consequences of racism" (Carpio, 2010, p. 34). Disability humor has functioned in a similar fashion, allowing disabled people to confront ableism with authentic depictions of their lives (Lockyer, 2015).

Black humor emerged in secret during slavery and was disseminated orally by slaves who were able to laugh at the absurdity of their predicament. During and after the Civil War, minstrel shows were produced by whites to mock African Americans. When Blacks were allowed to perform in minstrel shows, they subverted this kind of humor to showcase a more authentic style (Williams, 1977). During the early twentieth century, Black comedians such as Moms Mabley and Stephin Fetchit began performing for segregated audiences and were the first to publicly display authentic Black humor (Watkins, 1999; Wood, 2014; Regester, 1994). This paved the way for comedians such as Bill Cosby, Dick Gregory, and, later, Richard Pryor, who performed Black street humor in front of integrated audiences for the first time (Watkins, 1999). Television sitcoms such as Good Times and The Cosby Show brought Black humor into the homes of mainstream viewers beginning in the 1960's (Bodroghkozy, 2003; Palmer, 1994; Hopkins, 2012). Later, variety shows such as Saturday Night Live paved the way for Chris Rock, Dave Chappelle and 
Key and Peele to openly challenge the discourse of racism (Watkins, 1999; Weaver, 2010; Hunt, 2015). President Obama used this kind of humor to push back against pundits who claimed he was not born in America at his White House Correspondents' Dinners (Guerrero, 2016).

African American women, like disabled women, have used comedy to challenge sexism beginning in the 1980 's. Here, too, parallels can be drawn between Black humor and disability humor. Like minstrel shows, freak shows were used to exploit disabled people for the entertainment of nonminority culture. Similar to African Americans, disabled people use humor to challenge oppression and represent themselves more authentically. For African Americans, this oppression began in slavery (Dance, 1978).

\section{Historical roots of African American humor during slavery and Reconstruction}

It's difficult to account for the origins of Black humor because it is diverse and dates back

to the first Africans in America under slavery (Dance, 1978). The eighteenth century was the first time that lives were conceived in terms of monetary value (Knight, 2013). Slaves with musical talent had a higher monetary value and contributed to the image of the contented slave that their masters wanted them to project (Watkins, 1999). Slaves maintained their traditions through African folklore, but formed a new culture. "American slavery provides the backdrop of tragedy against which African Americans developed their distinct form of humor, in which the material of tragedy was converted into comedy. Self-deprecation continues to be a feature of African 
American humor, especially for exclusively Black audience" (Dance, 1978, pp. 77-78). This humor favors the emotions of fear, shame, and empathy over a logical argument (Dance, 1978).

During slavery, ridiculing the white masters was dangerous and could result in death of the slaves. Slaves had to go to the 'laughing barrel,' a physical structure providing privacy, where they could release their laughter without fear of consequences from their white masters (Harris, 1995). Slaves developed a private humor at the same time they presented themselves as happy-go-lucky and childlike. In fact, slaveholders encouraged slaves' merriment as a source of entertainment (Watkins, 1999). Private slave humor allowed for a venting of anger and provided a means of group solidarity. Songs were a way for slaves to carry news and entertainment (Lalla, 1990). Slaveholders tolerated sentiment expressed in song that they wouldn't have if expressed directly (Watkins, 1999). Black slaves outwitting their master is the earliest example of Black humor; they were called tricksters. Trickster tales were a prominent source of humor for slaves and were a source of resistance, whereas actual resistance could be life-threatening (Watkins, 1999). "For Black Americans, humor has often functioned as a way of affirming their humanity in the face of its violent denial" (Carpio, 2010, p. 34). Humor was used to advocate for slaves' rights to freedom (Carpio, 2010). However, the vast majority of slave humor remained hidden because of the oral tradition and because they could have gotten in serious trouble if their humor was discovered (Watkins, 1999). 
Abolitionist and former slave Frederick Douglass was known for using humor in his speeches against slavery. In fact, during his time as a slave, he was recognized for his comedic imitations. His masters saw his gift and arranged to have him educated. During his time as a plantation slave, he used minstrel humor, but later distanced himself from minstrelsy when he became an abolitionist (Ganter, 2003). He used the language of pro-slavery activists to advocate for the abolition of slavery. "The genius of Douglass's comic strategy is that he redirects the slaveholders' logic, inverting their sense of social status and entitlement" (Ganter, 2003, p. 358). Douglass joked about being a light-skinned African American. "Douglass quips, 'I find I am hardly black enough, but by keeping my hair as woolly as possible I make out to pass for at least half a Negro at any rate"' (Chaney, 2010, p. 76). Douglass used humor to expose his audiences' prejudice, going from an outsider to becoming an equal. He deliberately used the genre of "plantation comedy" to expose the injustices of slavery (Ganter, 2003). During his time as a newspaper editor for The North Star, he praised a satirical newspaper called Punch for its antislavery cartoons, which were read globally (Chaney, 2010).

At the end of slavery, and after the Civil War, the public began to demand affordable entertainment for the common man. This is when minstrel shows and freak shows also gained popularity. These were both bizarre and unusual, providing low-brow entertainment (Watkins, 1999). Minstrel shows entertained white audiences, although slaves were expected to provide entertainment during their enslavement. Whites in Blackface would enact highly stereotyped 
comedic performances of African Americans without having actual contact with Black people.

Blacks started to perform in these minstrel shows and used the Black stereotypes perpetuated by whites in order to appease a white audience and make a living (Bloomquist, 2015).

Superiority theory can be used to explain minstrel shows because laughing at Black people in a disparaging way made white people feel better about themselves (Green and Linders, 2016). Minstrel songs were originally written by whites to ridicule Blacks (Watkins, 1999). Black performers in early minstrel shows denounced Jim Crow and celebrated Black communities, but they were only able to do this by perpetuating racist stereotypes in other ways (Weaver, 2010). When Blacks performed for Black audiences, they used the same minstrel show format, but had more subversive messages and were able to represent themselves more accurately (Bloomquist, 2015). All Black minstrel troupes attempted to display authentic Black humor starting in 1855 . When Black minstrel shows became profitable, they were taken over by White managers. Black minstrel shows provided a venue for the countries' first Black musicians and entertainers. The humor of minstrel shows changed after Emancipation from depicting Blacks as happy fools to more dangerous and a threat to the larger culture. Towards the end of slavery, minstrel shows portrayed plantation lives as ideal to slaves and White Northern audiences were reassured by minstrel shows that Blacks would be content to remain in the South as second class citizens. Blacks became the primary audiences for most Black-centered minstrel shows after Reconstruction. They began transforming racist jokes into more authentic Black humor. For Black audiences, minstrel 
shows provided them with Black celebrities with whom they could identify. Whites preferred attending minstrel shows with White actors in Blackface. Wealthier whites did not attend minstrel shows (Watkins, 1999).

Slaves used humor to cope with their living conditions and to subvert their masters' authority in subtle ways. Furthermore, Frederick Douglass used the proponents of slavery in humorous ways to ridicule the ideology behind slavery. After the Civil War, Blacks performed in minstrel shows for White audiences using racist humor, but sometimes had more subversive messages for other Blacks in the audience. With Black northward migration starting in the 1920's, Black humor found new northern audiences. "The act becomes a dialectic in which the comedians engage the audience in an examination of the pretenses and incongruities of American society. The synthesis is that America, like the Black race, is not what it should be, not what it's going to be, but certainly not what it was" (Williams, 1977, p. 15). Black humor has functioned as an antidote to oppression, but until the middle of the 20th century it had to be performed in secret (Carpio, 2010). There is little documentation of private Black humor until the 1920's (Watkins, 1999).

\section{Early Twentieth Century Black Humor}

Black women began to perform for Black audiences in the late 1800's (Allen, 2005). Jackie

Mabley was born at the end of slavery and became the first African American female comedian to perform in comedy without a male partner (Wood, 2014). Mabley began in tent shows in the early 1900's and in Blackface (Watkins, 1999). She developed a character called "Moms Mabley" in her early twenties, but success came decades later. She performed in ordinary house clothes, 
depicting an elderly Black woman who becomes desexualized. She used domestic scenes to push back against nostalgia and victimization found in Black culture (Wood, 2014). Mabley's act directly contradicted the stereotype of the Mammy, which had existed since slavery. The Mammy was fiercely loyal to her white owners and helped raise their children; she was viewed as asexual and not a threat to her mistress (Euell, 1997). Moms Mabley relied on Black folklore for some of her routines and became one of the first Black comedians to do a monologue. She worked with other well-known African American comedians, but she was at her best alone with just a microphone. She undercut sexism and racism directed at her with humor. She appeared in musical comedies in the 1920's and 1930's (Watkins, 1999).

Her brand of humor was too risky for early Hollywood films, but Mabley earned major roles in the 1970's. In Boarding House Blues, she played the house mother for struggling artists; the movie displayed much of her cynical humor (Watkins, 1999). "Her corporeally centered performances displayed the Black female body as a site and source of pleasure, anger, sexual desire, and political resistance" (Wood, 2014, p. 92). Her performances made her an active participant in her own story instead of a passive observer (Wood, 2014). "Comedy was also Mabley's mode of communicating a specific kind of civil rights rhetoric that addressed issues of location, mobility, and safety for Black Americans" (Wood, 2014, p. 99). Moms Mabley joked about segregation, specific racist encounters, and voter registration by taking the absurd and making it laughable (Harris, 1995). She was one of the last African American comedians to be 
invited to perform in front of white audiences in the 1970's because her material was thought to be too racy (Watkins, 1999). "These jokes go a step further by exposing and squaring the systems that put the female body on display for the purposes of heterosexual male consumption, objectification, and violence" (Wood, 2014, p. 93). Mabley's performances challenged heterosexuality and the stereotypes of older Black women's bodies (Wood, 2014).

Black comedy teams were rejected by early radio; Whites mocking Blacks were acceptable, but Black people themselves were not. Amos n' Andy premiered on radio in 1928 and was a highly stereotyped comedy show where Whites portrayed Blacks as ignorant (Watkins, 1999; Havig, 1992). The show's creators, Gosden and Correll, had written a show for a regional radio station called Sam n' Henry, but when it went to national radio, it was rebranded Amos n' Andy for copyright reasons (Havig, 1992). It was the most popular show in radio history and portrayed two Black farmhands migrating North and dealing with city living. The show lost its popularity in the 1930's. Nevertheless, the show moved to television in the 1950's and was the first show to cast Black characters not only as servants, but also gave them the opportunity for other roles. Amos n' Andy was offensive to middle-class Blacks when it premiered on television from 1951-1953, but represented the only somewhat authentic Black comedy on broadcast television (Watkins, 1999; Pinsker, 2003; Havig, 1992). Audiences found the characters to be more ridiculous on television than the earlier radio broadcast. The scripts were written by a team of white writers who were unfamiliar with the Black community (Horton, 1993). In 1951, the NAACP protested the show as 
highly stereotyped and forced it off the air two years later (Watkins, 1999; Pinsker, 2003; Havig, 1992).

Lincoln Theodore Rosevelt Perry, who adopted the stage name Stepin Fetchit, started his show business career in 1913 as part of a traveling carnival show. He began his acting in the 1920's and 1930's with many servant roles, which became a Hollywood stereotype. The African American press disapproved of his stage name, which he created by putting together the words "step and fetch it" (Euell, 1997). Often, he exaggerated to comedic effect the laziness and fear that slaves used to get out of barbarous workloads (Watkins, 1999). The "coon" character had existed in the minds of Whites since slavery; the coon was lazy and shiftless, providing proof that Blacks were not equipped for freedom. Perry presented himself as illiterate in order to be able to improvise the lines he was given by directors (Euell, 1997). As the "coon" character suggested, playing the fool could save lives. Black audiences understood this and found it funny (Watkins, 1999). He provided unflattering depictions of African Americans in his comedy acts. He was one of the wealthiest African American performers of his time because Whites appreciated his disparaging humor. He wrote editorials for an African American owned newspaper, but as his performances became more stereotyped, he was ostracized and ridiculed by the Black press; he was more concerned with making money than with his reputation in the Black press (Regester, 1994). In fact, tricksters who were respectful while dealing with Whites were able to navigate an 
environment hostile to Blacks. Trickster humor has existed since slavery, but early Hollywood ignored most authentic Black humor (Euell, 1997).

\section{Early African American Stand-Up Comedy}

In the 1960's, Black comedians found common ground based on intellectual humor with

Whites who were sympathetic to the ideals of the Civil Rights movement. This was ironic given that, in the past, Black humor was perceived by whites as simplistic. Comedian Dick Gregory began his career while still in high school with satirical monologues that disclosed how Blacks felt about racism (Watkins, 1999). He made a conscious decision not to use sexually charged jokes, for which other African American comedians were known (McAllister, 2011). Gregory was a pioneer of politically conscious humor, critiquing racism in an unequal society. He was also a Civil Rights activist who was jailed for participating in racial justice protests. He performed at predominantly African American venues briefly during the beginning of his career, preferring to entertain in front of integrated audiences. He once told an integrated audience, "If I've said anything to upset you, maybe that's what I'm here for" (Haggins, 2007, p. 19). Later in his career, he would subvert racist heckling with humorous wordplay. For example, he would joke, "You hear what that guy just called me? Roy Rogers' horse. He called me Trigger!” (Watkins, 1999, p. 432).

Gregory was one of the first Black comedians to perform in front of racially integrated audiences in the early 1960's. One joke he performed was about ordering fried chicken in the South. When he entered the restaurant, the white waitress told him that they don't serve colored people and his reply was, “That's all right, I don't eat colored people. Bring me a whole fried 
chicken" (Watkins, 1999, p. 497). When the chicken was brought to him, members of the KKK approached him and said, “'Boy, we're givin' you fair warnin'. Anything you do to that chicken, we're gonna do to you....' So I put down my knife and fork, and I picked up that chicken, and I kissed it" (Watkins, 1999, p. 497). He understood that Whites were uncomfortable when listening to Black racial humor. His solution was to appeal to them as an individual. He made jokes about himself before he made any jokes about Whites, striving not to appear bitter (Watkins, 1999). He was able to create a rare space where Blacks and Whites felt equal during his comedy. He responded to a heckler at one of his performances by saying, "Trying to get you to shut up is like trying to explain integration to a lynch mob" (McAllister, 2011, p. 211). In this way, he prevented Whites in the audience from feeling sorry for him (McAllister, 2011).

Richard Pryor was a pioneer stand-up comedian who frequently addressed racism and race relations. Because his family owned a brothel and he was Black, he was stigmatized in public school. He was alienated from school, but had two educational experiences in grade school that shaped his future as a comedian. In sixth grade, his teacher made an agreement that if he got to school on time and did not interrupt the class, the teacher would let him entertain the class for ten minutes once per week. He also met a university drama major who got him into a drama club in the ninth grade (Watkins, 1999).

He moved from Los Angeles to Berkeley, which was a hotbed for student activism, where he embraced Black history and folklore. He was inspired by Black writers and began to see himself 
in a larger context (Watkins, 1999). "Rather than attempting to convey the similarities between black and white social norms, Pryor instead sought to play on the innate differences between the two" (Hunt, 2015, p. 838). At the beginning of his career, Richard Pryor never cursed and instead told charming jokes modeled after Bill Cosby. He began performing more edgy jokes for mixed audiences, desegregating Black humor (Carpio, 2010). By Richard Pryor's time, African American humor had become more radicalized, but the audiences were racially integrated (Green and Linders, 2016). He was popular with younger Black audiences under thirty-five, who were rejecting assimilationist humor in favor of empowered ethnic humor and embracing the Black Power movement (Watkins, 1999). His comedy made Black struggles visible to white audiences in a way that was not threatening to them (Hunt, 2015). He was the first African American comedian who made jokes to an integrated audience that Black people told among themselves (Watkins, 1999). "Pryor's portrayal of character also seeks to get at the sensitive, realistic understanding of Black working class life and to turn stereotypes into individuals" (Williams, 1977, p. 16). For example, his character Mudbone allowed him to reminisce about the old days and use examples of traditional folklore and rural wit. Much of African American humor is jokefree, attitudinal and visual. It relies on attitudes and delivery. His reflected ghetto life and behavior, which he had observed growing up. His genius was not in his jokes, but in his delivery, especially when he changed characters. He made Black street humor universally relatable. He joked about aspects of Black culture that were less than admirable, and mocked the hypocrisy of White Americans (Watkins, 1999). This was the first time White audiences were exposed to authentic 
comedic portrayals of working class African Americans. He reminded his audiences that African Americans lived precarious lives due to institutionalized racism (Williams, 1977). "Pryor, Chappelle, and other Black comics who perform for mainstream audiences may do so not simply in service of integration but also a salacious desire to attain humanity via the satisfaction of white spectators" (Hunt, 2015, p. 849). This format of humor became more visible to mainstream American audiences when it was broadcast on television.

\section{The Evolution of Contemporary Black Comedy}

Television has allowed more Black comedy to be viewed by larger audiences than in the past (Weaver, 2010). In the 1990's, Chris Rock, who wrote for Saturday Night Live, became known after his 1996 HBO special Bring the Pain. His comedy style is brash and irreverent. He jokes about inequities of divorce laws and fidelity in relationships (Watkins, 1999). HBO's Def Comedy Jam was very popular, but only two comedians featured have crossed over to the mainstream stage: Chris Rock and Dave Chappelle. "Rock's comedy deals uncompromisingly with American race and ethnic relations, and racism, providing many examples of reverse discourse. Rock resist[ed] and attack[ed] white racist attitudes to black vernacular and linguistic competence" (Weaver, 2010, p. 40). Chappelle's Show was successful on Comedy Central, but he cancelled it because he felt that afraid that white audiences were laughing in favor of the stereotypes that he was mocking (Hunt, 2015).

Keegan-Michael Key and Jordan Peele created Key and Peele, which ran from 2012 to 2015 on Comedy Central. They had a skit called Negrotown, which was about a utopia where 
racism didn't exist and Black people did not have to fear for their lives. The main character, Wally, wakes from his concussion and realizes he is in jail after a cop hit his head and he was just imagining the utopia. They also satirized Obama, giving him an anger translator named Luther who used Black vernacular to translate what Obama was saying. The premise was that Obama wasn't allowed to show his anger because he was trying to resist stereotypes of the irrational Black person (Guerrero, 2016). Obama himself used humor to perform a different version of Black masculinity while addressing oppression in the White House. There were four key functions of the humor he used. He used it to clarify and identify with people; this is unifying humor. He also used humor to differentiate between himself and his opponents and to enforce his viewpoints; this is divisive humor. For example, at the White House Correspondents' Dinner in 2011, he joked about releasing his "birth video" in response to accusations that he was not born in America and therefore was not eligible to be president. The video was taken from the Disney animated movie The Lion King in which the lion cub, Simba, is presented to the African kingdom (Isaksen, 2017).

Historically, men have had an easier time using their bodies for physical comedy than women and more so for Black women (Carpio, 2010). Boundaries are enforced to a greater degree for Black female comedians than Black male comedians (Allen, 2005)."Black women lack adequate opportunities to exert control over the imagery and discourse that circulate around Black womanhood, and this limitation in turn makes it more difficult for Black women satirists to push the boundaries of social identities and market their own representations to mass-media audiences" 
(Finley, 2016b, p. 257) For working class Black women comedians in the 1970's and 1990's, exploring sexuality through jokes was a way to control their immediate environment. Informed by mass media portrayals, humor likewise may be used against working class Black women to justify forms of oppression. Because experiences of Black women comedians have been misrepresented by mainstream media, the challenge is to develop an intersubjective atmosphere (Finley, 2016a).

Black women comedians used humor in order to liberate themselves from patriarchy and racism. Satire can challenge historic narratives about Black women (Finley, 2016ab). "Satire, a form of critical scrutiny that directs 'ridicule' at an object of study, is often associated with critique because it can mock problematic targets (such as stereotypes) through humor rather than stern indictment. Satire involves 'laughing at' someone whose behavior or beliefs deserve ridicule" (Thorton, 2011, p. 439). Images of Black women, which originated during slavery, are oppressive (Bell, 2015). A legacy of slavery is that Black women's bodies are viewed as undesirable, ugly and monstrous. Black women use bitterness to push back against racism and sexism (Finley, 2016b). "Stand-up comedians also consider, consciously or not, how to work racial and gender identities in their performances. Depending on the location, venue, and audience, comedians may choose to present themselves differently, or to emphasize different aspects of self, in terms of what kind of racialized and gendered person they put forth" (Antoine, 2016, p. 38). African American women have limited access to performance venues because they are dominated by White men. 
Time constraints mean that they have less time to deliver a monologue, so they have one-liner jokes instead (Allen, 2005). Eventually, second wave Black feminism eased these tensions by allowing women to openly discuss sexual pleasure. Black politics in the 1970's allowed for authentic expression based on the needs of a working class Black community. Sex was freely discussed publicly (Finley, 2016a).

Sex jokes allowed Black women who confronted stereotypes and patriarchy to reclaim their humanity and desires rather than being shamed and objectified (Finley, 2016a). During the 1980's, Black women were not taken seriously in the comedy industry, especially in variety shows like $S N L$, which were written and performed primarily by White men (Finley, 2016b). It wasn't until a decade later that more serious topics such as erotic sexual disclosures became popular in Black women comedians' performances (Finley, 2016a). "In terms of composition, African American women's fun making is conveyed through an elaborate combination of repartee, irony, sarcasm, and body language that includes vamping, physical stunts, and erotic flippancy" (Allen, 2005, p. 99). Stand-up comedy can make visible racist and sexist social structures. Pushing the edge can challenge hegemonic discourse of race and gender (Antoine, 2016). Black stand-up comedy became a display of power in which White audience members were made uncomfortable by being outnumbered. This difference was pointed out when in a studio audience. The humor was playful, but was constructed in a way that demonstrated to White people what it was like to be Black in White America (Schulman, 1994). Comedy allowed for Black women to challenge stereotypes 
about their bodies. Comic politics had to challenge the status quo in order to resist cultural stereotypes (Finley, 2016b).

"These representational strategies have the potential to undercut stereotypical tropes that circulate about black women as unruly, incompetent, irresponsible, and interchangeable - tropes so deeply embedded (such as the Angry Black Woman, the Welfare Queen, and the Bad Black Mother) that they often prevent black women from speaking and being heard. We might recognize black women's postmodern satire as a form of cultural performance, distinguished by its transgressive potential" (Finley, 2016b, p. 237). "Whether or not nonblack audiences are watching, the fact that this brand of black comic performance finds popularity sans any essential sociopolitical comprehension or coherence is metaphorical. It represents the possibilities for black comics and black audiences to meditate upon and discuss black suffering outside the scope of political discourse" (Hunt, 2015, p. 856). Comedy is a powerful tool for African Americans to represent themselves more positively and "...even though it is rarely credited, the modern landscape would be barren without African American female comedy" (Allen, 2005, p. 114).

\section{Black Humor on Television Sitcoms}

Sitcoms address social issues and have been historically inclusive of Blacks as main characters (Gray, 1986). Good Times, which aired from 1974-1979, was the first TV show to represent a Black family with the father present. It featured an intact working class Black family 
and addressed social and political issues such as racism and Black poverty in the aftermath of the Civil Rights movement. It was also the first TV sitcom to show a Black couple who had a strong romantic and sexual relationship. Good Times addressed working class Black problems such as: youth gangs, the high cost of uninsured medical care, price fixing at neighborhood grocery stores, and hypertension in Black men (Bodroghkozy, 2003). For example, in one episode, the son, Michael, didn't do well on IQ tests and it was explained that IQ tests were biased towards White people, putting Black people at a disadvantage. Race and class were significant factors on the show (Hopkins, 2012). The show was initially written by Eric Monte and Mike Evans, both African Americans, and attempted to be realistic. However, after the third season, the series had no Black writers and the series was no longer authentic. The actor portraying the patriarchal role left the show and the family became fatherless. The last season of the show presented one of the sons, JJ, as acting like a clown and exaggerating his facial expressions, mimicking minstrel shows of the past. Viewership declined between the third season and the final season (Bodroghkozy, 2003).

The 1980s saw an increase in Black-led television families who were as successful and attractive as their white counterparts (Payne, 1994). The Cosby Show followed a typical sitcom format except that the characters were Black (Palmer, 1994). Bill Cosby created a fictional world where racism wasn't an issue or was never addressed (Hopkins, 2012). Cosby allied himself with the powerful. The only struggles in the show occurred within the Black community (Palmer, 1994). The Cosby Show portrayed fatherhood and manhood in a positive way while addressing issues of 
sexism. It showed Blacks as human beings and depicted the shared concerns that all people have (Inniss and Feagin, 1995). Black-cast sitcoms were seen by some as representing all Black people (Martin, Jr., 2014). Colorblindness is an ideological stance that racism is no longer an issue. Pluralist shows have Black people in Black worlds, which parallels white society, whereas assimilationist shows have Blacks in fictional white worlds (Thorton, 2011). The absence of racism on sitcoms can lead White people to believe that racism is no longer an issue in society (Inniss and Feagin, 1995).

Non-minorities who do not interact with African Americans receive their information about them through the media. Viewers believe that television depicts African Americans realistically and this serves to fill their knowledge gap. Broadcast television can influence viewers' ideas. Unlike The Cosby Show, the sitcom Blackish, which premiered on ABC in 2014, discusses racism and race relations. This may be because of the time periods when the shows have aired. In both The Cosby Show and Blackish, the parents are educated, dedicated to their families, and have professional careers. This was not common on television before the 1980's. Today's television viewers can see the African American family as equal (Stamps, 2017). While television sitcoms showcase fictional portrayals of African American families, comedians entertain audiences with genuine moments of humor from their lives. 


\section{Comparing and Contrasting African American Comedy and Disability Comedy}

Disability humor has emerged within the last twenty years and is much newer than African

American humor. Both groups have developed comedy in response to oppression and injustice embedded in a discriminatory society. African Americans have faced prejudice and legal segregation while disabled people have been segregated by both physical and attitudinal barriers as well as laws (Watkins, 1999; Oliver and Barnes, 2012). African American and disabled people were exploited, in minstrel shows and freak shows, to entertain members of the dominant culture. As a result, both groups have been viewed as tragic, which makes genuine humor harder to embrace (Bogden, 1988; Watkins, 1999). Additional hardships are faced by Black and disabled women, who must confront racism and ableism as well as sexism (Miles, 2019).

Both African Americans and disabled people use humor in response to oppression by the wider society (Watkins, 1999; Lockyer, 2016). For example, Richard Pryor joked about the lack of social justice afforded to Blacks. He said, "I came here looking for justice. And that's what I found - Just. Us." (Watkins, 1999). Similarly, Maria, one of my participants, joked about the definition of disability, which she said is a "mental or physical impairment that substantially results in having to deal with assholes." Both of these jokes are about interactions with people who are largely ignorant about how social practices can become discriminatory.

Disabled people and African Americans have experienced barriers to performing on stage.

Disabled people, particularly those with mobility impairments, still experience physical barriers 
when performing or attending comedy shows while African Americans have experienced legal segregation (Watkins, 1999; Lockyer, 2015; Reid, Staughton and Smith, 2006). For example, Moms Mabley performed in front of predominantly Black audiences because she was thought to be too racy for white audiences. Richard Pryor was one of the first Black comedians to perform in front of integrated audiences with acceptance. Bill Cosby told clean jokes and therefore it was permissible that he could perform in front of integrated audiences (Watkins, 1999). Disabled people also have transportation barriers, which affects where and when they can perform. Wheelchair users face physical barriers when venues are not accessible (Lockyer, 2015). As I found in my research, Cathy experienced discrimination from Uber drivers who were unwilling to fold up her wheelchair and put it in their trunk. Violet refused to perform at inaccessible venues, stating that she would not support a show that doesn't accommodate her needs as a performer. Jasmine, who is a little person, had difficulty accessing the stage at venues with many stairs. Although disabled people and African Americans are now invited to perform comedy, in the past, both identities were part of entertainment that was exploitive (Watkins, 1999; Bogden, 1988).

Disabled people were displayed as oddities in freak shows, while African Americans were mocked by White entertainers wearing Blackface in minstrel shows. Thomas Dilward was the only African American performer who was allowed to participate in White minstrel shows before the Civil War because he was a little person and therefore not threatening to the White actors. Because he was disabled and also Black, people were curious about him as a spectacle and his race wasn't 
as offensive. In fact, the shows he worked for attempted to obscure his African ancestry. In both entertainment contexts, audiences were curious about people they thought were exotic, but maintained a distance with those they found inferior. In early minstrel shows, White entertainers mimicked and exaggerated what they thought were Black antics. After the Civil War, African Americans began to perform in minstrel shows and used subversive humor that only Blacks in the audience understood. However, even Black performers were still required to wear Blackface by White managers, who began to take an interest in Black minstrel shows when they became profitable (Watkins, 1999; Bogden, 1988). The legacy of this kind of entertainment has led to audience members' discomfort with authentic humor from marginalized groups. For example, nondisabled audience members who attend shows by disabled comedians are unsure of whether or not they can laugh at the jokes. During my research, Maria told me that at one of her shows, a woman in the audience covered up her face every time Maria stuttered. When Richard Pryor began performing authentic Black street humor in front of White audiences, they were not sure how to react. Some even felt guilty (Watkins, 1999). This is because being disabled and being Black have both been associated with tragedy.

Black comedians and disabled comedians have to work harder to develop humor in antiracist and anti-ableist jokes. During my research, David told the audience that they were permitted to laugh at him and his jokes about his disability. Many audience members I interviewed were uncertain if they could laugh at jokes the comedians told about being disabled. The history of 
exploitative entertainment in freak shows and minstrel shows has led to contemporary audiences being afraid to laugh at authentic humor from minority entertainers. Moms Mabley experienced this when she told jokes about her sexuality while dressed as an elderly grandmother (Watkins, 1999; Wood, 2014).

In fact, Black women and disabled women have been denied their sexuality and use comedy to reclaim it. During slavery, female slaves were entrusted with caring for children of their White masters while their own children may have been neglected, abused, or sold (Finley, 2016). This led to the stereotypical figure of Mammy, who was seen as docile and committed to her White family. She was seen as only a caretaker and not a fully realized sexual being. In contemporary society, disabled women are denied their sexuality, while the stereotype of Black women has changed such that they are now seen as overly sexual. Much of the comedy of Black women and disabled women refutes this (Fulton, 2004). For example, my participant Cathy joked about her sexuality, saying that when people ask her if she is still able to have sex after her accident, she tells them that her clitoris was not in her feet. Jasmine told many jokes about being married and her relationship with her husband. Contemporary African American female comedians have joked about being taken into police custody and making sexual innuendos about being handcuffed (Allen, 2005).

\section{Using Humor Theory to Analyze the Work of Black Comedians}

Humor theory attempts to differentiate between humorous and non-humorous situations.

The incongruity theory posits that humor arises when two normally unrelated concepts are 
associated with each other (Warren and McGraw, 2015). Much of slave humor dealt with the incongruities of the tragedies of slavery and the slaves' subtle forms of resistance. Later, Dick Gregory used incongruity in his joke about his interactions with the KKK while eating fried chicken. They threatened to kill him depending on what he would do with the chicken, so he picked it up and kissed it. Mabley used incongruity humor when she dressed as an elderly grandmother, but used sexually explicit material.

Superiority theory argues that people compare themselves to someone they find ridiculous and see humor in the comparison (Lintott, 2016; Moran, 2003). Tricksters used superiority humor to subvert the expectations of their White masters in a non-threatening manner. They outsmarted their owners while making fun of them. President Obama used this kind of humor to ridicule conspiracy theories about his birthplace. In the TV show Good Times, superiority humor is used when Michael does poorly on an IQ test and the tests are ridiculed for being biased against Black people. This is a situation where Whites are meant to feel superior to Blacks, but the humor of the show flips the expectation around (Bodroghkozy, 2003).

Frued's relief theory states that people find humor after a build-up of tension is released (Bingham and Green, 2016). One example is President Obama's use of relief humor during his 2011 White House Correspondents' Dinner speech, when he told the audience he was going to show his birth video, but showed a clip from the movie, The Lion King, featuring the presentation of the baby lion, Simba. There was a build-up of suspense when the President said he was going 
to show his birth video, but the audience experienced relief and laughter when the Disney cartoon played instead (Isaksen, 2017). Humor theory highlights a difference between events that are funny and those that are not. Incongruities alone do not make the situation funny and feeling superior by itself does not result in humor, nor is relief always humorous (Warren and McGraw, 2015). In addition to examining theories of humor, humor studies and disability studies are emerging fields of scholarship and there are many opportunities for future research. 


\section{Recommendations for Future Research}

Future scholarship in humor studies and disability studies should explore the experiences of nondisabled colleagues of disabled comedians who may have insights into their performances. Television sitcoms are under-researched for how they portray disabled characters, although there is some scholarship. Disabled comedians told me that some venues are inaccessible to comedians with physical and mobility impairments; venues' compliance with the Americans with Disabilities Act should be studied. Feminist theory and the social model of disability could be used to examine the experiences of disabled women comedians. Queer theory and the social model of disability may help illuminate the work of queer disabled comedians. The intersections of racism and ableism in comedy have not been explored, although they are connected. Nondisabled comedians' use of disability stereotypes and disabling language is under-researched.

\section{Conclusion: How Understanding Black Humor Can Inform Disability Humor}

African American humor began during slavery as a way to escape when physical escape was not possible. Private slave humor provided a means of group solidarity and venting against injustice (Williams, 1977; Watkins, 1999). After the Civil War, minstrel shows, in which whites performed in Blackface, were popular and when Blacks began to perform in them, they used an insider humor that only Blacks in the segregated audience understood (Watkins, 1999). In the early twentieth century, Moms Mabley and Stephin Fetchit began performing for segregated audiences using a more authentic Black humor. Richard Pryor brought Black street humor to comedy shows beginning in the 1950's (Watkins, 1999; Wood, 2014; Regester, 1994). Beginning in the 1970's, 
television sitcoms such as Good Times and The Cosby Show brought authentic Black humor into homes (Watkins, 1999; Bodroghkozy, 2003; Palmer, 1994; Hopkins, 2012). Contemporary comedians, such as Dave Chappelle, Key and Peele, and Chris Rock have continued this tradition, bringing African American humor to mainstream audiences (Watkins, 1999; Weaver, 2010; Hunt, 2015).

Because African American humor and disability humor were created in response to oppression, there are some similarities (Watkins, 1999; Lockyer, 2015). However, there are also important differences. Disability humor is much more recent and is still developing (Lockyer, 2015). Disabled comedians are not as well recognized as famous African American comedians. Tom, who was the most famous participant in my study, is sometimes not recognized as a performer when he is backstage. Disabled comedians lag behind African American comedians in terms of recognition and they are less likely to be paid and treated as professionals. For example, Jack told me he was surprised when he was booked at a venue in Australia, he was provided hotel accommodations and was well compensated.

Disabled comedians experience sympathy and pity while Black comedians historically have encountered hostility. One of my participants, Maria, told me how angry she gets when audience members respond with sympathy when she stutters during a performance. Moms Mabley was one of the last comedians of her generation to be allowed to perform for integrated audiences because her material was thought to be too risque. Because she was a Black woman discussing 
sexual topics, this reflected both racism and sexism (Wood, 2014; Watkins, 1999). In contemporary society, the stereotype for disabled women is reversed; they are supposedly asexual. In my study, Cathy and Jasmine joked about their sex lives in order to combat this stereotype.

Freak shows and minstrel shows had a similar goal of entertaining mainstream audiences with the oddities of visibly disabled people and Black people. When minstrel shows became profitable, White people began to manage them, furthering the exploitation of African Americans. Freak shows were always managed by nondisabled people. One of the differences between freak shows and minstrel shows is that, eventually African Americans started to manage and profit from minstrel shows, but the same cannot be said for disabled people who worked in freak shows (Watkins, 1999). Both the African American Civil Rights movement and the Disability Rights movement attempted to combat these injustices. In part because of the legacy of freak shows, mainstream audiences are hesitant to laugh at authentic disability humor. However, Black comedians are more recognized in the mainstream. Exploitation of Blacks and disabled people led both groups to organize the Civil Rights movement and the disability rights movement (Watkins, 1999; Lockyer, 2015).

The African American Civil Rights movement is older and more recognized than the disability rights movement. In fact, the disability rights movement has used the successes of the Civil Rights movement to argue for equality for disabled people (Bond, 2014). This movement has succeeded, but is not as well-known or taught in schools (Lalvani, 2015). Ableism is not as well 
understood as racism, although both still persist and intersect with one another. The barriers that disabled comedians face are different than the barriers African Americans have faced, and they compound each other (Watkins, 1999; Oliver and Barnes, 2012). The laws protecting the civil rights of disabled people were enacted more recently in the 1970's and 1990's (Section 504 of the Rehabilitation Act of 1973; Americans with Disabilities Act, 1990). Unlike African Americans, for some disabled people to gain access to venues, there must be physical changes made to buildings, which can be expensive (Lockyer, 2015; Reid, Staughton and Smith, 2006).

African Americans began appearing on sitcoms in the 1950's with the premiere of Amos n'Andy. The show was highly stereotyped and portrayed Blacks as unsophisticated and uneducated (Watkins, 1999; Pinsker, 2003; Havig, 1992). However, in the 1970's, Black sitcoms emerged such as Good Times, The Jeffersons and The Cosby Show, which portrayed Black families more humanely (Bodroghkozy, 2003; Gray, 1986; Hopkins, 2012). Meanwhile, when actors portray characters who have characteristics of disability, they are not identified as disabled people. For example, in the television shows Community and The Big Bang Theory, two characters are coded as autistic by viewers, but their disability identities were never explicitly stated on either series (Walters, 2013). Contemporary sitcoms with African American lead characters, such as Blackish, address racism more explicitly (Stamps, 2017).

Authentic disability humor is created by disabled people and reflects their experiences in a way that is not disparaging. It confronts stereotypes and forces audience members to reevaluate 
their assumptions about disabled people. Like Black humor, it emerged from oppression. Venues are slowly becoming more accessible to disabled people as people are becoming more aware of the ways in which disabled people are oppressed. However, more needs to be done so that disabled people are recognized as equals. Disabled people who want to pursue comedy need support from educators, families, and their communities in order for this to be a viable career option. Economic barriers can be removed by paying disabled comedians competitive wages for performances. Transportation is still a barrier for aspiring comedians with physical disabilities, especially those who use wheelchairs and other mobility devices, and services must be provided in order to accommodate their needs.

Aspiring disabled comedians need more access to live performances on television, such as in late night variety shows, to reach a wider audience. Even after earning recognition on a broadcast reality show, Tom, the most famous participant in my study, is still not well recognized by the general public. He mentioned that some major influences for him were Richard Pryor and another disabled comedian, Chris Fonseca; however, Fonseca is not as well known as Pryor. In order for disabled comedians to be successful, they would have to be viewed as competent and equal. In fictional media, more sitcoms need to be developed with disabled people in lead roles and behind the camera, equivalent to television shows like Blackish and Good Times. Television networks and streaming services should hire disabled writers in writers' rooms, giving them the opportunity 
to write scripts. Until disabled comedians are recognized as professionals and paid competitively for their work, none of these recommendations are applicable. 


\section{References}

Allen, C. (2005). "Shaking that thing" and all its wonders: African American female comedy. Studies in American Humor, (12), 97-120.

Annas, G. J. (1984). Law and the life sciences: When suicide prevention becomes brutality: The case of Elizabeth Bouvia. The Hastings Center Report, 14(2), 20. doi:10.2307/3561879

Annas, G. J. (1986). At law: Elizabeth Bouvia: Whose space is this anyway? The Hastings Center Report, (2), 24. doi:10.2307/3563087

Antoine, K. (2016). "Pushing the edge" of race and gender hegemonies through stand-up comedy: Performing slavery as anti-racist critique. Etnofoor, 28(1), 35-54.

Backer, A. L., \& Haller, B. (2014). Stepping backwards with disability humor? The case of NY Gov. David Paterson's representation on Saturday Night Live. Disability Studies Quarterly, 34(1), doi: http://dx.doi.org/10.18061/dsq.v34i1.3459

Baird, K., \& Mitchell, T. (2014). Using feminist phenomenology to explore women's experiences of domestic violence in pregnancy. British Journal of Midwifery, 22(6), 416-426.

Becker, A. B., \& Haller, B. A. (2014). When political comedy turns personal: Humor types, audience evaluations, and attitudes. Howard Journal Of Communications, 25(1), 34-55. doi:10.1080/10646175.2013.835607

Ben-Moshe, L. \& Magaña, M. (2014). An introduction to race, gender, and disability: intersectionality, disability studies, and families of color. Women, Gender, and Families of Color. (2). 105-114.

Benedet, J., \& Grant, I. (2014). Sexual assault and the meaning of power and authority for women with mental disabilities. Feminist Legal Studies, 22(2), 131-154.

Benedict, S., Shields, L., \& O'Donnell, A. J. (2009). Children's "euthanasia” in Nazi Germany. Journal of Pediatric Nursing, 24, 506-516. doi:10.1016/j.pedn.2008.07.012

Berryman, M., SooHoo, S., \& Nevin, A. (2013). Culturally responsive methodologies. Bingley, UK: Emerald.

Bingham, S. C., \& Green, S. E. (2016). Aesthetic as analysis: Synthesizing theories of humor and disability through stand-up comedy. Humanity \& Society, 40(3), 278-305.

Bloomquist, J. (2015). The minstrel legacy: African American English and the historical construction of "Black" identities in entertainment. Journal of African American Studies, 19(4), 410-425.

Bodroghkozy, A. (2003). Good times in race relations? CBS's Good Times and the legacy of civil rights in 1970s prime-time television. Screen, 44(4), 404-428.

Bogdan, R. (1988). Freak show : presenting human oddities for amusement and profit. Illinois: University of Chicago Press. 
Bond, J. (2014). From civil rights to human rights. Sign Language Studies, 15(1), 10-20.

Brechin, A., \& Swain, J. (1988). Professional/client relationships: creating a working alliance with people with learning difficulties. Disability, Handicap \& Society, 3(3). 213-226.

Bricher, G. (2000). Disabled people, health professionals and the social model of disability: Can there be a research relationship? Disability \& Society, 15(5), 781-793.

Carpio, G. (2008). Laughing fit to kill: Black humor in the fictions of slavery. England: Oxford University Press.

Chaney, M. A. (2010). Heartfelt thanks to Punch for the picture: Frederick Douglass and the transnational jokework of slave caricature. American Literature, 82(1), 57-90.

Chapple, A., \& Ziebland, S. (2004). The role of humor for men with testicular cancer. Qualitative Health Research, 14(8), 1123-1139.

Crook, B. (2015). 'So often they do not get recruited': Exploring service user and staff perspectives on participation in learning disability research and the barriers that inhibit it. British Journal of Learning Disabilities, 44, 130-137.

Dance, D. (1978). Wit and humor in the slave narratives. Journal of Afro-American Issues, 5(2), 125-134.

Danforth, S. (2007). Disability as metaphor: Examining the conceptual framing of emotional behavioral disorder in American public education. Educational Studies, 42(1), 8-27.

Danforth, S., \& Rhodes, W. C. (1997). Deconstructing disability: A philosophy for inclusion. Remedial and Special Education, 18(6), 357-366.

Davidsen, A. S. (2013). Phenomenological Approaches in Psychology and Health Sciences. Qualitative Research in Psychology, 10(3), 318-339. doi: 10.1080/14780887.2011.608466

Davidson, M. (2008). Disability theory. Disability Studies Quarterly, 28(4), 32. doi: $0.18061 /$ dsq.v28i4.160

Davis, L. J. (2006). The disability studies reader. New York, NY: Routledge.

Demjén, Z. (2016). Laughing at cancer: Humour, empowerment, solidarity and coping online. Journal of Pragmatics, 101, 18-30. doi:10.1016/j.pragma.2016.05.010

Dilts, A. (2012). Incurable blackness: Criminal disenfranchisement, mental disability, and the white citizen. Disability Studies Quarterly, 32(3), 8.

Dohmen, J. (2016). Disability as abject: Kristeva, disability, and resistance. Hypatia, 31(4), $762-$ 778. doi:10.1111/hypa.12266

Down, J. H. (1995). Observations on an ethnic classification of idiots. Mental Retardation, 33(1), 54-56. 
Earle, V. (2010). Phenomenology as research method or substantive metaphysics? An overview of phenomenology's uses in nursing. Nursing Philosophy: An International Journal For Healthcare Professionals, 11(4), 286-296.

Euell, K. (1997). Signifyin(g) ritual: Subverting stereotypes, salvaging icons. African American Review, 31(4), 667-675.

Ferri, B. A., \& Gregg, N. (1998). Women with disabilities: Missing voices. Women's Studies International Forum, 21(4), 429-439.

Finlay, L. (2009). Ambiguous encounters: A relational approach to phenomenological research. The Indo-Pacific Journal of Phenomenology. 9(1), 1-17.

Finley, J. (2016). Black women's satire as (Black) postmodern performance. Studies in American Humor, 2(2), 236-265.

Fink, M. (2013). 'People who look like things': Representations of disability in The Simpsons. Journal Of Literary And Cultural Disability Studies, 7(3), 255-270. doi:10.3828/jlcds.2013.23

Fulton, D. S. (2004). Comic views and metaphysical dilemmas: Shattering cultural images through self-definition and representation by Black comediennes. Journal of American Folklore, 117(463), 81-96.

Gabel, S., \& Peters, S. (2004). Presage of a paradigm shift? Beyond the social model of disability toward resistance theories of disability. Disability \& Society, 19(6), 585-600. doi:10.1080/0968759042000252515

Gallagher, H. (2001). What the Nazi 'euthanasia program' can tell us about disability oppression. Journal Of Disability Policy Studies, 12(2), 96-99.

Gallucci, C. (2008). Districtwide instructional reform: Using sociocultural theory to link professional learning to organizational support. American Journal Of Education, 114(4), 541-581. doi:10.1086/589314

Ganter, G. (2003). " He made us laugh some": Frederick Douglass's humor. African American Review, 37(4), 535-552.

Garland-Thomson, R. (2002). Integrating disability, transforming feminist theory. NWSA Journal, 14(3), 1-32.

Geisler, F. M., \& de Assunçãoa, V. L. (2014). No occasion for pleasure: The self-worth contingency of a setback and coping with humor. Europe's Journal Of Psychology, 10(3), 520-531. doi:10.5964/ejop.v10i3.743

Govindshenoy, M., \& Spencer, N. (2007). Abuse of the disabled child: a systematic review of population-based studies. Child: Care, Health \& Development, 33(5), 552-558.

Gray, H. (1986). Television and the new black man: Black male images in prime-time situation comedy. Media, Culture \& Society, 8(2), 223-242. 
Green, A. L., \& Linders, A. (2016). The impact of comedy on racial and ethnic discourse. Sociological Inquiry, 86(2), 241-269.

Greene, M. J. (2014). On the inside looking in: Methodological insights and challenges in conducting qualitative insider research. The Qualitative Report, 19(29), 1-13.

Grue, J. (2016). The problem with inspiration porn: A tentative definition and a provisional critique. Disability \& Society, 31(5-6), 838-849.

Guerrero, L. (2016). Can I live?: Contemporary Black satire and the state of postmodern double consciousness. Studies in American Humor, 2(2), 266-279.

Gutierrez, G. G. (2006). Sociocultural theory and its application to call: A study of the computer and its relevance as a mediational tool in the process of collaborative activity. Recall, 18(2), 230-251.

Haggins, B. (2007). Chapter 1: From Negro to Black: Coming of Comic Age in the Civil Rights Era. New Brunswick: Rutgers University Press. Retrieved from http://search.ebscohost.com.libproxy.chapman.edu/login.aspx?direct=true\&AuthType=ip, uid $\& d b=e d s p m u \& A N=e d s p m u . M U S E 9780813542652.5 \&$ site=eds-live

Haller, B. A. (2010). Representing disability in an ableist world: Essays on mass media. Louisville, KY: Avocado Press.

Haller, B., \& Ralph, S. (2003). John Callahan's Pelswick cartoon and a new phase of disability humor. Disability Studies Quarterly, 23(3-4), http://dx.doi.org/10.18061/dsq.v23i3/4.431

Harris, T. (2012). Adventures in a "foreign country": African American humor and the south. Southern Cultures, 1(4), 457-465.

Havig, A. (1992). Blackface radio. Reviews in American History, 20(3), 360-365.

Hopkins, P. D. (2012). Deconstructing Good Times and The Cosby Show: In search of my "authentic" Black experience. Journal of Black Studies, 43(8), 953-975.

Horton, J.O. (1993). Humor and the American racial imagination. American Quarterly, 45(1), 166170.

Hunt, K. (2015). Off the record: A critical perspective on Def Comedy Jam. The Journal of Popular Culture, 48(5), 836-858.

Inniss, L. B., \& Feagin, J. R. (1995). The Cosby Show: The view from the black middle class. Journal of Black Studies, 25(6), 692-711.

Isaksen, J. L. (2017). The power of Obama's racio-rhetorical humor: Rethinking Black masculinities. Howard Journal of Communications, 28(1), 6-19.

James, A., \& Edel, L. (1965). The diary of Alice James. London, England: R. Hart-Davis. Joke Bank - Yo Mamma Jokes. (2019). Laugh Factory. Retrieved from: http://www.laughfactory.com/jokes/yo-momma-jokes 
Kane, F. (1985). Keeping Elizabeth Bouvia alive for the public good. The Hastings Center Report, (6), 5. doi:10.2307/3563061

Kleiman, S (2004). Phenomenology: to wonder and search for meanings. Nurse Researcher, 11(4), 7-19.

Knight, C. (2012). 'Fasten your shackles': Remembering slavery and laughing about it in George C. Wolfe's “The Colored Museum”. African American Review, 45(3), 355-369.

Lalla, B. (1990). Black laughter: Foundations of irony in the earliest Jamaican literature. Journal of Black Studies, 20(4), 414-425.

Lalvani, P. (2015). "We are not aliens": Exploring the meaning of disability and the nature of belongingness in a fourth grade classroom. Disability Studies Quarterly, 35(4). Retrieved from: http://dsq-sds.org/article/view/4963/4107.

Lester, S. (1999). An introduction to phenomenological research.Stan Lester Developments, Taunton. Retrieved from: http://www.sld.demon.co.uk/resmethy.pdf

Lewis, T. T. (2019). Americans with Disabilities Act. Salem Press Encyclopedia. Amenia, NY: Salem Press.

Lintott, S. (2016). Superiority in humor theory. Journal of Aesthetics \& Art Criticism, 74(4), 347358. doi:10.1111/jaac.12321

Lockyer, S. (2015). From comedy targets to comedy-makers: Disability and comedy in live performance. Disability \& Society, 30(9-10), 1397-1412.

Lombardo, P. A. (2003). Facing Carrie Buck. The Hastings Center Report, (2), 14. doi: $10.2307 / 3528148$

Longmore, P. K. (1987). Elizabeth Bouvia, assisted suicide and social prejudice. Issues In Law \& Medicine, 3(2),141-168.

Longmore, P. K. (1995). Medical decision making and people with disabilities: A clash of cultures. Journal of Law, Medicine \& Ethics, 23(1), 82-87.

Mahoney, A., \& Poling, A. (2011). Sexual abuse prevention for people with severe developmental disabilities. Journal of Developmental \& Physical Disabilities, 23(4), 369-376. doi:10.1007/s10882-011-9244-2

Martin Jr, A. L. (2015). Scripting black gayness: Television authorship in black-cast sitcoms. Television \& New Media, 16(7), 648-663.

Marziali, E., McDonald, L., \& Donahue, P. (2008). The role of coping humor in the physical and mental health of older adults. Aging \& Mental Health, 12(6), 713-718.

McAllister, M. (2011). Chapter 6. White people be like...: Black solo and racial difference. Chapel Hill: The University of North Carolina Press. Retrieved from 
http://search.ebscohost.com.libproxy.chapman.edu/login.aspx?direct=true\&AuthType=ip, uid $\& \mathrm{db}=$ edspmu\&AN=edspmu.MUSE9781469602431.10\&site=eds-live

McBryde Johnson, H. (2013). Unspeakable conversations. In L.J. Davis (4th ed). The disability studies reader. (pp. 507-517). New York, NY: Routledge.

McDonald, P. (2012). The Philosophy of Humour. Penrith, CA: Humanities-Ebooks.

McKeown, S. \& Darke, P. (2013). “Are they laughing at us or with us?” Disability in FOX's animated series Family Guy. In Mogk, M. (2013). Different bodies: Essays on disability in film and television. Jefferson, NC: McFarland \& Company.

Miles, A. L. (2019). "Strong Black women": African American women with disabilities, intersecting identities, and inequality. Gender \& Society, 33(1), 41-63.

Mitchell, D. T., \& Snyder, S. L. (2000). Narrative prosthesis : Disability and the dependencies of discourse. Ann Arbor: University of Michigan Press.

Mollow, A. (2014). Criphystemologies: What disability theory needs to know about hysteria. Journal Of Literary \& Cultural Disability Studies, 8(2), 185-201. doi:10.3828/jlcds.2014.15

Moran, C. C. (2003). Beyond content: Does humor help coping? Disability Studies Quarterly, 23(3-4).

Morcom, V. (2014). Scaffolding social and emotional learning in an elementary classroom community: A sociocultural perspective. International Journal Of Educational Research, 67, 18-29. doi:10.1016/j.ijer.2014.04.002

Nocella, A. I. (2008). Emergence of disability pedagogy. Journal For Critical Education Policy Studies, 6(2), 77-94.

Oliver, M. (1990). The politics of disablement: A sociological approach. New York, NY: St Martin's.

Oliver, M., \& Barnes, C. (2012). The new politics of disablement. Macmillan International Higher Education.

Oliver, M. (2013). The social model of disability: Thirty years on. Disability \& Society, 28(7), 1024-1026. doi:10.1080/09687599.2013.818773

Orelove, F. P., Hollahan, D. J., \& Myles, K. T. (2000). Maltreatment of children with disabilities: Training needs for a collaborative response. Child Abuse And Neglect, 24(2), 185-194.

Ostrow, S. C., (2011). Fighting disability stereotypes with comics: "I cannot see you, but I know you are staring at me". Art Education, 64(6), 20-23.

Padilla. R. (2003) Clara: A Phenomenology of Disability. American Journal of Occupational Therapy, 57, 413-423. 
Palmer, G. (1994). "The Cosby Show"—an ideologically based analysis. Critical Survey, 6(2), 188-194.

Payne, M. A. (1994). The "ideal" Black family? A Caribbean view of The Cosby Show. Journal of Black Studies, 25(2), 231-249.

Peckham, N. (2007). The vulnerability and sexual abuse of people with learning disabilities. British Journal Of Learning Disabilities, 35(2), 131-137.

Peckham, N., Corbett, A., Howlett, S., McKee, A., \& Pattison, S. (2007). The delivery of a survivors' group for learning disabled women with significant learning disabilities who have been sexually abused. British Journal Of Learning Disabilities, 35(4), 236-244.

Peters, S., Gabel, S., \& Symeonidou, S. (2009). Resistance, transformation and the politics of hope: Imagining a way forward for the disabled people's movement. Disability \& Society, 24(5), 543-556.

Pickens, T. A. (2013). 'It's a jungle out there': Blackness and disability in Monk. Disability Studies Quarterly, 33(3).

Pinsker, S. (2003). The new minstreldom, or why so much in contemporary black culture went wrong. The Virginia Quarterly Review, 79(2), 280.

Priest, H. (2002). An approach to the phenomenological analysis of data. Nurse Researcher, 10(2), $50-63$.

Regester, C. (1994). Stepin Fetchit: The man, the image, and the African American press. Film History, 6(4), 502-521.

Reid, D. K., Stoughton, E. H., \& Smith, R. M. (2006). The humorous construction of disability: 'Stand-up' comedians in the United States. Disability \& Society, 21(6), 629-643.

Reid-Hresko, J., \& Reid, D. K. (2005). Deconstructing disability: Three episodes of South Park. Disability Studies Quarterly, 25(4).

Rieger, A., \& McGrail, E. (2015). Exploring children's literature with authentic representations of disability. Kappa Delta Pi Record, 51(1), 18-23.

Rieger, A. (2005). "It was a joke for him and a life for me": A discourse on disability related humor among families of children with disabilities. Disability Studies Quarterly, 25(4).

Robert, P. (2003). Disability oppression in the contemporary U.S. capitalist workplace. Science \& Society, 67(2), 136-159.

Rodgers, C. (1987). Maternal support for the Down's syndrome stereotype: The effect of direct experience of the condition. Journal Of Mental Deficiency Research, 31(3), 271-278.

Saldaña, J. (2016). The coding manual for qualitative researchers. Los Angeles, CA: Sage. 
Scamell, M., Altaweli, R., \& McCourt, C. (2016). Sarah's birth. How the medicalisation of childbirth may be shaped in different settings: Vignette from a study of routine intervention in Jeddah, Saudi Arabia. Women And Birth, 30(1), E39-E45.

Samuels, E. (2002). Critical divides: Judith Butler's body theory and the question of disability. NWSA Journal, 14(3), 58-76.

Schulman, N. (1994). The house that black built: Television stand-up comedy as minor discourse. Journal of Popular Film and Television, 22(3), 108-115.

Seidler, C. (2011). Fighting disability stereotypes with comics: "I Cannot See You, But I Know You Are Staring at Me". Art Education, 3(1), 20-23.

Shain, A. (2013). Perspectives on comedy and performance as radical disability activism. Journal of Literary And Cultural Disability Studies, 7(3), 337-346. doi:10.3828/jlcds.2013.28

Shakespeare, T. (2006). Disability rights and wrongs. London, England: Routledge.

Shakespeare, T. (1999). Joking a part. Body and Society, 5(4), 47-52.

Shepardson, D. P. (1999). Learning science in a first grade science activity: A Vygotskian perspective. Science Education, 83(5), 621-38.

Shultz, K., \& Germeroth, D. (1998). Should we laugh or should we cry? John Callahan's humor as a tool to change societal attitudes toward disability. Howard Journal of Communications, 9(3), 229-244. doi:10.1080/106461798247005

Siebers, T. (2008). Disability theory. Ann Arbor: Univ. of Michigan Press.

Simmons, W. (2019). Joyful human rights. Philadelphia: Univ. of Pennsylvania Press.

Singer, P. (2013). Discussing infanticide. Journal of Medical Ethics, 39(5), 260-260.

Smith, D. A. (2013). Handi-/Cappin' slaves and laughter by the dozens: Divine dismemberment and disability humor in the US. Journal of Literary And Cultural Disability Studies, 7(3), 289-304. doi:10.3828/jlcds.2013.25

Smith, R. M., \& Sapon-Shevin, M. A. R. A. (2008). Disability humor, insults, and inclusive practice. Social Advocacy and Systems Change, 1(2), 1-18.

Sobsey, D., Randall, W., \& Parrila, R. K. (1997). Gender differences in abused children with and without disabilities. Child Abuse and Neglect, 21(8), 707-720

Stamps, D. (2017). The social construction of the African American family on broadcast television: A comparative analysis of The Cosby Show and Blackish. Howard Journal of Communications, 28(4), 405-420.

Starks, H., \& Brown Trinidad, S. (2007). Choose your method: A comparison of phenomenology, discourse analysis, and grounded theory. Qualitative health research, 17(10), 1372-1380. 
Stone, A. (2017). Lunacy and liberation: Black crime, disability, and the production and eradication of the early national enemy. Early American Literature, 52(1), 109-140.

Stubblefield, A. (2009). The entanglement of race and cognitive dis/ability. Metaphilosophy, 40(34), 531-551.

Sullivan, P., \& Knutson, J. (2000). Maltreatment and disabilities: A population-based epidemiological study. Child Abuse \& Neglect, 24(10), 1257-1273.

Terrion, J. L., \& Ashforth, B. E. (2002). From 'I' to 'we': The role of putdown humor and identity in the development of a temporary group. Human Relations, 55(1), 55-88.

Thornton, D. J. (2011). Psych's comedic tale of black-white friendship and the lighthearted affect of "post-race" America. Critical Studies in Media Communication, 28(5), 424-449.

Title II of the Americans with Disabilities Act, Section 504 of the Rehabilitation Act of 1973 Discrimination Complaint Form. (2012). Retrieved from: https://www.ada.gov/t2cmpfrm.htm.

Tomlinson, S. (1982). A sociology of special education. United Kingdom: Routledge \& Kegan Paul.

Traustadottir, R., \& Sjgurjonsdottir, B. (2008). The mother behind the mother: three generations of mothers with intellectual disabilities and their family support networks. Journal of Applied Research in Intellectual Disabilities. 21(4), 331-340.

Varpio, L., Ajjawi, R., Monrouxe, L., O’Brien, B., \& Rees, C. (2017). Shedding the cobra effect: problematising thematic emergence, triangulation, saturation and member checking. Medical Education. 51(1), 40-50.

Vaughn, P., \& Turner, C. (2016). Decoding via coding: Analyzing qualitative text data through thematic coding and survey methodologies. Journal of Library Administration, 56(1), 41 51.

Verdugo, M. A., \& Bermejo, B. G. (1997). The mentally retarded person as a victim of maltreatment. Aggression and Violent Behavior, 2(2), 143-165. doi:10.1016/S13591789(96)00020-1

Walters, S. (2013). Cool aspie humor: cognitive difference and Kenneth Burke's comic corrective in The Big Bang Theory and Community. Journal of Literary \& Cultural Disability Studies, 7(3), 271-288.

Warner, D \& Brown, T (2011). Understanding how race/ethnicity and gender define agetrajectories of disability: An intersectionality approach. Social Science and Medicine. 72(8), 1236-1248.

Warren, C., \& McGraw, A. P. (2016). Differentiating what is humorous from what is not. Journal of Personality \& Social Psychology, 110(3), 407-430. doi:10.1037/pspi0000041 
Watkins, M. (1999). On the real side: A history of African American comedy from slavery to Chris Rock. Illinois: Chicago Review Press.

Weaver, S. (2010). The 'Other' laughs back: Humour and resistance in anti-racist comedy. Sociology, 44(1), 31-48.

Wehbi, S. (2010). Lebanese women disability rights activists: War-time experiences. Women's Studies International Forum, 33(5), 455-463. doi:10.1016/j.wsif.2010.05.001

Weiss, G. (2016). De-naturalizing the natural attitude: A Husserlian Legacy to social phenomenology. Journal of Phenomenological Psychology, 47(1), 1-16.

White, R., Benedict, M. I., Wulff, L., \& Kelley, M. (1987). Physical disabilities as risk factors for child maltreatment: A selected review. American Journal of Orthopsychiatry, 57(1), 93101. doi:10.1111/j.1939-0025.1987.tb03513.x

Williams, E.G. (1977). The comedy of Richard Pryor as social satire. American Humor, 4(2), 15.

Winchcombe, M. (2008). Making disability equipment ordinary: Choice, control, and the retail model. International Journal of Therapy and Rehabilitation. 15(3), 115-118.

Wood, K. H. (2014). Laughter in the archives: Jackie "Moms" Mabley and the haunted diva. QED: A Journal in GLBTQ Worldmaking, 1(3), 85-108. 